\title{
Randglossen zum altportugiesischen Liederbuch.
}

Einleitung. II. Ein Mantel-Lied. III. Vom Mittagessen hispanischer Monarchen. IV. Penna-veira. V. Ein Seemann möcht' ich werden. VI. Ginetes - Non ven al Maio. VII. Eine Jerusalempilgerin und andre Kreuzfahrer. VIII. Tell' Affonso de Meneses. IX. Wolf-Dietrich. X. Das Zwiespaltslied des Bonifazio Calvo. XI. Im Nordosten der Halbinsel. XII. Romanze von Don Fernando. XIII. Don Arrigo. XIV. Guarvaya. XV. Vasco Martins de Resende. XVI. Der Sang von der Wachtel. XVII. Grafen-Enkelinnen. XVIII. Grüne Augen. XIX. Oh pino pino! pino florido! XX. Zebrareiter. XXI. Frauen- und Mädchenlieder - Cantos de ledino. XXII. Serranilhas. XXIII. En un tiempo cogiflores. XXIV. Cantigas de vilao. XXV. Flickenlieder. XXVI. Provenzalisches und Altfranzösisches. XXVII. Sel dissi mai. XXVIII. Maios e Maias. XXIX. Tristan und Isolde und andre bretonische Stoffe. XXX. Livros de Linhagem. XXXI. Die Apokryphen der altportugiesischen Litteratur. XXXII. Langzeil-Gedichte und allerlei Metrisches.

\section{EINLEITUNG.}

Mit der Veröffentlichung meiner Beiträge zur kulturhistorischen und sprachlichen Ausdeutung der gallizisch-portugiesischen Liederbücher fahre ich gerade jetzt fort, 1 um den Cancioneiro da Ajuda, zu dem die Stoffmassen allzu sehr angewachsen sind, zu entlasten; gleichzeitig aber, um gewisse im Einleitungsbande dazu enthaltene Thesen durch eingehende Erörterung von darauf bezüglichen Einzelnheiten heller zu beleuchten.

Abgeschlossen ist freilich kaum eine dieser Randglossen. Dazu hätte ich die Geschichtsquellen viel genauer durchforschen müssen, als es mir während dor toxtkritischen und litteralurgeschichtlichen Studien zum Liederbuche mit den mir in der eignen Werkstatt und in nächster Nähe zu Gebote stehenden Hülfsmitteln möglich war. Nur als Materialiensammlungen wolle man sie betrachten.

Regen dieselben gerade durch ihre Unfertigkeit in Spanien oder wo sonst man über die notwendigen Urkunden- und Chronikensammlungen verfügt zu Widerspruch und Ergänzung an, so ist die Zeit und Mühe, die ich an den spröden Stoff gewendet habe, keine verlorene gewesen.

1 Der Anfang (Randglosse I: Der Ammenstreit) erschien 1896 in Zeitschrift XX, $145 \mathrm{ff}$. - Weiteres, über die 32 oben genannten Stoffe hinaus, wird nachfolgen.

Zeitschr. E. rom. Phil. XXV. 
$\mathrm{Dafs}$ ich dem Leser die erläuterten Texte der Regel nach vorführe, so wie ich sie nach langem Umgang damit, leider aber ohne CV und CB vor Augen zu haben, zu restaurieren vermag, wird man billigen, da ja eine brauchbare kritische Ausgabe des Gesamt-Liederbuches noch nicht vorliegt. Desgleichen dafs ich selbst einiges Garstige nicht umgehe, wenn es zur Feststellung der Wahrheit beiträgt.

Ich beginne mit Liedern Alfons' $\mathrm{X}$. oder auf ihn bezüglichen, weil er als König, als Gelehrter, als Mensch und als Dichter ungleich tieferes Interesse verdient als alle übrigen Troubadours zusammen.

Cesare de Lollis, der sich mit den profanen Gedichten des Kastilianers in erspriefslicher Weise beschäftigt hat, und Ernesto Monaci, dem wir die erste Erschliefsung der Liederbücher verdanken, seien diese Blätter gewidmet - aus Dankbarkeit für ihre Leistungen, aber auch mit der ausgesprochenen Absicht, sie zur Veröffentlichung der ganz unentbehrlichen Lesarten aus dem Cancioneiro Colocci-Brancuti und damit zur indirekten Bestätigung oder Verurteilung meiner Restaurations- und Interpretationsversuche zu bewegen.

\section{Ein Mantel-Lied.}

So aufserordentlich sorgfältig Cesare de Lollis seine Untersuchung über die uns leider in beklagenswert schlechtem Zustande erhaltenen weltlichen Gedichte des gelehrten Alfons von Kastilien auch geführt hat, 1 so werden dieselben doch noch für lange Zeit Anlafs zu Erörterungen und Berichtigungen hergeben. Auch zu Nachträgen, da keineswegs alles Nötige von dem italienischen Gelehrten in Betracht gezogen worden ist. Abgesehen von den zahlreichen Liedern, in denen ein $R e y$, ohne Angabe seines Namens und seines Reiches, vorkommt, ${ }^{2}$ sowie von den seltneren, wo etwas bestimmter ein König Alfons, ein König von Kastilien, ein König von Leon und Kastilien erwähnt wird, scheint mir besonders erwägenswert, wer jener Rey oder Senhor - Rey don Affonso - gewesen sein mag, der in einigen unbeachtet gelassenen Tenzonen als Dichter auftritt.

1 Cantigas de Amor e de Maldizer de Alfonso el Sabio, Rè di Castiglia in Stud. Fil. Rom. vol. I $31-66$ (1887).

${ }^{2}$ CV 37. 45. 157. 334. 347. 419. 420. 428. 424. 458. 468. 505. 509. 519. 520. 534. 553. 572. 578. 597. 608. 613. 631. 632. 633. 634. 638. 639. 707. 708. 752. 755. 756. 758. 759. 853. 854. 885. 910. 915. 921. 932. 947. 953. 962. 963. 1015. 1024. 1032. 1036. 1087. 1038. 1043. 1053. 1054. 1082. 1084. 1108. 1131. 1143. 1157. 1172. 1175. 1184 . 1186. 1189. 1193. 1202. - CB 104. 464. 465. 475. 1508. 1512. 1514. 1516. 1518. 1520. 1521. 1524. 1525. 1531. 1532. 1538. 1550. - Ohne Scheidung solcher, in denen von Königen von Portugal (Sancho II., Alfons III., D. Denis, Alfons IV.), Kastilien und Leon (Ferdinand III., Alfons X., Sancho IV., Alfons XI.) oder Aragon (Jaime I.) die Rede ist. 
Drei einschlägige Stücke (CB 385, CV 1158, CB 357) habe ich bis jetzt untersucht und spreche sie, nach eingehender Ueberlegung, Alfons X. zu. Das, welches wir als Mantellied bezeichnen dürfen, ist überschrieben:

Vaasco Gil fez esta cantiga ${ }^{1}$ d'escarnh' 2 e de maldizer.

Es lautet:

Rei don Alfonso, se Deus vus pardon, d' esto vus venho [ora] preguntar

[e peço] que punhedes de mi dar tal recado que seja con razon:

5 ¿Quen dá seu manto, que lh' o guard' alguen, e lh' o non dá tal qual o deu, por én que manda [én] o Livro de Leon?

„Don Vaasco, eu fui ja clerizon

e degredaes soía estudar:

10 enas escolas u sola entrar

dos maestres aprendi tal liçon:

que manto d' outren non filhe per ren;

mais se o m' eu melhoro, faço ben

e non sõo por aquesto ladron."

15 Rei don Alfonso, ladron por atal

en nulha terra nunca chamar vi;

nen vos, senhor, non o oistes a mi,

ca se o dissesse, diria mal.

Ante tenho-[o] por trageitador

20 - ise Deus mi valha! nunca vi melhor -

quen assi torna pena de cendal.

„Don Vaasco, dizer-vus quer' eu al

d' aqueste preito que eu aprendi:

oi dizer que trageiton assi

25 ja ua vez un rei de Portuğal:

e por se meter por mais sabedor

ouv(e) un dia de trageitar sabor...

fez-se cavaleiro do Espital." $\quad$ (CB $1512=886$.

Lesarten, die ich berichtigt habe: I cātiga - 2 edescarnhe - Z.3 venho preguntar quer ora punhade -7 Solche pleonastische Wiederholung von en ist nichts Seltnes; doch könnte man auch lesen: que manda(n) eno livro de Leon ? - 8 derizon - $9 E$ degreda - $13 \circ \mathrm{m}^{\prime}$ eu mit ethischem Dativ? oder 0 meu? Mir scheint die erste Deutung einen passenderen Sinn zu enthalten - 17 vistes würde besser ins Versmals passen - 22 qrea al $28 \mathrm{fes}$ - Die üblichen Schlufskadenzen, in denen das Facit gezogen zu werden pflegt, fehlen.

Don Vasco Gil hat in den Händen eines Königs Alfons seinen Mantel belassen. Wie er sagt, zur Aufbewahrung. Nehmen wir an, da man einem König doch nicht so ohne weiteres seinen Umhang zum Aufheben übergiebt, dafs er sein Eigentum dem Herrscher zum leiblichen Schutze ausgeliefert hat, im Feldlager, auf der Jagd, 
bei Unwetter oder aber zum moralischen Schutze bei irgend einem nächtlichen Abenteuer. - Daraus ersieht man, dafs er zu den Vertrauensmännern des Monarchen gehörte (Privados oder Validos). Ein solcher aber wufste auch, wie willkommen dem musenfreundlichen Monarchen eine lustige gereimte Behandlung jedweden Vorkommnisses zu sein pflegte. Darum wirft der Höfling scherzend, als er das Kleidungsstück in veränderter Gestalt, anscheinend neu hergerichtet, zurück erhält, die Frage auf: „Wenn Einer Einem den Mantel borgt und erhält ihn nicht so zurück, wie er ihn hergegeben hat, mit welcher Strafe belegt ihn dann das leonesische Buch?" - „Zwar habe ich in Scholarentracht dereinst Decretalien studiert und von den Magistern gelernt, man solle Niemand seines Mantels berauben. Dafs aber ein Dieb sei, wer ihn verbessert, das habe ich nicht gelernt." - So ungefähr lautet des Königs Antwort. Das Wort Dieb weist der Vertraute des Herrschers natürlich zurück. Vielmehr nenne er den einen Tausendkünstler, der es verstehe, Zindel in Pelzwerk zu verwandeln. Als historisches Beispiel ähnlicher Taschenspielerei wird dann noch auf einen König von Portugal hingewiesen, der einst, aus Schlauheit, den Hospitaliter-Mantel angelegt habe. -

Dunklen Stoffs genug für den Kommentator. Zu viel sogar für einen, der, den Quellen nahe und doch so fern, über so dürftige historische Hülfsmittel verfügt wie ich. Eine Ueberzeugung drängt sich freilich sofort auf. Ein König Alfons, zu dem von Gesetz und Rechtspflege gesprochen wird, und der selbst auf seine kirchenrechtlichen Studien Bezug nimmt, kann kein andrer sein als der gelehrte Schöpfer des encyklopädischen Setenario, des Fuero Real mit den Nuevas Leyes, des Espejo de todos los derechos, sowie der berühmten Siete Partidas - der eifrige Förderer der Universität Salamanca, und zu gleicher Zeit der fruchtbarste Poet seiner Tage.

Trotzdem mufs der Nachweis erbracht werden. Das livro de Leon, der portugiesische König-Hospitaliter, cendal wie pena, maestres wie degredaes geben aufserdem noch $z \mathbf{z}$ suchen. Ob auch $\mathbf{z u}$ finden?

Zunächst, was wissen wir über den in so vertrauten Beziehungen zu König Alfons stehenden D. Vasco Gil, der sich in dieser Tenzone rechtsbeflissen zeigt, und vom Partner an eine portugiesische rechtskräftige fą̧anha erinnert wird? Der König giebt ihm den Don-Titel. ${ }^{1}$ Und da die Tenzone zwar eine scherzhaft spöttelnde, aber doch mafs- und formvoll ist, müssen wir die darin enthaltenen Angaben für wirkliche, nicht aber, wie in einigen schmähenden Streitgedichten, in denen Spielleute wie Pero da Ponte und Lourenço gehänselt werden, für Persiflage halten. ${ }^{2}$ Jener Hinweis

1 In der Textüberschrift und im Index fehlt derselbe.

2 CV 68 und 1034. 
sowohl wie der Name Vaasco deutet auf einen vornehmen Portugiesen. Nur von einem solchen berichten aber die Adelsbücher der Troubadour-Epoche, und nur ein solcher tritt als Dichter in den Cancioneiros auf. Er gehört zu einer jener kleinen Dynastien aus der Nordprovinz (Entre Doiro e Minho), die in den ersten Jahrhunderten den Regenten ihr Herrscheramt streitig machten. Sein Vater ist der alte, zu Pombeiro begrabene Landgraf Gil Vasques de Soverosa, der von 1200 bis gegen I 240 am portugiesischen Hofe unter drei Königen eine der vornehmsten Rollen gespielt hat, ${ }^{1}$ zuletzt als einer der wenigen treuen Berater und Kriegsgenossen Sancho's II. ${ }^{2}$ Ein Halbbruder somit des Recken D. Martim Gil, des vielgehafsten Vertrauten jenes Monarchen, als dessen Kämpe er im J. I 245 die Schlacht bei Porto gegen die Partei der Bischöfe und des Grafen von Boulogne leitete und gewann. Während dieser D. Martim Gil aus der ersten Ehe des alten Egidius Velasci oder Valasquiz mit D. Maria Ayres de Fornellos stammt ${ }^{3}$ - und somit den, ihrer ersten Jugendliebe zu Sancho I. entsprossenen Königssohn D. Martim Sanches seinen Halbbruder nannte ${ }^{4}$-, ging Vasco Gil aus der zweiten, bzw. dritten Ehe mit D. Sancha Gonçalves d' Orvaneia ${ }^{5}$ hervor, die man um 1210 wird ansetzen dürfen (spätestens). Durch noch eine Ehe mit einer Giroa, sowie durch eine seiner zahlreichen leiblichen Schwestern - D. Teresa Gil, die in der Königsburg zu Leon längere Zeit als Favoritin Alfons' IX. thronte, während eine der Bastardtöchter dieses Paares später im Palast Alfons' X. glänzte, und eine andre im Nordosten der Halbinsel im Stammschlofs der Herren von Cameros regierte ${ }^{6}$

1 Mon. Lus. XV c. 4; XVI c. 52. - Herculano, Hist. Port. II 358. 388. 495. 496. - In den Jahren 1235-1240 war Gil Vasques Statthalter von Sousa (tenens Sausam, s. Mon. Lus. IV, Escrit. XIV); 1240 gehörte er noch zu den Lebenden. - Seinen Namen liest man unter zahlreichen der in den P. M. H.: Leges 35I-620 mitgeteilten Urkunden, nämlich unter fast allen von Alfons II. bestätigten Ortsrechten.

8 Während der Minderjährigkeit des Monarchen war er ein gewaltthätiger Länderusurpator gewesen. - S. Herc. II 500-506 und Nova Malta I $\S 275$ und II $\oint 187$.

8 Dies Bündnis mus vor 1200 geschlossen worden sein.

- D. Martim Sanches verliels Portugal 121 I, beim Ableben seines Vaters, um sich dem Hasse des Thronerben zil entziehen. Am leonesischen Hofe kam er natürlich zu hohen Ehren, und ward mit drei oder vier Grafschaften belehnt: 1219 verwaltete er Limia und Sarria (Risco, Hist. Leon. Ap. 6 p. 402); 1222 Limia, Toronho und Montenegro (Esp. Sagr. XLI Ap. 29 p. 357). Dafs er auch Trastámar regierte und freiherrlich einem gallizischen Adligen überantwortete, wird im Grafenbuch (P. M. H.: Script. 198. 294) behauptet, und von den meisten späteren Geschichtsschreibern wiederholt, z. B. von Duarte Nunes de Leão in seiner Genealogia (Schott, Hisp. Illustr. II 1257). Von seinen Kriegsthaten und dem ritterlichen Sinn, den er an den Tag legte, wenn er gegen Portugal zu Felde ziehen mulste, berichtet der Graf von Barcellos (Script. 1. c.). - Lucas von Tuy gedenkt des Sieges bei Tejada (Schott IV I14), der in die letzten glorreichen Tage Alfons' IX. fällt. Vgl. auch Esp. Sagr. XXXVI App. p. 142.

5 Orbanelia in lat. Dokumenten.

- Vgl. Randglosse XI und CA Kap. VI Biogr. 58. 
waren die damals üblichen Verbindungen mit den ausländischen Dynasten und Vasallen hergestellt.1 - An der Seite des Vaters und des älteren Bruders erscheint Vasco Gil am portugiesischen Hofe. ${ }^{2}$ Als Valascus Egidii unterzeichnet er 1238 einen Ausgleich zwischen dem König und dem Bischof von Porto, D. Pedro Salvador. ${ }^{3} \mathrm{Dafs}$ er im Bürgerkrieg die Schicksale des Bruders teilte, für seinen rechtmälsigen Herrn das Schwert zog, ${ }^{4}$ bei dessen Sturze ihn nach Kastilien begleitete, ebendort, während Sancho als büfsender Mönch den kurzen Rest seines Lebens zu Toledo verbrachte, in der Nähe des kastilischen Thronerben am ruhmreichen andalusischen Feldzug mitwirkte, ist mehr als eine blofse Vermutung. Vasco zählt nämlich zu den 300 Adligen, unter welche Alfons X. nach seinem Regierungsantritt die 1248 eroberte Stadt Sevilla verteilte. 5 An Macht und Ansehn hat er jedoch dem Martim Gil den Rang nicht abgelaufen. Während jener in Kastilien verschiedene Schenkungsurkunden unterzeichnet - z. B. 25. Mai 1254 die Urkunde, durch welche die Ortschaften Cabra und Santisteban an

1 Script. 176. 197. 293. Die daselbst verzeichneten genealogischen Angaben sind nicht frei von Widersprüchen. Das zur Kenntnis der TroubadourEpoche Wesentlichste ist folgendes.

Aus der ersten Ehe des Alten von Soverosa mit der verlassenen Geliebten des Königs gingen Martim Gil und Teresa Gil hervor. Das Livro Velho (153) nennt noch einen Fernão Gil, den das Livro do Conde als Sohn zweiter Ehe bezeichet. Martim Gil vermählte sich in Leon mit einer Castro, aus dem Geschlecht der Pertigueiros de Santiago. Von ihnen stammt der erste Herr von Albuquerque ab. - Teresa Gil, die mit dem Bruder 12 II nach Leon übersiedelte, schenkte dem unverwüstlichen Alfons IX. vier oder fünf Kinder: darunter Martim Affonso, der einer portug. Sousa die Hand reichte und Maria Affonso, mit welcher, als junger Wittwe des Alvaro Fernándes de Lara „o que jaz em Fiteiro" (cf. Rod. Tol. IX c. 9), Alfons X. Beziehungen anknüpfte, denen das Königskind Bringueira entstammt (vgl. Randglosse X).

$\mathrm{Zu}$ den Kindern aus zweiter Ehe mit Sancha Gonçalves d' Orvaneia im Livro Velho (Script. 176) kommt sie erst in dritter Reihe - gehört aufser unserm Vasco eine D. Guiomar, und ein Manrique (im Livro Velho Anrique), von dem weiter unten die Rede sein wird (Anm. 5).

Die dritte bzw. zweite Gemahlin, die Spanierin Maria Gonçalves Giron, brachte der Familie einen Zuwachs von weiteren fün Kindern, von denen nur eines, $D$. Dordia (d. i. Dordea $=$ Dorothea), für unsere Untersuchungen in Betracht kommt.

Mit ihr und der Halbschwester Guiomar beschäftigt sich Jozo de Guilhade im 37. Liede des CV, das ich am Schlusse mitteile.

2 Herc. II 358 und 496.

3 Diss. Chron. IV 2 App. No. 3.

- In einem Kampfe unweit Leiria's, über den nichts Näheres bekannt ist, geriet er 1245 oder 1248 in Gefangenschaft. - Herc. II 412 Anm. 2: 414 und 425 .

5 Mon. Lus. XV c. 4 nennt in der Liste der portug. Sevilla-Streiter, gleich nach dem Infanten D. Pedro, unsern D. Vasco Gil und seine Brüder Manrique und João. - In der Urkunde, wie D. Pablo de Espinosa sie in der Segunda Parte de la Historia y Grandesa de la Gran Ciudad de Sevilla druckt (1630), steht der Infant unter den Fürsten (f. 1), die drei Bräder Gil aber gleich zu Anfang der portug. Ritter, unter welche Gelmus verteilt wurde (f. 7 v). Zu den Granden, welche 1250 das Fuero de Sevilla unterzeichneten, gehört er nicht. 
Ubeda fielen, in Gemeinschaft mit zwei andern portugiesischen Sevilla-Kämpfern ${ }^{1}-$, kann ich wenigstens Vasco's Namen unter solchen Schriftstücken nicht nachweisen. Und ebenso wenig in der Heimat, wohin beide zurückgekehrt zu sein scheinen, nachdem des Grafen von Boulogne Thronrecht mehr als durch päpstlichen Machtspruch durch Sancho's Tod unumstörslich, und weitere Opposition gegenstandslos geworden, momentane Eintracht Portugals mit Kastilien aber durch Alfons' III. Ehebund mit einer Tochter Alfons' $\mathrm{X}$. hergestellt war.

Martim Gil finden wir seit 1255 in der Nähe Alfons' III.2 Von Vasco wissen wir nur, dafs er sich in Portugal mit einer Tochter des D. Fernand' Eannes (mit dem Zunamen Cheira) aus dem Geschlecht derer de Riba de Vizela e de Cambra, genannt D. Froilhe Fernandes, vermählt hat. ${ }^{3}$ Kaum später als 1255 , da einer seiner Söhne, als er 1277 in dem von neuem entfachten Bürgerkriege im Kampfe bei Gouvea fiel, 4 bereits ein Töchterchen besafs, D. Guiomar Gil II., mit welcher sich gegen Ende des Jahrhunderts ein João Rodrigues de Briteiros vermählte, der in einer späteren Randglosse wieder auftauchen wird. ${ }^{5}$

Der Zeitabschnitt, in dem also der historische D. Vasco Gil mit König Alfons in Kastilien zu dichten Gelegenheit gehabt hätte, umfafst die Zeit von 1247 bis etwa 55. Da der Fürst jedoch als König angeredet wird, verkürzt sich die Frist, in der die Tenzone entstanden sein muls, auf die ersten vier Regierungsjahre. An Alfons IX. zu denken, dessen Beziehungen zu den Soverosas laut S. I34 Anm. I ebenso intime waren wie die Alfons' X., ist somit nicht zulässig, trotzdem die Bezugnahme auf das Livro de Leon dazu zwang, ihn zuerst nicht aus den Augen zu lassen.

1 Nobl. And. II c. I. Vgl. ebenda c. 9 die Schenkungsurkunde über die an Baeza abgetretene Torre de Gil de Olit. Freilich kann es sich hier, und in allen einschlägigen Fällen, auch um einen andern gleichnamigen portug. Magnaten handeln, den Sohn des Gil Martins de Riba de Vizela. Um so mehr als in der letztgenannten Urkunde dieser unmittelbar vor D. Martim Gil unterzeichnet.

${ }^{2}$ Herc. II 412. - P. M. H.: Leges 665.683. erwähnt.

8 Script. 153. 176. 199. 295. - Cheira wird im Spottlied CV 1080

- Nova Malta I § I83; II § 149. I98 u. 54. - Ueber den Bürgerkrieg gegen Ende der Regierung Alfons III. s. Herc. III 150. - Mon. Lus. XV c. 4 und Script. 4: Era MCCCXV feria Va comissum fuit bellum inter Petrum stephani de thaauare et fernandum alfonsi de Caambria in quo bello ex parte fernandi alfonsi (seines leiblichen Vetters) nobilis quidam nomine donus Egidius ualasci solus interiit et nullus alius (Chron. Conimbr.).

5 Gil Vasques II. war mit Aldonça Annes da Maia vermählt (cf. Nova Malta I \$ 235), deren Reize Alfons III. bestrickt haben sollen. - Ein andrer Sohn des Dichters, D. Martim Vasques, fiel 1286 bei Alfaiates an der Seite des rebellischen Alvaro Nunes de Lara. Script. 295 und Mon. Lus. XVI c. 51 (wo übrigens sein Name nicht erwähnt ist). - Eine seiner Töchter, Sancha Vasques, heiratete Fernam Fernandes de Lima e Baião, mit dem Beinamen $P \not a-C e n t e i o=R o g g e n b r o d$. Beider Sohn, D. João Fernandes de Lima - des Vasco Enkel also - vermählte sich mit einer Tochter des Troubadours D. João d'A boim. 
Die fragende Erwähnung dieses Gesetzbuches, gleichviel ob das Fuero Juago oder das Fuero de Leon gemeint ist, in die Zeit $1252-55 \mathrm{zu}$ verlegen, geht auch darum sehr wohl an, weil sich der König gerade damals aufs eifrigste seiner grolsartigen gesetzgeberischen Thätigkeit widmete. Noch vor 1253 wurde das Fuero Real nebst den Nuevas Leyes sowie der Espejo de todos los derechos redigiert (d. h. ehe Alfons den Titel de Algarve angenommen hatte), worauf von 1256-63 an dem umfassenden, als Siete Partidas weltbekannten Libro de las Leyes gearbeitet wurde.

Noch einen Zug aus dem Leben des Vasco Gil vermag ich anzuführen, der dafür spricht, dafs wir ihn mit dem rechtskundigen Poeten identifizieren dürfen, der König Alfons anredet. Ursprünglich war derselbe nämlich zum Geistlichen bestimmt gewesen. Wie das Grafenbuch angiebt, hatte er die ersten Weihen bis zum SubDiaconus empfangen: foy d' epistola; vertauschte dann jedoch das lange Gewand os longos pannos mit dem Ritterharnisch. Gleichwie der König aber hätte er dementsprechend sagen können:

$$
\begin{aligned}
& \text { eu fui ja clerizon } \\
& \text { e degredaes soia estudar, }
\end{aligned}
$$

denn ein Adliger wie er hatte Anwartschaft auf die höchsten Prälatenwürden, und mulste regelrechte Studien absolviert haben. ${ }^{1}$

Anscheinend könnte man zweierlei unter dem Livro de Leon verstehen. Das Livro Juzgo und das Fuero de Leon. ${ }^{2}$ Das westgotische Gesetzbuch blieb bekanntlich in Leon Jahrhunderte lang rechtskräftig, selbst noch nach der endgültigen Vereinigung von Löwe und Turm unter Ferdinand III., ja selbst noch nachdem Alfons X. seine reformatorische Thätigkeit entfaltet hatte, in dem idealen Bestreben, den allmählich den Mauren entrissenen Provinzen und ihren mit Sonderrechten verschiedenster Art privilegierten Städten und Städtchen ein einheitliches nationales Recht zu geben, aus römischen Gesetzen, Westgoten-Sitte, Kirchensatzungen und dem in den Foraes und im Fuero viejo niedergelegten traditionellen Brauch kunstvoll in einander gearbeitet. ${ }^{3}$

1 Aus den Schenkungen, welche Gil Vasques der Alte und sein Sohn den Hospitalitern und speziell dem Kloster Pombeiro zuwies, darf man nicht folgern, dafs der Dichter dem Orden zugehörte. Zum Teil waren dieselben nichts als Herausgabe von königl. Besitztümern, welche während der Minderjährigkeit Sancho's II. usurpiert worden waren. Das gilt z. B. von der Villa de Sesmires e toda a terra de falles. Der Monarch hatte dieselben seinem Kapellan geschenkt; dessen Sohne wurden sie vom Herrn von Soverora entrissen, der sie, als es zum Sterben kam, den Hospitalitern vermachte. Nova Malta I $\$ 183$ und 275 ; II 98. 149. 187 .

2 Oder noch ein drittes? Ist das Liber Legis oder Fudicium Legionense, das in $\$ 15$ der Cortes de Leon v. J. 1188 erwähnt wird, nur ein andrer Name für das Fuero fuzgo? Oder ist darunter eine Sammlung zu verstehen, in welche die bunos mores, façanhas, d. h. Rechtssprüche, eingetragen wurden, die für spätere Fälle als Vorbild dienen sollten?

3 Auch was der Grofskanzler Kastiliens in seiner Chronik Peters des Grausamen zum Jahre I 35 I (c. I9) berichtet, verdient Beachtung. Der Schlufs- 
Man erinnere sich ferner, dals das Liber Judicum auch über Leon hinaus Gültigkeit erlangte; dars noch Ferdinand III. es für Carmona und Cordova in die Vulgärsprache umsetzen liefs, ${ }^{1}$ sowie dafs es etwas später auch auf Murcia ausgedehnt ward; und drittens dafs im gallizischen Santiago de Compostella und allen ihm unterstellten Orten wenigstens Appellation an das Libro gestattet war. ${ }^{2}$

Seine Gültigkeit war freilich eine stark beschränkte. Beschränkt eben durch das aus dem Gewohnheitsrecht hervorgegangene, für das Volk bestimmte Livro de Leon, welches Alfons V. - el de los buenos fueros - auf der 1020 nach Leon berufenen Prälaten- und Magnatenversammlung redigieren und bestätigen liefs. Mit seinen 49 bedeutsamen, weltliche wie geistliche Bedürfnisse gleichmärsig berücksichtigenden Dekreten ward es rasch mehr denn ein blofser Freibrief für die Stadt, ein das Fuero Juzgo z. T. vervollständigendes, z. T. ersetzendes Corpus juris für das ganze sich dehnende und entwickelnde Königreich ${ }^{3}$ und, wie der ältere Kodex, hinaus über die eigentlichen Grenzen des Landes, ${ }^{4}$ und blieb es bis ans Ende des 13. Jhs. und noch ins 14. hinein (bis etwa 1356).

Ich meine - mit dem Vorbehalt, der sich aus S. 136 Anm. 2 ergiebt - , dals die Troubadours dies letztere im Sinne hatten, 5 nicht aber den ja auch in Portugal herrschenden Goten-Kodex allein. Zwar wird derselbe in den alten Handschriften und von den Benutzern bald Liber, bald Forum genannt. Der Zusatz de Leon kann jedoch von Rechts wegen nur den jüngeren Kodex, und zwar vornehmlich Kanon 20-48, charakterisieren. Dafs man auch diesen unterschiedslos bald Liber, bald Foro genannt hat, beweisen zum Ueberflufs unsere Cantigas.

satz lautet: E llama-se, en Toledo, Castellano todo aquel que es de tierra del señorio del Rey de Castilla do non se juzga por el Libro furgo. Desgleichen in der alten Chronik Alfons' X. (c. 9) die auf des Gelehrten Gesetzesspiegel bezügliche Stelle: mandó facer el fuero de las leyes, en que asummo muy brevemente muchas leyes de los derechos. $E$ dio lo por ley e por fuero a la ciudad de Burgos e a otras cidades e villas del regno de Castilla, ca en el regno de Leon avian el Fuero fuzgo que los Godos ovieron fecho en Toledo.

1 Schäfer, Geschichte Spaniens II 412-418; Amador de los Rios II 410; Baist, Grundrifs § 24 .

2 An welches Libro dic Richter von Santingo de Compostella appellieren

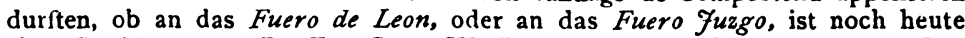
eine Streitfrage. - Zu Esp. Sagr. XXXV c. V (mit Anhang) s. Lopes Ferreiro, Fueros Municipales de Santiago, 1895. - Cf. Rev. crit. I I3I.

8 Rod. Tol. $(+1247)$ sagt von ihm: leges gothicas reparavit et alias addidit qua in regno Legionis etiam hodie observantur (V Ig. Cf. VI 9 u. 13). - Luc. Tud. 89: Dedit ei bonos foros et mores quos debet habere tam civitas quam totum legionense regnum a flumine Pisuerga usque ad extremam Gallaeciae partem in perpetuum.

- Aguirre, Concilia Hisp. IV 386. - Marina, Ensayo Hist. Crit. 156. - Esp. Sagr. XXXV c. V u. Ap. 12 u. 16. - Aschbach, Spanien und Portugal unter Almoraviden und Almohaden S. 365. - Schäfer, Gesch. Span. II 414 . - P. M. H.: Leges I 135.

b Die leonesischen Richter, an welche appelliert werden durfte, hiefsen fueces del Libro $y$ del Fuero. 
Der Bezeichnung livro de Leon bedient sich, aufser D. Vasco Gil, noch ein gallizisch-portugiesischer Dichter, wie ich zeigen werde. ${ }^{1}$ Vom foro de Leon sprechen mehrere. ${ }^{2}$ Alle natürlich ohne des Gesetzes Inhalt und Wortlaut genau im Kopfe zu haben; vielmehr mit dichterischer Freiheit in Fällen, wo sie ebenso gut kurzweg das Gesetzbuch, das Gesetz hätten sagen können eine Verallgemeinerung, die bis 1255 begreiflich ist ${ }^{3}$-, und länger, da, wie gesagt, das grolse philosophierende Hauptwerk Alfons' des Gelehrten niemals Anwendung fand, selbst in Kastilien nicht.

Wo ein gallizischer segrel - Affons' Eannes do Cotom, dessen Hauptthätigkeit sich am Hofe Ferdinands III. und Alfons' X. abspielt - in einem burlesken Schmutzlied ausdrücklich versichert

$$
\begin{aligned}
& \text { pero juro-vus que non sei } \\
& \text { ben este foro de Leon, } \\
& \text { ca pouc' á que aqui cheguei }
\end{aligned}
$$

meint er nichts als ,ich kenne die Landessitte hier in Leon nicht", gerade so wie ein andrer Dichter einmal a for de Castella im Sinne von "nach kastilischer Art" verwendet."

Wo hingegen Ayras Peres Vuitorom, der eifrigste Verteidiger Sancho's II., der mit Vasco Gil sicher bekannt war, von einem zu Unrecht freigesprochenen Verräter handelt, der wegen aleiv' e traiçon nach leonesischem Gesetz Todesstrafe verdient hätte, ${ }^{6}$ und auch wo der Admiral Pay Gomes Charinho von gewissen Vorrechten redet, ${ }^{i}$ ist die obige Auslegung nicht statthaft.

Und erst recht nicht, wo ein andrer Gallizier, der mittelalterlich rüde aber lustige Schelm João Ayres de Santiago, in einem unsaubren Spottliede auf das Livro de Leon verweist. Er stellt sich darin liebeskrank; klagt die Schöne, die an seinem Tode Schuld ist, des Mordes an; und verlangt in zweideutiger Weise Anwendung einer die Volksphantasie naturgemäls erregenden, grausigen Kriminalbestimmung, nach welcher der Todschläger im Grabe lebendig unter seinem Opfer zu liegen kam: sepelialur vivus et interfectus super eum projiciatur. ${ }^{8}$

Diese Bestimmung findet sich jedoch keineswegs in dem Texte, auf den der Spötter sich beruft, sondern, auf hispanischem Gebiete, in den Ortsrechten von Cuenca, Sepulveda, Baena, Plasencia, und, auf portugiesischem, ausschliefslich im foral des fränkischen

1 João Ayres de Santiago, CV 1076.

2 A yras Peres Vuiturom CV 1096. - Affons' Eannes do Cotom CV 1113. - Pay Gomes Charinho CV 1158.

8 Nach diesem Datum wurde das fuero real verschiedenen kastilischen Städten verliehen und der Espejo oft zu Rate gezogen.

- CV W13. - Darin handelt es sich in gröbster Weise um das Wort: Und sie soll vom Manne gebären.

s CV 1028.

- CV 1096. - S. am Ende dieser Studie den Liederanhang (3).

7 CV 1158. - Es bildet den Gegenstand von Randglosse III.

8 CV 1076. - S. Liederanhang (4). 
Ortes Lourinhan und in Marmelar.1 Im Fuero de Leon $\$ 24$ wird hingegen, wie schon im Westgotenrecht, Mord durch eine Geldsumme gesühnt: $100-500$ Solidos, oder die Hälfte der fahrenden Habe des Missethäters; und auch das nur, falls derselbe innerhalb neun Tagen ergriffen werden konnte.

Eine Bestimmung über den Manteldieb enthält übrigens das Fuero de Leon ebenso wenig wie das Fuero Juzgo. Ich würde eine solche eher in den Aufzeichnungen vermuten, welche die Grundlage des Fuero viejo bilden.2 Wenigstens findet sich die entsprechende Verfügung auf portug. Boden in einem Adelserlals Alfons' III. Stabelecimento em como as casas dos filhos d' algo devem ser guardadas. Sie lautet:

Item: quemquer que filhar capa ou çerame ou pele ou alguma vestidura ou cobertura, peyte-a en dobro, ataa IX dias. E se o nom peytar fique eno consentimento (sic! - statt cousimento = remaneat in causimento) do meyrinho e peyte a mim por cada huum, dous maravedis. ${ }^{3}$

Den Doppelwert hat der königliche Mantelempfänger unsrer Tenzone genau genommen wohl nicht gezahlt. Jedenfalls aber einen höheren: schweres Pelzwerk (pena), ${ }^{4}$ an Stelle von leichtem Seiden-Zindel (cendal), 5 der nur für bestimmte Kleidungsstücke, wie Frauenblusen oder -röcke, den Modeforderungen entsprach, ${ }^{6}$ als

1 Leges 448 u. 489 . - Herc. IV 86. 461 ; I 403.

2 Ueber das traditionelle Gewohnheitsrecht des kastilischen Adels siehe Lafuente I 382.

3 Leges 191. - Cf. ib. 190: Decretum Domini Regis. Quicumque acceperit alicui capam zuramen pellem aut aliquam uestem aut aliquod cooperimentum pectet ipsum in duplo usque ad nouem dies, et si illud non pectauerit remaneat in causimento de meirino et pectet mihi pro unoquoque II morabitinos. - Cf. Mon. Lus. XV c. 13.

- Ueber pennas s. Leges 192-196. - Vgl. Randglosse IV u. XIV.

5 Wären diese Randglossen speziell für Portugal bestimmt, so müfste ich über cendal, zendal, sindal Längeres und Breiteres mitteilen, da ein so gründlicher Kenner des Mittelalters wie Gama Barros I 534 bekennt, er wisse nicht was das im Elucidario fehlende Wort bedeute. Da ich dem Ausland jedoch nichts wesentlich Neues über Stoff, Farbe, Wert und Verwendung zu bieten habe, verweise ich die hiesigen Forscher auf Fr. Michel's Recherches sur les Etoffes de soie (Paris 1852) und P. Meyer's Anmerkungen zum FlamencaRoman; Du Cange s. v. cendalus, sendadus. - Was Portugal betrifft, so sei nur bemerkt, dafs cendal auffallenderweise in der Preistabelle vom J. 1253 nicht vorkommt, wohl aber in der Kleiderordnung Alfons' IV. Im Liederbuch begegnen wir ibm in CV 847 und 948 (in Braga's Ausgabe auch noch in No. I03 I); bei Alfons $X$. in CM 292, 14. - Als Futterstoff steht es meist gegensätzlich der penna, d. h. dem Pelzfutter gegenüber. Wo es sich um Wertangabe handelt, neben Sammet und Purpur oder Scharlachtuch.

- CV 048:

E pesa-m' én e é mi mal que lh' escarniron seu brial que era nov' e de cendal.

Im unmittelbar folgenden Spottlied wird dasselbe Kleidungsstück als brial de Sevilha bezeichnet. Aus den voranstehenden (945 - 947) haben wir erfahren, dals es zur Weihnachtszeit einer schönen Infançða geschenkt worden war. Wieder ein andres Gedicht (CV 796) klärt darüber auf, was für ein Oberkleid der Frauen-brial gewesen sein muls. 
Schmuck des Mantels eines Rico-homem aber dem Monarchen mifsfallen, wenn nicht gar gegen einen Paragraphen der Kleiderordnung verstolsen mochte. Ich sage als Schmuck (guarniçao), und stelle mir vor, es handle sich um eine Einfassung - wie sie die hochinteressante Preistabelle Alfons' III. vom J. I 253 unter cum penna oder scotada cum penna versteht.1

An einen Mantelparagraphen wie den obigen aber dachten Alfons X. und Vasco Gil, aller Wahrscheinlichkeit nach. Das portugiesische Dekret war bald nach den Côrtes de Guimarães (1 250) erlassen worden. ${ }^{2}$ Den entsprechenden und gewifs vorbildlichen hispanischen Text vermag ich nicht anzuführen, zweifle aber nicht an seinem Vorhandensein schon vor den Côrtes de Valladolid vom J. 1258. Auch eine Art Kleiderordnung muls an beiden Höfen damals erlassen worden sein, mit Einzelbestimmungen ähnlich den von Alfons IV. verfügten. ${ }^{3}$ Das schliefse ich aus einem Spottliede des CV, worin einem filzigen Infançon von demselben alfonsinischen Troubadour, der sich mit den Schwestern unsres Vasco Gil beschäftigt hat, 4 vorgeworfen wird, er übertrete des Königs Gebot - o degredo del rey; denn dieser habe verfügt, der Mantel des Infancon solle alle zwei Jahre erneuert werden, er aber trage den seinen nun schon im dritten oder vierten Jahre. 5

Das Studium der Dekretalien, auf das König Alfons sich in seiner Entgegnung bezieht, könnte man mit einiger Wahrscheinlichkeit in die Epoche der Vorarbeiten zur Gesetzes-Reform verlegen, in der die Tenzone entstanden ist, um so mehr als schon Ferdinand III. dieselbe geplant und zu ihr angeregt hatte. Der Wortlaut zwingt jedoch, an vergangene Zeiten, also an des Gelehrten Mocedades, zu denken. Zwar wurde Salamanca erst 1254 (durch die Bullen Papst Alexander's IV. vom 25. Mai, 13. Juli und 1. Oktober) erweitert und den drei europäischen Estudos Generales - Paris, Oxford, Bologna - gleichgestellt, nachdem Alfons

1 Für „Futter" wurde forro, für „gefüttert" dobrado gesagt, Leges I 96. Von der garnacha, dem tabardo und manto cum penna und sine penna ist daselbst mehrfach die Rede. Und in der ungedruckten Verordnung von 1340 findet sich sogar com penna ou com cendal mit Bezug auf tabardo, manto oder pannos (im Sinne von "Anzug") Dutzende von Malen, wo auseinandergesetzt ist, welches Tuch, welcher Schnitt und welcher Besatz dem König und der Königsfamilie, dem Rico-homem, dem Cavalleiro, Escudeiro und Cidadão erlaubt war, und wie oft er sich beim Schneider neu einkleiden durfte. Siehe Gama Barros I 533-536.

2 Die Hauptdekrete Alfons' III. über seinen eignen Haushalt und den seiner Unterthanen fallen in die Zeit von 1250-1261 (Leges 192-210).

3 Es wird darin unter vielem andern festgestellt, der Magnat dürfe sich jährlich drei Anzüge com perna ou com cendal, der Ritter ihrer zwei, der Escudeiro sich jährlich einen neuen Anzug sem penna nem cendal zulegen. - In der ungleich einfacheren und sparsameren Zeit Alfons' III. muIste, dem Anschein nach, ein Anzug selbst dem Rico-homem und Infanzon ganze zwei Jahre dauern.

- João de Guilhade, CV 37.

5 CV 1103. S. den Liederanhang (5). Vgl. CV 1168. 
zwei Jahre zuvor (9. November 1 252) die Statuten ausgefertigt hatte, kraft deren er vier Lehrstühle für Juristerei stiftete und reichlich dotierte. ${ }^{1}$ Doch war kanonisches Recht ebenda schon früher in der 1220 von Alfons IX. errichteten und I 239 von Ferdinand III. erweiterten Theologie-Schule von ausländischen Doctoren gelesen worden.2 Und nicht minder in der bereits 1209 zu Palencia unter minder glücklichen Auspicien gegründeten kastilischen Akademie. ${ }^{3}$

Die Selbstaussage des Königs in unsrer Canzone - brauchbar als Beweis dafür dafs er thatsächlich eine Hochschule besucht hat - zeigt nicht, ob das in Leon oder Kastilien geschehen ist; doch hört man in seinen eignen Liedern und in denen der Zeitgenossen sowie in Prosawerken des I 3. Jhs. immer nur von escholas und escholares de Salamanca. 4 Nie aber von den escholas de Palencia, die durch das rasche Aufblühen der jüngeren Schwester bald in den Schatten gestellt wurden.

$\mathrm{Ob}$ des Königs Maestres die gleichen gewesen sind, die er später zur Ausarbeitung seiner Ideen heranzog? Mestre Roldan? Jacome Ruiz? Mestre Martin?

Dals er als Student das Gewand des Klerikers getragen hat, darf man als selbstverständlich gern glauben. Clerizon - übrigens eine hispanische, keine gallizisch-portugiesische Bildung ${ }^{5}$ - benennt heute den Chorknaben (monacillo), während die Scheideform clerizonte allgemeiner auf denjenigen angewendet wird, der, ohne ordinierter Priester zu sein, in geistlicher Tracht einhergeht; im tadelnden Sinne auch auf den Kleriker, der im Aeufsern und im Betragen den Anforderungen guter Sitte nicht nachkommt. Im Portu-

1 Mando e tengo por bien que haya un maestro en Leyes e yo le dé quinientos maravedts de salario por el año: e que haya un Bachiller Legista. Otrost mando que haya un Maestro en Decretos e yo le dé trescientos maravedis cada año. Otrost mando que haya dos Maestros en Decretales $e$ yo que les dé quinientos maravedis cada año. Ordenanģas Reales X 51 , I in den Adiciones zur Partida II 31, I-I I, wo Ausführliches über die Estudios Generales steht.

2 Vidal, Memoria Hist. sobre la Universidad de Salamanca 1869. Braga, Hist. Univ. I 76. - Luc. Tud. (in Schott IV I 13 ) sagt: Hic [= Adefonsus Rex Legionis] salutari consilio evocavit magistros peritissimos in sacris scripturis \&o constituit scholas fieri Salmantia.

8 Luc. Tud. (Schott IV 109) Eo tempore (vor der Schlacht bei Las Navas) Rex Adefonsus evoiavit magistros theologicos et aliarum artium liberalium \& Palentia scholas instituit procurante reverendissimo \&o nobilissimo viro Tellione eiusdem civitatis episcopo. Quia ut antiquitas refert, semper ibi viguit scholastica sapientia, viguit \& militia. - Rod. Tol. VIII c. 34 ... sapientes a Gallis et Italia convocavit ut sapientia disciplina a regno suo nunquam abesset et magistros omnium facultatum Palentia congregavit quibus et magno stipendio est largitus: ut omni studium cupienti quasi manna aliquando in os influeret sapientia cuiuslibet facultatis. Et licet hoc fuit studium interruptum, tamen per Dei gratiam adhuc durat (Schott II 128). Vgl. Risco 382. die Rede.

- CM 291. Vgl. Script. 285. - CV 410. 1181.1197 ist von einem escolar

- Auch dadurch ist der Rei Don Alfonso als Kastilier gekennzeichnet. 
giesischen diente das entsprechende clerigon vorwiegend zur Benennung des Scholaren, dessen longos pannos geistlichen Zuschnitt gehabt haben und noch heute bewahren. ${ }^{1}$

Nicht dem straffälligen Manteldieb, dem geschickten Gaukler will der Vasall seinen König gleichstellen. Das für denselben vorgeschlagene Wort trageitador, das nicht zu den verpönten Schmähworten, sondern dem usuellen Volkswörterschatze angehört, 2 war und ist noch heute, neben estrugeitante, die übliche Bezeichnung für den Jongleur, Taschenspieler und Nekromanten. ${ }^{3}$

Welcher unter den vier Königen von Portugal, die vor I 255 zu den Toten gehörten, mag dem König Alfons als Typus des Muster-Gauklers und Manteltauschers vorgeschwebt haben? Die Antwort: natürlich der, welcher den weifsen Mantel mit dem roten Kreuz der Hospitaliter getragen hat, scheint einfach; und ist es doch nicht, bei unsrer erstaunlichen Unkenntnis über das Leben der altportugiesischen Dynasten und ihr Verhältnis zu den Ritterorden.

Sancho II. ( $\dagger$ 1 248), an den man zu allererst denkt, weil es der einzige ist, von dem die Geschichte meldet, er habe im Leben wie im Tode jenes geistliche Gewand getragen, dem er den $\mathrm{Zu}$ namen Capello dankt, ist ausgeschlossen. Alfons, der ihn von Angesicht zu Angesicht gesehen, ihn von Portugal nach Kastilien geleitet und das Schwert für ihn gezogen hatte, 4 konnte wenige Jahre später unmöglich vergessen haben, in welcher ungewöhnlichen Tracht der im Kriege so tapfre, im Frieden lässige Monarch einherging. Um so weniger als sein Grabmonument, das ihn als

1 In fi-de-clerigon (CV 1201) hat es böse Nebenbedeutung.

2 Mit Recht wird im Glossar zu den Marienliedern des Königs das prov. trasgitar trasgiet trasgitamens neben trasgeito CM 77 gestellt (wozu noch tragitador käme); mit Unrecht aber wird behauptet, die gallizische Form sei Lehngut. Das ist sie ebenso wenig wie das kastilische trasechador (Alex. 1822).

- Vgl. Ordenaçzes Aff. III 15. 18, wo vom trageitador gehandelt wird. Trageitos sind alle Gaukeleien - bei Soropita (16. Jh.): sabe mais tregeitos que um cigano -, aber auch spottende Geberden. Im alten Gemeinderecht der Stadt Evora (14. Jh.) findet sich z. B. in einer kuriosen Verordnung über böse Weiberzungen (\$113 Renda das bravas) die Bestimmung: e mandarom que nem per tregeytos nem per remoques nem per cantigas se nom doestem (Doc. Ebor. I 150) und (ib. 189): $E$ porem ordenou e mandou que daqui endiante qualquer molher que em praça ou em rua ... doestar per pallavra ou trejeito ou per almara (?) nu em remoque... pague por a primeira vez 50 rs.; e por a segunda seja presa e da cadea, jazendo hi tres dias, pague 100 rs.; e per a terceira vez seja enfreada e degradada pubricamente com o freo na boca fora da cidade e seos termos, ataa merce del Rey. - Heute ist die Wendung tregeitar esgares (= Fratzen schneiden, Faxen machen) recht beliebt.

- Die portug. Chroniken berichten nur, Alfons habe ihn geleitet: $E$ des alli emviou Rey dom Sancho pollo ifante dom afomso filho del Rey dom fernando de castella, e de leam, e el foy com el com muy gram cauallaria e leuou ho consigo pera castela (Script. 31). Andre Schriftstuicke beweisen, dafs es 1248 zum Kampf gekommen ist. Die Cron. Gen. kann ich nicht zu Rate ziehen. Das ganze Kap. 7 in der spanischen Cron. Alf. ist unbrauchbar. 
Franziskaner mit Kutte, Kapuze, Strick und Sandalen zeigt, in Toledo vor den Augen beider Dichter stand.1 Unmöglich konnte er auch von Sancho mit aprendi und oi dizer berichten. Und gerade einem der treuesten Vasallen des verleumdeten Entthronten gegenüber, dessen Schicksal den König so ergriffen hat, dafs er noch im Alter, verlassen nicht nur von seinen Vasallen, sondern von den eignen Kindern, ausrief:

\section{Nunca assi foy vendudo rei don Sanch' en Portugal. 2}

Es mufs sich um einen vor Lebzeiten oder in der ersten Kindheit Alfons' $X$. verstorbenen handeln:

Nicht um Alfons II. ( $\dagger$ 1 223), den harten Bedränger des Klerus, der sich den Hospitalitern durchaus nicht geneigt zeigte und ihren Uebergriffen auf dem Gesetzeswege entgegentrat. ${ }^{3}$

Es bleiben somit nur Sancho I. ( $\dagger$ 1 211 ) und Affonso I. Henriques übrig ( $\dagger$ I 185$)$. Beide, besonders aber der jüngere, räumten dem Orden grofse Freiheiten ein und beschenkten ihn mit Ländereien und Geldmitteln. ${ }^{4}$ Von keinem aber wissen wir, dafs er ihm beitrat. Von keinem auch, dals er dadurch irgendwelche Vorteile hätte erringen können.

Die Frage bleibt also ungelöst.

Die unbestimmte Form, wie der tenzonierende Monarch seine Anspielungen auf eine ihm gerüchtweise zu Ohren gekommene

1 André de Resende erzählt in seinem Briefe Ad Barth. Kebedum (p. 215), er habe den Entthronten zu Toledo in schemate monachi ex divi Francisci in quod propensus fuerat institutum gesehen. - Auch der Name Capello, der nicht erst im 14. Jh. im Grafenbuch auftaucht (Script. 255), sondern schon im 13. üblich war (ib. 21 u. 22 und Cron. Alf. c. 7; cf. Herc. II 328) und von den Zeitgenossen, wahrscheinlich im Heerlager des "Grafen", wie Alfons III. damals hiels (CV 1088 u. 1089), geprägt worden ist, spricht deutlich genug. (Capeludos und Capuchos = Kapuziner oder Kapuzer nannte das Volk später die Jünger des Heiligen von Assisi). - Frei Manuel de Esperança in seiner Cronica Serafica I 4 c. 36, \& 3 und D. José Barbosa im Catalogo das Rainhas p. 147 legen den Sachverhalt verständig dar. - Das Bestreben des unzuverlässigen Nicolau de S. Maria nicht nur Sancho II., sondern auch Sancho I. und Affonso Henriques dem Augustiner-Orden einzureihen, hat keine historische Grundlage (Chron. dos Conegos Regrantes), ward aber trotzdem von anderen geteilt, z. B. Anaceph. 99; Aschbach II.

2 CM 235.

- Leges 170. 555. 718.

- Von Affonso Henriques heifst es in der Chron. Breve: E este Rey dom affonso comegou a hordem de santiago e deu ao esprital de jerusalem oiteenta mil marauidis em ouro pera comprar herdade de tanta renda per que dessem aos enffermos da enffermaria senhos pades quentes $e$ senhos uasos de uinho porque metessem cada dia em oraçom este Rey dom affonso. - Im Grafenbuch, wo sie mit sachlichen Varianten und natürlich auch in veränderter Orthographie erscheint (Script. 255), wird noch hinzugefügt: e deu gramdes liberdades aa dita ordem do Espital no priorado de Portugal. Ueber das Thatsächliche erhält man Auskunft in Gama Barros' trefflicher Hist. da Admanistrafado I 367 ff. - Sancho I. schenkte den Hospitalitern die Feste Belver (ib. und Mon. Lus. IX c. II). - Vgl. Nova Malta. 
Mantel-Anekdote vorbringt, berechtigt jedoch $\mathrm{zu}$ folgender Vermutung. Sie kann den einzigen Fürsten aus dem burgundischportugiesischen Königshause, der thatsächlich dem Orden angehört hat, betreffen: den im Jahre 1207 verstorbenen XX. Grofsmeister D. Affonso de Portugal, einen Bastardsohn des ersten und Halbbruder des zweiten Königs. ${ }^{1}$

Was Wunder, wenn mehr als ein halbes Jahrhundert nach den Ereignissen (I 194 war er Meister geworden) die Sage sich des abenteuerlichen cavalleiro do Espital aus königlichem Geblüte bemächtigte und die heute unbekannten Gründe zu seinem Eintritt in den Orden als Gaukelei oder gelungenen Schelmenstreich gedeutet hätte, ihn obenein noch mit seinem gleichnamigen Vater (D. Affonso I.) verwechselnd?

Der Gedanke, der Mantel, mit dem Alfons X. die Dienste des D. Vasco Gil belohnt hat, sei der einem Commendador do Hospital zukommende gewesen, liegt nahe. ${ }^{2}$ Aber pafst dazu, dafs Pelzwerk (pena) an demselben $\mathrm{zu}$ sehen war?

Im Liederbuch findet sich noch eine Tenzone von bitterböser Art, in der ein D. Vaasco mit einem unbekannten Spielmann Pero Martĩiz die Entartung des Ordens geifselt. ${ }^{3}$ Auf die Frage, wer Meister (commendador) in der Knauserei, in Lüge, in Unzucht und in der Verleumdung sei, wird zuerst entgegnet, der Maldizentes seien an die tausend; dann aber werden die hervorragendsten in den übrigen drei Lastern namhaft gemacht. Darunter ein Don Roy Gil. Ein Prior dieses Namens regierte den Orden von 1 233-1 244, bestätigt von Sancho II. ${ }^{4}$ 1 238 finden wir D. Vasco Gil in dieses Königs nächster Umgebung. Kein andrer D. Vasco tritt als Dichter in den Liederbüchern auf. Die Tenzone ward unter den Liedern des D. Joa o Soares Coelho aufbewahrt, der, wie unser Poet, sowohl am portugiesischen als auch

1 Hist. Gen. I 61. - In der St. Johanniskirche zu Santarem (S. João de Alporão) lautete seine Grabschrift:

In ara MCCXXXV Kalendjs Martii obiit Frater

Alphonsus Magister Hospitalis Hierusalem.

Quisquis ades qui morte cadis perlege plora

Sum quod eris, fueram quod es, pro me precor ora.

Seit 1845 wird der Grabstein im Klosterhof von S. Francisco aufbewahrt. Andere haben gelesen: Era MCCXLV. X Kal. Martii.

2 CV 1132 .

3 CV 1020.

- Figueiredo, Nova Malta I 256 u. 295-30I; II § 15. - Die Schenkung von Palmella, Alcacer, Cezimbra an den Ritterorden von Santiago und die von Arronches an Sancta Cruz de Coimbra unterzeichnen (1235 und 1236) unter andern Rodericus Prior Hospitalis, D. Egid. Velasci tenens Sausam und D. Mart. Egidii tenens Ripam Minii, d. h. der Vater und der Bruder des Dichters. - Herc. II 495. 496. - Der in der Tenzone gleichfalls geschmähte Roy Martins könnte der so genannte Commendador de Tavara sein, der noch 1251 in der Nähe Alfons' III. auftritt (Leges 190), doch besonders unter dem Vorgänger von sich reden machte. S. Figueiredo, Nova Malta, Lisb. 1800 , I $\$ 290$. 
am kastilischen Hofe, und zwar scheinbar in engen Beziehungen zu den hier wie dort regierenden Königen nachgewiesen ist. Es ist also sehr wohl möglich, dafs D. Vasco Gil Verfasser der Tenzone ist. Doch nur möglich. Und stände es fest, so wäre auch damit weder erwiesen, dals der Mantel, der den Gegenstand dieser Glosse bildet, zum Ornat eines Hospitaliter-Komthurs gehört hat, noch dals D. Vasco Gil wirklich jemals ein solcher gewesen ist.

Aus den übrigen Versen des Vasco Gil ergiebt sich nichts über sein Leben und Wirken. Weitere Spottlieder fehlen. Seine Liebeslieder aber (CA 144-156) sowie das einzige erhaltene Mädchenlied (CV 266) unterscheiden sich durch keinerlei Sonderzüge von denen seiner Zeitgenossen. $\mathrm{Ob}$ sie in Portugal unter Sancho II., oder am Hofe des Gelehrten, oder nach der Heimkehr entstanden sind, als der Dichter um D. Froilhe Fernandes warb, mufs dahingestellt bleiben. 1

\section{Liederanhang.}

(2.) CV 37.

Joăo de Guilhade.

Deus! como se foron perder e matar mui bras donzelas, quaes vus direi: foi Dordia Gil[es] e foi Guiomar que prenderon ordin! Mais, se foss' eu rei,

5 eu as mandaria por én [a] queimar porque foron mund' e prez desemparar!

Non metedes mentes en qual perdiçon fezeron no mund' e se foron perder? Com' outras arlotas viven na raçon,

10 por muito de ben que poderon fazer. Mais eu por alguen ja mort' ei de prender que non vej' e moiro por alguen veer.

Outra bớa dona que pelo rein'(o) á de bon prez e rica e de bon parecer,

15 se mi-a Deus amostra, gran ben mi fará, ca nunca prazer verei sen a veer. ¿Que farei, coitado? moiro per alguen (que non vej' e moiro por veer alguen) [que ja non me pode faser nenhun ben].

CV. 2 uiui - boas - 3 Oordia gil. Das Patronymicum hat sich nicht eingebürgert. Um die fehlende Silbe zu gewinnen, wende ich die Form an, die dem lat. Egidii der Urkunden genau entsprechen würde. - 7 pdicō 8 feson - 9 arllotas - racon - 10 podom faz - 13 ouc do $\bar{a}$ - Beyno -

1 Danach mufs präcisiert werden was in Gröbers Grundr. IIb S. 109 und bei Lang, $C D$. p. XXVIII und XXXV über Vasco Gil ausgesagt wird.

Zeitschr. f. rom. Phil. XXV. 
18 Die reimlose Zeile ist Wiederholung von 12. Ein offenbares Schreiberversehen, das hoffentlich durch Einsicht des CB zu berichtigen sein wird besser als durch meine Konjektur.

Mit dem naiv-häretischen Inhalt vergleiche man (CB 1528) die Klagen des Grafen Gil Peres bei einem ähnlichen Anlafs. Aos olhos de muitos nao tinham talvez grande sabor de hereticas as palavras do trovador J. de G. quando affirmava que se fosse rei, mandava queimar as donsellas Ordia Gil e Guiomar porque se foram perder e matar em religião - so schliefst Gama Barros seine Darlegung der Kloster-Entartung im 14. Jh. und der Weherufe des Frei Alvaro Paes. - Dafür dafs auch im I3., zur Zeit Guilhade's und des Vasco Gil, die Sittenlosigkeit der Mönchs- und Ritterorden Anlafs zu Klagen gab, enthalten die Liederbücher und die Adelsbücher Beweismaterial die Masse.

\section{(3.) CV 1098.}

Ayras Peres Vuiturom.

Joan Nicolas soube guarecer de mort' un om' assi per sa razon que foi julgad' a foro de Leon que non devia de mort' estorcer.

5 e socorreu-s' assi con esta lei "que non deve justiça fazer rei en ome que na mão [non] colher'."

E pois el viu que devi' a prender mort' aquel om' assi, disse -lh' enton:

Io „ponho que fez aleiv' e traizon e cousa ja per que dev' a morrer." Dizede vos, se a terra leixar' que me non achen $i$ a justiçar, ¿se poden en mi justiça fazer?

I Fohan incholas - 4 demo castorger - 5 efa correu fsafsy 6 rustiga - 14 rustigar - 14 podera.

\section{(4.) CV 1078.}

Joăo Ayras de Santiago.

Ay, Justiça, mal fazedes que non queredes ora dereito filhar de Mor da Cana porque foi matar Joan Ayras, ca fez mui sen razon.

5 Mais se dereito queredes fazer, ela so el devedes a meter, ca o manda o livro de Leon.

Ca lhi queria gran ben e des $\mathrm{i}$ nunca lhi chamava se non "senhor"“ Io e quando lh' el queria mui milhor, 
foi o ela logo matar ali.

Mais, Justiça, pois tan gran torto fez, metede - a ja so el ia vez, ca o mandan, e dereit' é assi.

I5 E quando mais Joan Ayras cuidou que ouvesse de Mor da Cana ben, foi o ela logo matar por én tanto que el en seu poder entrou. Mais, Justiça, pois que assi é ja

20 metan-a so el, et padecer-á a que o a mui gran torto matou.

E quen-nos ambos vir' jazer dirá: „bẽeito sej(a) aquel que o julgou“.

3 In Zeile 16 steht caua. Braga nennt die Heldin dementsprechend Cava; doch wird Cana das Richtigere sein, da es ein gallizischer Orts- und Familienname ist, der auch sonst noch im Liederbuch vorkommt - 8 q $r a-9$ senor - 10 qra - 13 solle - 14 eno manda d d' eyte as $\int y$ - 17 mara 20 met' ana (das wäre meteran-na, wodurch die Zeile um eine Silbe zu lang wird) - 21 trio -23 beeyto

Wie man sieht, stellt sich João Ayres als sterbend vor Liebe hin, klagt Mor da Cana des Mordes an, und verlangt vom Richter Anwendung des Gesetzes, auf das ich im Texte Bezug nahm. Wäre im Liede irgend ein Hinweis auf Krieg und Kriegsrecht, so könnte man an die Gesetzbestimmung im Espejo de todos los derechos denken (III 8, 4; Opus. Leg. I 1 23), durch welche für Unruhstifter im Feldlager angeordnet wird: Et qui matare a otro, metanle so el muerto.

\section{(5.) CV 1108.}

Jozo de Guilhade.

Par Deus, infanzon, queredes perder a terra, pois non temedes el rei; ca ja britades seu degred', e sei que lh' o faremos mui cedo saber;

5 ca vus mandaron a capa, de pran, trager $d o[u] s$ anos, e provar vus an que vo'-la viron tres anos trager.

E provar-vus-á das carnes quenquer que duas carnes vus mandan comer

to e non queredes vos d' $d_{a}$ cozer; e no degredo non á ja mester nen ja da capa non ei a falar, ca ben tres anos a vimos andar no vosso col' e de vossa molher.

I5 E fará el rei côrte este mes e mandaran - vus, infanzon, chamar e vos querredes a capa levar e provar-an-vus, pero que vus pes, 
da vossa capa e (do) vosso gardacos

20

en cas del rei vus provaremos nos

que an tres anos e passa por tres.

1 Par den - 3 birtades - 6. 7. 13 aug - 14 deuessa - 16 emādam uos - 20 emas - 21 trans - $p$.

Die Anspielung auf die zwei Fleischgerichte, die auf des Ritters Tische aufgetragen werden durften, 'betrifft die Verordnung vom I I. April I 258 \& I4 (Leges 209). Cf. Randgl. III.

\section{(6.) CV 1220.}

Pero Martziz, ora por caridade

vos que vus tẽedes por sabedor

dizede-mi ¿quen é comendador

eno Spital ora da escassidade?

5 ou na franqueza? ou quen no forniz?

ou quen en quanto mal se faz e diz?

Se o sabedes, dizede verdade.

„Pois, don Vaasc', un pouco $\mathrm{m}$ ' ascoitade:

Os que mal fazen e dizen son mil;

10 eno forniz é [mestre] don Roy Gil;

e Roy Martĩiz é [o] na falsidade;

e (e)na (e)scasseza é-o seu prior.

Non vus pod' om' esto partir melhor;

se mais quiserdes, por mais perguntade."

15 Pero Martiz, mui ben respondestes, pero sabia-m' eu esto per mi, ca todos tres eran senhores $i$, das comendas comendadores estes; e partistes-mi-o tan ben que m' é mal.

20 Mais ar quer' ora de vos saber al: que (mi) digades de quen o aprendestes.

„Vos, don Vaasc', ora me cometestes

d' outros preitos. Des $i$ ar dig' assi :

non mi deu algo, pero lh' o pedi,

25 o priol; e f..i e vos f...estes

con Roy Gil(es); e meus preitos talhei

con frei Rodrigu' e mentiu-m'os; e sei

per aquest' a sa fazenda d' aquestes."

Pero Martitis, respondestes tan ben

30 en tod' esto que fuistes i con sen

de trobador; e cuid' eu que leestes.

Vos, don Vaasco, tod' esso m' é ben (?)

ei sis' e sei trobar e leo ben;

¡mais que tàrdi que mi-o vos entendestes!

I martuz. Die Dichtenden sprachen den Namen bald zweisilbig (I. I1. 29), bald dreisilbig. - 2 teedes - 5 Aus der Antwort in Z. 11 entnehme 
ich, dals hier falseza stehen mürste. - $6 f a s-9$ mal - 10 Man könnte auch Rodrigo statt Roy setzen - 11 m'tiiz - 12 p'ol - 14 quisedes 15 respondedes - 16 min - 19 epar ustos mho - 26 roygal - 27 mentiumuhs - 30 foystes - 31 e trob. - 32 Der Reim ist nicht in Ordnung. Die Findas sind überhaupt nicht regelrecht gebaut.

\section{III.}

Vom Mittagbrod hispanischer Könige.

Die zweite Tenzone, als deren bis heute unerkannten Mitarbeiter ich Alfons X. betrachte, geht von einem hochstehenden Beamten aus, der seinen Herrn ohne nähere Bezeichnung mit Senhor anredet.

Dieser Beamte, der zu fragen anhebt, ist ein gallizischer Edelmann, von dessen Thaten die Chroniken Alfons' X., seines Nachfolgers und seines Enkels, mancherlei zu berichten wissen. ${ }^{1} \mathrm{Da}$ ich sein Leben schon anderwärts mit möglichster Genauigkeit erzählt habe, ${ }^{2}$ sei hier nur das Wesentlichste erwähnt. Der 1295 durch die Gewaltthat eines politischen Gegners aus dem Weg geräumte Pay Gomes Charinho hat im J. I284 unter Sancho IV., und vielleicht auch schon unter dem Vorgänger, als Flottenadmiral Dienste geleistet. Laut Angabe eines seiner Lieder ${ }^{3}$ war er bei der Belagerung von Jaen (1246) mit thätig. Nach Aussage seiner Grabschrift hat er an der Einnahme von Sevilla (1248) hervorragenden Anteil gehabt. Er ist Verfasser des höfisch mafsvollen, doch charakteristischen politischen Sirventes, in welchem ein König von Kastilien und Leon in Tadel und Lob mit dem Ozean verglichen wird, unter Anerkennung seiner grofsartigen Freigebigkeit sowie seines hohen Sinnes, aber auch unter Betonung seines Wankelmuts und Jähzorns. ${ }^{5}$ Damit kann nur der gelehrte hispanische Dichterkönig gemeint sein.

Und da keiner von seinen Söhnen Poet war, in Z. 9 aber das Wort rey fällt, aus dem Munde des Antwortenden und mit deutlicher Bezugnahme auf ihn selbst, ${ }^{3}$ scheint mir die Urheberschaft gesichert.

Doch hören wir das nicht ohne weiteres klare Gedicht.

Û̉a pregunta vus quero fazer, Senhor, que mi devedes a solver (?). ¿Por quê vẽestes jantares comer que ome nunca de vosso logar

1 Cron. Alf. c. 76. - Cron. Sancho c. 7. - Cron. Fern. c. I.

2 In der Einleitung zum CA Kap. VI Biogr. XXVII.

3 CV 429.

- CA 256.

5 Sonst hätte man in dem Senhor den Kronforderer und Infanten D. Juan suchen dürfen, in dessen Diensten Charinho stand und von dem sein Tod gerächt wurde. 
5 comeu? Esto como pode seer?

ca vej' ende os erdeiros queixar.

„P[a]ay Gomes, quer' eu vus responder por vos fazer a verdade saber:

¡ouv'-aquí reys [e] de mayor poder

10 en conquerer e terras guaanhar, mais non quen ouvesse mayor prazer de comer, quando lhi dan bon jantar!“

Senhor, por esto non digu' eu de non de ben jantardes, ca é gran razon;

15 mai'-lus erdeiros fôr' an de Leon: guerreian vosco, porque an pavor d' aver sob(re) (l)o seu con vosc(o) entençon e xe lhis parar outr' anno peyor.

„P[a]ay Gomes, assi Deus mi perdon,

20 muy gran temp' á que non foi en Carrion, nen mi deron meu jantar en Monçon;

e por esto non søo pecador de comer ben, pois [que] mi-o dan en don, ca de muy bon jantar ei gran sabor."

(CV 1158 = Ind. 1624.)

Ohne erklärende Prosaüberschrift, wie fast alle aus Kastilien stammenden, der präalfonsinischen oder alfonsinischen Zeit angehörigen Texte. - Ich habe mehrfach nachbessern müssen. Im diplomatischen Abdruck des CV steht in Z. I hũa - 2 afazer - der Schreiber hat also irrtümlich das Reimwort aus Z. 1 wiederholt - 3 noiestes - 5 esto que pode seer, so dals eine Silbe fehlt - 7 (u. 19) Pae, so dafs abermals die Zeile zu kurz gerät. Die gute alte Form Paay findet sich im Index vor No. 145; in der Ueberschrift $2 u$ CB 144 (= 116) und sonst öfters - 8 preus - $9 c \bar{o}$ qirer e en tiräs $q .-$ 15 foy - 16 quarian - Etwa querian? Dann mülste man die unwahrscheinliche Lesart annehmen: mai'-lus erdeiros foro de Leon | querian vosco 18 out'no - $20 \bar{g} m$ téra - 21 foi, als 1 . Sg. statt des später allein üblichen fui, wie dutzendfach in den mitgeteilten Texten. - carrhou für carrhon, die alte Schreibart von Carrion - 22 e p' esto no s8o p. - 24 b8o, vgl. V 4.

Die Dichter spielen mit dem Worte jantar. Dasselbe bedeutet bekanntlich aufser dem gewöhnlichen Mittagsessen auch die Abgabe, welche auf der Halbinsel in Friedenszeiten (einmal jährlich, oder mehrfach, anfangs in Naturalien) für den Unterhalt der Könige von den Gemeinden und Klöstern gezahlt wurde, wo jene gerade mit grolsem oder kleinem Gefolge rasteten,1 später aber in Soldos

1 Die übliche Erklärung lautet: certa imposiça de mantimento para a casa e pessoa del rey quando hia fazer justica pelo reyno; oder: para jantar dos Reys quando väo pellas terras fazer justiģa (Elucid. s. v.). - Ueber die yantares in Spanien vgl. Schäfer, Gesch. Span. II 471. 514; in Portugal Herculano IV 402-408; Gama Barros I 342-349; Schäfer, Gesch. Port. I 274 u. I 166; s. auch Elucid. s. v. jantar - colheita - censo - parada - servigo - comedura - comeduria; - J. P. Ribeiro, Diss. Chron. IV 2 p. 124; Refl. Hist. I 58. - Mon. Lus. XVI c. 27 (mit Bezug auf die erste Reise des 
und Maravedis. Einesteils wird scherzend auf die gesegnete, kurz vor Abfassung der Tenzone wieder einmal bewährte Elslust des Königs hingewiesen; ${ }^{1}$ andrenteils auf unberechtigte Einforderung der Jantar-Abgabe. Bevorberechtete, die unerlaubterweise zur Leistung herbeigezogen worden waren, hatten dieselbe teils erfüllt, als grofsmütige Geber (en don), teils sie abgewiesen: in beiden Fällen aber gemurrt und Beschwerde geführt.

Genannt werden Carrion und Monzon. Da es sich offenbar um nahe beisammen gelegene Plätze handelt, die nach einander vom reisenden Rechtspfleger besucht wurden, denke ich an Carrion de los Condes und das in derselben Gegend gelegene Monzon de Campos, früher gemeinhin Monzon de Palencia genannt.2

Hier muls ich eine Parenthese machen. Mit meiner Bemerkung über Monzon stehe ich in Widerspruch zu C. de Lollis. ${ }^{3}$ Die Klage oder Anklage des dichtenden Königs

$$
\text { non mi deron meu jantar en Monson }
$$

erinnerte den belesenen Hispanisten offenbar an eine hübsche Stelle aus den angeblichen Memoiren En-Jaime's des Eroberers, worin derselbe, die Verarmung des Reiches schildernd, unter anderm sagt: e no hauiem a $j$ dia quant nos entram en Montso que menjar, si era la terra destroyda e enpenyorada. 4 Darum vermutet er, mit der in unserer Tenzone genannten Ortschaft sei die aragonesische Festung gemeint, aus welcher der künftige Eroberer von Valencia noch im Knabenalter entfloh (1210). Und dieser Einfall verleitete ihn weiterhin dazu, das jantar zum bovage umzuwandeln, 5 einer seit 12 I I (und noch 1217) in Aragon von jedem Ochsengespann und später auch vom Kleinvieh erhobenen Steuer. ${ }^{6}$ Als ob nicht auch in Aragon das jantar Sitte gewesen wäre. ${ }^{7}$ Als ob Jaime mit Carrion zu thun gehabt hätte! Als ob Charinho an seinem Hofe erschienen

Königs D. Denis durch sein Land, 1279). Dazu Nova Malta passim; Esp. Sagr. passim (z. B. XXI 65. 66. 82). - In Spanien sagte man übrigens la yantar, wie u. a. aus den weiter unten mitgeteilten Texten erhellt.

1 Einen andern Hinweis auf scine Efslust findet der Leser in einem Scherzliede Alfons' X. gegen einen Geistlichen, dessen Passions-Predigten ihm zu lang dünkten (CV 73). Er spricht darin von gutem Salm und Ourenser Wein. Es beginnt:

$$
\begin{aligned}
& \text { Com' eu em dia de pascoa queria ben comer, } \\
& \text { assi queria bon son legeiro de dizer, } \\
& \text { pera meestre foan! }
\end{aligned}
$$

2 Rod. Tol. VII c. 2.

s Stud. Fil. Rom. I 37 Anm. Vgl. meine Einwendungen in Randgl. XI.

- En facme c. II.

5 Anche Payo Gomes Charrinho (sic) al n. 1158 che ì una cantiga d' escarnho probabilmente occasionata dall' imposta straordinaria del bovaggio (1217) ricorda questa specie di reclusione di Giacomo I alludendo piü specificamente alla miseria che circondo il povero re nel recinto di Monzon.

- Schäfer, Gesch. Span. III 290. - Schmidt, Gesch. Arag. 171 u. 450. Fueros de Aragon p. 104.

Schmidt 1. c.

7 Nur führte er im Osten den Namen cena. Vgl. Schäfer l.c. und 
wäre! Als ob der aragonesische Monarch gedichtet hätte! - noch dazu gallizisch-portugiesisch - und $z$ war in seiner bedrängten Jugendzeit! - Da der Zusammenhang, in dem ich meine Auffassung darlege, zur Genüge zeigt, dafs es sich um Alfons X. und um Monzon de Palencia handelt, 1 darf ich die Parenthese schon hier schliefsen.

Dals und wann der König von Kastilien und Leon die betreffende Strecke seines Reiches rechtsprechend durchzog, und ob er dabei Monzon und Carrion betreten hat, kann ich freilich nicht dokumentarisch nachweisen. Doch ist es aller Wahrscheinlichkeit nach geschehen, als er die, nach 15 jährigen Erfahrungen mit dem Espejo de los derechos, drohende Rebellion der mit der neuen Gesetzgebung gleichmälsig unzufriedenen leonesischen und kastilischen Granden und Ritter, die bereits nach Helfershelfern in Navarra und Granada Umschau hielten, zu beschwichtigen versuchte. ${ }^{2}$ Von Lerma und Burgos, wo er längere Zeit, zwischen I 270 und I27 I, verweilte, wird er auch den Ritt über den Pisuerga von Palencia nach Monzon und Carrion und weiter bis zum Esla in das Herz des Zwillings-Kronreiches hinein unternommen haben, ob auch die Chronik über diese Einzelnheiten und über den Kampf um die jantares schweigt. 3 Gebucht sind nur die Hauptanklagen, wie sie 1274 auf den Cortes zu Burgos und dann zu Almagro formuliert wurden - in dem Satze gipfelnd, König Alfons achte die alten Freiheiten nicht: que desaforaba a Castilla e Leon. Privilegien, die von der uns beschäftigenden Abgabe, befreiten, waren relativ selten, und konnte die Verletzung derselben nur von einer Minorität empfunden werden. Denn das jantar (ein altes Stückchen Civilliste) gehörte von Alters her zu den vier Dingen, deren die Landesherren in Kastilien sich nicht entäufserten: justicia (Gerichtsbarkeit) - fonsadera (Landesverteidigung) - moneda (Münze) yantar (Dynastenverpflegung) 4 - oder doch nur ganz ausnahmsweise. Wie grofsen Wert sie darauf legten, geht daraus hervor, dafs selbst bei Schenkungen von Schlössern, Burgen und Villen an Königs-Frauen und -Kinder sie sich der jantares nicht $\mathrm{zu}$ entäufsern pflegten. ${ }^{b}$

1 In CV 987 ist thatsächlich die Cinca-Stadt gemeint. Vgl. Randgl. XI.

2 Cronica c. 20-58. - Im Résumé bei Lafuente I 426. - Eine andere Reise durch sein Reich, besonders durch Leon, behufs Rechtspflege unternahm er im J. 1277 (Cron. c. 69).

3 Die servicios bilden nebst den dineros einen wesentlichen Teil der Anklage. Das jantar trug in Portugal bisweilen diesen Namen; doch handelt es sich in den span. Texten, wie aus Cron. Alf. $X$ c. 12. 21.25 und Cron. Fern. $I V$ c. 20 erhellt, um Kriegsdienst und Kriegsabgaben.

- Estas quatro cosas son naturales del señorio del Rey que non deve dar a ningun home nin las partir de si que pertenescen a el por razon del señorio natural: justicia moneda fonsadera e sus yantares. Aus den Ordenamientos der Cortes von Náxera (1 138 ) ging dieser Satz in das traditionelle Gewohnheitsrecht von Kastilien über und blieb bis 1356 gültig. - Fuero Viejo I 1. - Cf. Herc. IV 402; Gama Barros I 81; Schäfer, Gesch. Span. I 166.

5 Im Friedensvertrag von 1206 bedingt sich der König von Kastilien 
Um solche Ausnahmen leonesischen Ursprungs, die der König nicht geachtet hatte, muls es sich bei Charinho natürlich handeln. Von einer Stadt, der solche Mifsachtung widerfuhr und die sich dagegen aussprach - ehe die gemeinsame Erhebung der Geschädigten stattfand - und der auch Alfons ausdrücklich versprach, nach dem Rechten zu sehen, sobald er sie auf seiner Reise beträte, hat sich wenigstens Nachricht erhalten. Und zwar handelt es sich gerade um die Hauptstadt des alten Reiches: Leon.

Otrosi se querellaron los personeros del concejo que el obispo les tomaba la yantar del rey... e desian que el concejo debia haver esta yantar ... por donacion de los reyes \& amostraron previllejos delrey D. Alfonso de Leon \& del Rey D. Fernando sobre esta rason ... en que yasia escripto que estos Reyes daban al concejo generalmente quanto derecho havian en la alfos de Leon ... e quando el Rey veniese a la tierra que el obispo lle diese yantar. ${ }^{1}$

Der von Sevilla aus im J. 1266 und 1269 vom König ergehende Bescheid lautet, man solle warten:

fasta que el Rey veniese en la tierra e estonces que el concejo le diria la verdad del fecho \& que el Rey faria y como señor lo que por bien toviese. ${ }^{2}$

Dafs die leonesischen Freiheiten nicht aufgehoben wurden, brauche ich hier nicht zu wiederholen. Noch 1293 , als die Gemeinden sich verbrüderten zur Wahrung ihrer Hoheitsrechte, und dem König seine vier Naturrechte nicht vorzuenthalten schwuren, schränkten sie dieselben mit Bezug auf die comestiones ein.

Yantar ali du la solian haver los reys de fuero una vez en el año quando venieren al logar, assi como la daban al rey $\mathrm{D}$. Alfonso de Leon el bueno, que venció la batalla de Merida \& a so fijo el Rey D. Fernando; e non a otro ninguno si non al merino mayor una vez en el año en aquellos logares du la deben dar de derecho, guardando los previllegios \& las cartas que los concejos han en esta razon."

von seinem leonesischen Vetter aus, dafs derselbe von den ihm überlassenen Scblössern keinerlei Dienstleistung zu verlangen habe aufser dem jantar: sino que coma en ellos una vegada cada año (Esp. Sagr. XXXVI Ap. p. 134).- Als Alfons IX. im J. 1209, wie ich im CA Kap. VI, Biogr. XXXVII erzählt habe, Ardon, Rueda und Villarpando an seine Gemahlin abtrat, verzichtete er nicht auf sein fantar-Recht noch auf die Moneda-Abgabe: excepto quod retineo in ipsis villis comestionem moderatam et meam monetam sicut in alio regno meo (Esp. Sagr. XXXVI Ap. p. 147). - Alfons X. verfuhr ebenso, als er 1283 der Königin von Portugal, seiner Tochter Beatrix, die Städte Serpa, Moura, Noudar und Mouråo zusprach (Mon. Lus. XVI c. 27).

1 Esp. Sagr. XXXV Ap. XII p. 434 - eine über altleonesische Rechtsgebräuche ergiebig unterweisende Urkunde.

2 Ib. 144 .

3 Ib. XXXVI Ap. LXXI p. 162: Carta de hermandad que los concejos del reyno de Leon y de Galicia hicieron en las cortes celebradas en Valladolid, año de 1293. 
Ob Carrion leonesisches Recht hatte, habe ich nicht feststellen können. Es ist wahrscheinlich. Wie schwankend die Ostgrenze lange Zeit blieb, dals das fuero de Leon bis zum Pisuerga Gültigkeit hatte, ${ }^{1}$ und dals die Supplement-Gesetze der Königin Urraca ( 1 IOg) Carrion mitbetrafen, sind wichtige Einzelnheiten.

Damit ist erklärt, wie in der Jantar-Tenzone vom foro de Leon - in dem schon in Randglosse II berührten, weiteren Sinne die Rede sein durfte.

Die zweimalige Erwähnung von erdeiros als solchen, die durch des Königs Ansprüche oder durch seine neue Gesetzgebung beeinträchtigt waren, könnte verleiten an Unterkunft (pousada) in einer der grofsen Kloster-Herbergen zu denken, wie sie gewöhnlich nebst dem König nur den Stiftern und ihren Nachkommen - den padroeiros, erdeiros oder naturaes - zukam. ${ }^{2}$ Natürlich veranlafste die Verpflichtung zu derlei jantares sowohl ungesetzliche Forderungen, als auch Klagen, Streitigkeiten und Mifsbräuche verschiedenster Art. Alle möglichen Bastarde und Agnaten verlangten ihr jantar. Die Berechtigten stellten sich häufiger ein, als es sich gebührte; brachten Gesellschaft mit, sogar weibliche; dazu grofsen Dienertrols mit Pferden, Falken, Hunden, und verlangten auserlesene Speisen. Es gab Klöster - in Portugal, das ich jetzt mit in Betracht ziehe - die jährlich für mehr als 300 Diners zu sorgen hatten. Darauf bezügliche Verordnungen Alfons' III. vom J. I 26 I ${ }^{3}$ stellen unter anderm fest, dafs in sämtlichen Cisterzienser-Abteien Portugals der König allein und sonst niemand in seiner Eigenschaft als padroeiro und herdeiro zu bewirten sei. ${ }^{4}$ Auch in diesem Falle werden andre mir unzugängliche hispanische und aragonesische Parallelstücke als Vorbilder gedient haben.

Originell und individuell scheint mir hingegen die kernige Verfügung einer biderben Klostergründerin aus der Provinz EntreDoiro-e-Minho, die an solch frevlem Gebahren Anstols nahm. In ihrem Testament bestimmt (1 268) D. Chamoa Gomes: 5 „Verlangt Eine oder Einer meiner Sippe als Erbberechtigter Unterkunft in diesem Kloster - im reizenden fruchtbaren Entr'-ambo'-los rios -, so gebe man ihm einen Spaten in die Hand, ihr aber Wolle nebst

1 Luc. Tud. in Schott IV 89: Dedit ei bonos foros et mores quos debet habere tam civitas quam totum legionense regnum a fumine Pisuerga usque ad extremam Gallacia partem in perpetuum.

2 Ueber erdeiros unterrichtet Gama Barros I 342-9; Herc. III 93; Elucid. s. v. casamento - defensor - igreja - natural - herdeiro. - Schäfer, Gesch. Port. I 166. - Ein Unterschied zwischen naturaes und erdeiros besteht nicht, trotz gegenteiliger Behauptung.

3 P. M. H.: Leges $198-210$.

- Item manda nosso senhor ElRey que os mosteiros de Çistel do seu rreino seiam enparados e nenhuum nom pouse en eles come padrom nem herdeiro, e nenhuum nom seia padrom desses mosteiros nem herdeiro senom ElRey (Leges 209).

5 Chámoa $<$ Flammula (Llambra Lambra). 
Rocken und Spindel; dazu ein Stück Brod, und Wasser so viel sie trinken wollen." 1

Doch zurück zu den Dekreten Alfons' III. Sie enthielten u. a. genaue Angaben über das Menu, aus dem das obligate KlosterJantar der Erdeiros zu bestehen habe; und ferner über diejenigen Speisen, welche Ricos-homes und Infançzes ihren Rittern, Knappen und Mannen zu bieten verpflichtet waren. ${ }^{2}$ Nimmt man dazu, was über des Königs eigenen Tisch bemerkt wird, so sehen die portugiesischen Malsnahmen wie ein Nachklang derer aus, die im Nachbarlande 1258 von den Cortes zu Valladolid ergingen. Einsicht in die bezüglichen Texte notgedrungen für später aufsparend, sei nur verzeichnet was ein Vulgarisator dazu bemerkt, weil es der Efslust des Monarchen zur Folie dienen kann:

En las [cortes] de Valladolid se llegó a poner tasa a los gastos de la casa real, se asignó para comer al rey y a la reina 150 maravedis diarios y se previno que mandase a los que se sentaban a su mesa que comiesen mas mesuradamiente y que no ficiesen tanta costa como facian. ${ }^{3}$

Die Jantar-Abgabe wurde natürlich sehr verschieden berechnet.4 Alfons IX. giebt in dem Friedenspakt von 1206 den von den abgetretenen Schlössern zu leistenden Betrag genau an - Valderas z. B. zahlte 60 Maravedis. ${ }^{5}$ Beim Regierungsantritt Ferdinands IV. (1295) erkannten ihm die kastilischen und leonesischen Gemeinden je 30 Maravedis jährlich $z^{4}{ }^{6}$ Dem rebellischen Thronforderer und Infanten D. Juan, zu dessen Partei unser Charinho gehörte, wurden noch in demselben Jahre die Einwohner von Palencia abtrünnig, weil er 5000-6000 Maravedis von ihnen verlangte. 7 - Die Unkosten in den portug. Klöstern wurden für jeden Adligen nur auf 2-10 Maravedis geschätzt. ${ }^{8}$ - Wenn der Merino im Namen des Königs als Rechtspfleger reiste, hatte er in Ciudad Rodrigo, und

1 J. P. Ribeiro, Refl. Hist. I 57.

2 S. unten.

- Lafuente I 467. - D. Jaime hatte für seine Staaten schon 1234 zu Tarragona Verordnungen über den gleichen Gegenstand erlassen.

- Im portug. Staatsarchiv soll cs ein Buch mit Preisbestimmungen für die von den verschiedenen Städten, Orden und Klöstern zu liefernden KönigsJantares geben.

- Esp. Sagr. XXXVI Ap. 147.

- Esp. Sagr. XXXVI Ap. 162.

- Cron. Fern. c. I: en las cortes de Valladolid fuera ordenado por todos los de la tierra que non diesen al Rey por su yantar en cada villa mas de 30 maravedis de la buena moneda que era estonces (que corria cada maravedi 180 maravedis) e que el infunte don fuan tomaba agora por yantar en cada villa cinco o seis mill muravedis e que asi lo avia fecho en cada lugar do fuera e que bien cuidaba que asi lo faria e lo demandaria agora en Palencia cuando y llegase. - Cf. Benavides, Memorias de D. Fernando IV, II p. 3 u. 7, wo aufser der Carta de hermandad de los concejos de Leon y Galicia die Carta de Herm. de los C. de Castilla abgedruckt ist.

- Leges 209. 
hatten die mitbeschäftigten Alcalden (im J. 1 209) je eine Henne oder ein halbes Zicklein und dazu Brot und Wein zu fordern. ${ }^{1}$

$\mathrm{Da}$ es nicht meine Absicht ist, einen kulturhistorischen Aufsatz abzurunden, sondern nur die zum Verständnis unserer Tenzone nötigen Aufklärungen zu bieten, breche ich hiermit ab.

An Spottgedichten auf jantares im gewöhnlichen Sinne - wenn auch das Juridische mit hineinklingt, da es sich um offizielle Leistungen des pendão e caldeira führenden Nobile handelt - giebt es ein reichliches Dutzend. ${ }^{2}$ Knauserige Ricos-homes und Infanģes, welche ihren Mannen und gelegentlich auch den gastierenden Troubadours und Spielleuten schlechte Herberge und ein karges Mittagsmahl vorsetzten, besonders an Fasttagen (die sich im ganzen auch damals keiner übermäfsigen Beliebtheit erfreut zu haben scheinen); - oder die gar einen solchen wandernden Cercalmon, wenn er zur Essenszeit an den Thorweg klopfte, mit Hunden hetzen liefsen, ${ }^{3}$ werden weidlich durchgehechelt. Einmal sehen wir in entgegengesetzter Art die undankbaren Gäste selbst aufs Korn genommen,4 denen keine Gastfreundschaft gut genug ist, und die sich, wenn überhaupt, so nur der Mutter Gottes und Sanct-Julian, dem Schutzpatron der Hospitaliter, verpflichtet glauben, wenn es ihnen auf Reisen in unwirtsamen Länderstrichen wohl ergeht. Eine Anspielung auf ein portug. Dekret über das Jantar der Ricos-homes, in der Satire des lustigen Guilhade, die ich als Anhang zur vorigen Glosse mitteilte, kennt der Leser bereits. Als solche fasse ich wenigstens die Drohung auf:

E provar-vus - á das carnes quenquer que duas carnes vus mandan comer e non queredes vos d' đa cozer. ${ }^{\mathrm{s}}$

Ist nun der Paragraph selbst auch nicht erhalten, so kann man schliefsen, wie ungefähr er gelautet haben muls, wenn man in der königl. Palast-Ordnung liest:

Enna cozinha delRey nom adubem senom de duas carnes e a huma seja de duas guisas ... Em no dia do pescado para o jantar de tres pescados, ou de dous; e huum pescado seja adubado de duas guisas. ${ }^{\circ}$

1 Leges 890.

2 CV 1001. 1002. 1027. 1028. 1046. 1047. 1084. 1103. 1163. 1166. 1167. 1168. 1170. 1171. 1177.

${ }^{3} \mathrm{CV} 894$ von $R$ uy $Q u e i m a d o$; und ib. 1002 von Gonçal' Eannes do Vinhal.

4 CV 1001.

5 CV 1103.

- Leges 199 \$ 14. Natürlich betraf die Verordnung nicht des Königs eigene Tafel. - In $\S$ I 6 heifst es Em na cozinha dElRey de seu corpo adubem para seu corpo como el mandar. - Von einer Mahlzeit Alfons' III. erfahren wir, dafs es an Brot, Wein, Kapaun, mariniertem Lendenbraten und jungem Zicklein nicht gefehlt hatte (CV 1084). 
Und dem entsprechend in den Erlassen über die Klöster:

que non combam no dia da carne se nom duas carnes, e huma carne seia adubada de duas guisas; e em aquel dia que as comerem nom combam pescado .... E sem[elh]auilmente no dia do pescado comham de tres pescados ou de dous, e huum seia adubado de duas guisas; e com estes pescados combam truytas e bogas ou solho, irze (etc.). ${ }^{1}$

Auch auf dem Gebiete der Jantar-Satyre scheint übrigens der kastilische Rei-Trovador - oder sagen wir lieber e in peninsularer Rei-Trovador, da es noch unentschieden ist, ob Alfons X. oder sein Grolsvater, der Leonese, Verfasser der Liedergruppe CB 456 -468 ist - seinen Höflingen und Söldnern mit tonangebendem Beispiel vorangegangen $\mathrm{zu}$ sein. Wie er lachend in gewandten Reimen einem seiner Magnaten nachsagt, derselbe habe als einzigen kulinarischen Genuls einen gekochten halben Hammelschwanz auftragen lassen:

\section{Direi - vus d' un ricome \\ com' aprendi que come! \\ Mandou cozer o vil ome meio rabo de carneiro: assi com' o cavaleiro!}

das kann der Leser, falls es ihn interessiert, in Randglosse I nachschlagen. ${ }^{2}$ Statt das Lied zu wiederholen, biete ich ihm die übrigen Speiselieder.

Freilich, selbst die königlichen spöttischen Gelegenheitsverse waren unter der südlichen Sonne nichts Neues. Einer der schmähsüchtigsten und brutalsten Troubadours provenzalischer Zunge, der Held zahlreicher Skandal - und Schurken-Anekdoten, ${ }^{3}$ der mehr als abenteuerliche Katalane Guilhem von Bergadan oder Berguedan, der gegen Ende des I 2. Jhs. am Hofe Alfons' VIII. wie auch im Palast zu Leon Gastrollen gegeben, hatte einst ein ähnliches Thema angeschlagen. ${ }^{4} \mathrm{Ob}$ er ein Heft mit Schmähliedern eigner und fremder Komposition zurückliefs (untermischt mit den erotischen Gedichten des Grafen Wilhelm von Poitou), ähnlich demjenigen, welches Alfons X. in den Händen des Dechanten von Cadiz wufste?s $\mathrm{Ob}$ aus diesen der gelehrte Beschützer aller realistischen Liederdichter den Anstors zu seinen unfätigen Cantigas de escarnh' e maldizer empfangen haben mag? Jedenfalls steht der provenzalische Verfasser der Schmähreime auf einen filzigen Edelmann, ${ }^{6}$ was Sinnes-

1 Leges I99 § 15. - In CV 1027. 1029. 1166 hören wir von truytas, pescados, peixotas, salmon, linguado, faneca.

2 Ztschr. XX 165.

3 Eine der Cento novelle antiche beschäftigt sich bekanntlich mit ihm.

4 S. über ihn Milá, Trovadores 284-322; Bartsch im Fahrbuch VI 231-288 u. VIII 126. - Seine Lieder veröffentlichte A. v. Keller schon 1849.

5 CV 68.

- Milá p. 317 No. 19. - Keller No. I r. - Es beginnt:

Eu non cuidaba chantar, quar rason non avia, mas Arnautz del Viglar 
art, Lebensführung, volksmäfsige Sprache, die metrische Gestaltung seiner Lieder, 1 das Schmähen von Personen, unverfrorene Benutzung niedriger Worte, sowie dunkle Anspielungen auf heimische Gebräuche und Unsitten betrifft, ${ }^{2}$ den gallizisch-portugiesischen Dichtern so nahe wie wenige andre Troubadours.

Doch das gehört in ein andres Kapitel.

\section{Liederanhang.}

\section{(8.) CV 1001.}

Gonçal' Eannes do Vinhal.

En gran coita andamos con el rey per esta cerra u con el andamos, se non fosse que quis Deus que achamos infançбes - quaes vus eu direy -

5 que entran nosqu' en dóas cada dia e jantan e cēan a gran perfia e burlhan côrte cada u chegamos.

Taes, par Deus, infançðes non sey e todos nos d' eles maravilhamos;

10 e pero os infançбes chamamos, vedes, amigos, tanto vos direy: eu per infançðes non os terria, mais son- $x$ ', a graça de sancta Maria e san Juyzo con que albergamos.

15 E sempre por sa vida rogarey, e dereit' é que todo'-lo façamos, pois d' eles todos tant' amor filhamos en sa terra - quanto vos eu direy: qualquer d' eles nos fez quanto devia, mais tant' é grande a nossa folia que nulhas graças lhis ende non damos.

I andarams - 5 dōas - 6 ceam - 8 baruas infanzzes cōes. Oder bedeutet es vielleicht: Nao conheģo Infanç⿸es que sejam taes barvas d. i. que sejam homens tao honrados? - 9 etodg ug - 10. II. amigus - 15 E stemp des - 16 fazam -17 cātamor - 18 tī̄a $-20 \bar{q}$ nda

$$
\begin{aligned}
& \text { m' en a mes en la via } \\
& \text { c' audi l' autrier clamar } \\
& \text { de mon sogre ab la corona } \\
& \text { qu' el no 'l det a l' ora nona } \\
& \text { del peis, e fe l' amaguar! }
\end{aligned}
$$

1 Bei ihm findet sich z. B. Bezugnahme auf den hispanischen Glauben an Vogelschau, der im gallizisch-portugiesischen Liederbuch einen so breiten Raum einnimmt.

2 Alfons' X. hurtiges Kriegslied $O$ genete Pois remete $O$ alfaras corredor (CV 74), wonach das Leonoreta-Lied des Lobeira gemodelt ist, hat sein metrisches Vorbild im 24. Liede des Guilhem von Bergadan: Un trichaire Preste laire Vol que chan pus suy chantaire. Vgl. Randgl. VI. 


\section{(9.) CV 1002.}

Von demselben.

Non levava un dinheiro (?)

ogan' u oùvi -a passar

per Campos, e quix pousar

en casa d' un cavaleiro

5 que se ten por infançon,

e soltou-mi-un can enton

e mordeu-mi-o seendeiro.

Por meu mal enton senlheiro

oùvi ali a chegar

Io - que non chegass'! - a logar

$u$ atal fais [cava]leiro,

ca el se fosse çaton (?)

non fora ao vergalhon

roso (?) do meu seendeiro.

15 Non vistes peyor parado

albergue do que achey

enton quand' a el cheguey;

nen vistes mais estirado

ome ca fuy d' un mastin,

20 e fez-mi tal o rocin

que semelhava lobado.

Non fuy eu ben acordado, poi'-lo da porta catey

dentro: porque o chamey,

25 pos-mi-o gran can enriçado

que nunc' a [morder] fez fin

ata que [el] fez en min

qual fez no rocin lobado.

I nen dulheyro - 2 ogane hu o ui pafsar - 9 ouualy a ch. - II fais leyro - 12 gatō. Vielleicht santon? - 17 ele - 25 enrricado. $\mathrm{Zu}$ enrisar $=$ "hetzcn" von *irritiare statt irritare? (cf. astur. enridar) vgl. Fuero $\mathcal{F}_{\text {usgo }}$ VIII 4. 19. - 28 lobado "vom Wolf in Angst versetzl".

(10.) CV 1027.

Roy Paes de Ribela.

Veend' un ricome cen truitas

én compra duas por muitas ..

e coz' end' a ua.

Por quanto xi quer, apenas

5 compra én duas pequenas ..

e coz' end' a ta! 
Venden cen truitas vivas

e compra én duas cativas

e coz' end' a đa!

I Ven hü r. dastruytas -2 que -4 ebenas -7 cruytas

(I I.) CV 1029.

Joào Servando.

Comeron infanções | en outro dia apartados na feira | de sancta Maria, e deron-lhi linguados / por melhoria que nunca vi $\tan$ bóos / desque naci.

5 Eu con os apartados | fui enton i

apartado da vida, I e non comi.

Direi - vus como foron $\mid \mathrm{i}$ apartados: deron-lhis das fanegas / e dos pescados atanto per que foron / muy lazerados,

10 que des quando foi nado, / nunca chus vi.

Eu con os apartados / fui enton $i$

apartado da vida, / e non comi.

Apartaron-se d'eles | por comer ben, melhor que comerian | en almazen,

15 e pois quando ao erger, | non podian én, tirar mui ben as / pernas arcassy (?)

Eu con os apartados | fui enton $i$

apartado da vida / e non comi.

1 infançzes - 3 por nu lhoria - 4 pontos - 6 dauida - Etwa d' ajuda? Oder da vila? Ich verstehe den Gedanken nicht. - 8 dis $e$ dos pafcados. Ob wir dez fanegas e dous pescados zu setzen haben? II co uos - entahy - 15 os erger - 17 eu com co arar tados

\section{(12.) CV 1046.}

Roy Paes de Ribela.

Preguntad' un ricome

mui rico que mal come, porque o faz?

El de fam'e de sede

5 mata ome; ben (0) sabede, porqué o faz.

Mal com'e faz nemiga!

Dizede-lhi que diga

porquê o faz.

\section{(13.) CV 1047.}

Roy Paes de Ribela.

Un ricomaz, un ricomaz

que de maos jantares faz! 
Quanta carne manda a cozer, quand' ome vay pola veer,

5 se s' ante muito non erger, sol non pode veer $u$ jaz!

Un ricomaz, un ricomaz que de maos jantares faz! Quen vee qual cozinha ten

Io de carne, se s'i non deten, non poderá estimar ben se $x$ ' est carne, se [é] pescaz!

Un ricomaz, un ricomaz que de maos jantares faz!

5 merger

\section{(14.) CV 1084.}

Ayras Peres Vuiturom.

Don (E)stevan, eu eyri comi en cas del rey - nunca vistes melhor e cantarei vo'-lo jantar aqui c' acha ome de falar i sabor:

5 non viron nunca ja outro tal pan os vossos olhos, nen ar veeran outro tal vinho qual eu $\mathrm{i}$ bevi.

Nen vistes nunca, se Deus mi perdon melhor jantar, e contar vo'-lo ei:

10 á dez anos que non vistes capon qual eu $i$ ouve, non vistes, ben sei melhor cabrito, nen vistes atal lombo de vinh' e d'alhos e de sal qual i a mi deu un de criazon.

I5 Nen vistes nunca nulh' ome comer com eu comi, nen vistes tal jantar, nen vistes mais viços' ome seer do que eu sèvi en nenhun logar, ca a min non minguava nulha ren, 20 e mais viços' ome de comer ben non vistes, nen avedes de veer.

1 estauain - 4 caxa - 6 uosfus - 7 a qual -9 e cōtaruoil(l)ey $14 \bar{q}$ lhi nami deu hi hü de criazon - 20 uyzosome

Der Spott gilt der Kurzsichtigkeit des D. Estevam, und nicht dem Essen an Königs Tisch.

\section{(15.) CV 1163.}

Pero da Ponte.

Un dia foi cavalgar de Burgos contra Carrion

Zeitschr. L rom. Phil. XXV. 


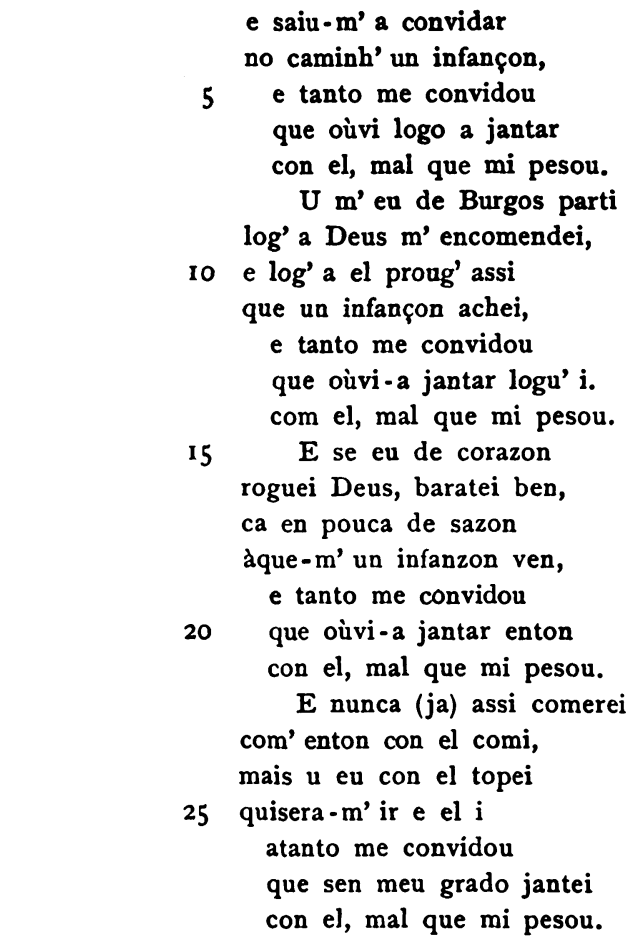

3 me conuydal - 7 conele - II infancon

\section{(16.) CV 1166.}

Noutro dia en Carrion queria[n] un salmon vender, e chegou $i$ un infanzon;

e tanto que o foy veer,

5 creceu-lhi d'el tal corazon que diss' a un seu om' enton: „Peix ora quer oj' eu comer,

Ca muit' á ja que non comi salmon que sempre desejei;

10 mais pois que o ach' or(a) aqui ja custa non recearei que oj' eu non cômia, de pran, ben da peixota e do pan, ca muit' á que ben non cẽei.

I5 Ca pois aqui salmon achei, querrei oj' eu mui ben cẽar, ca non sei u mi-o acharei 
des que me for d' este logar;

e do salmon que ora vi,

20 ante que $x$ ' o leven d' ali,

vay $-m$ ' ua peixota comprar.

Non quer' eu custa recear, pois salmon fresc(o) acho siquer (?), mais quer(0) ir ben d'el assuar

25 e enviar a mia molher

- que morre por el outrossi -

da balēa que vej' aqui,

e depois quite quen poder!

I cairhon für carrhon. Das Versmals verlangt: En outro dia 12 comha - 14 ceei - 16 cear - 20 beue $-21 m \bar{u} h a-c o p r$ 23 sinher $-25 p^{r}-28$ quitar debdas = Schulden bezahlen.

Als Lachsverkäufer haben wir den gallizischen Dichter nicht zu betrachten. Daher die Konjektur querian in Z. 2.

\section{(17.) CV 1167.}

$D^{\prime}$ un tal ricome vus quero contar que noutro dia a Segóvia chegou de como foi a vila a refeçar, pois o ricome na vila entrou;

5 ca o manjar que antes davan $i$ por dez soldos ou por maravedi, logu' esse dia cinc soldos tornou.

Ricome foi que vus Deus enviou que vus non quis assi desamparar,

Io que vus a vila assi refezou poi'-lo ricome vẽo no logar;

ca nunca eu tan gran miragre vi polo azougue refeçar assi mentr' o ricome mandava comprar.

$15 E$ a Deus devemos graças a dar d' este ricome que vus presentou, de mais en ano que era tan car' com' este foi que ogano passou; ca pois este ricom' entrou aqui,

20 nunca maa careza entrou $i$ mentr' o ricome na corte morou.

7 çine solds eor $\bar{n} o b$ - cinco würde die Zeile um eine Silbe zu lang machen. Die übliche alte Form war cinque. Vgl. duc - $10 \vec{q} n 9-$ 13 asougme - 14 mandara - $9 p^{\prime}$ - 15 Ca des - 17 tā caro im Reim zu dar

Offenbar ein herber Spott auf einen Machthaber, der für die Speisen, auf deren Ankauf er ein Recht hatte, zu wenig bezahlte. 


\section{(18.) CV 1168.}

Quen a sesta quiser dormir conselhá-lo-ei a razon: tanto que jante, pense d' ir á cozinha do infanzon.

5 E tal cozinha lh' achará, que tan fria casa non á na oste de quantas $i$ son!

Ainda vus eu mais direi: eu que un dia $\mathrm{i}$ dormi

Io tan bra sesta non levei des aquel dia'n que naci como dormir en tal logar u nunca Deus quis mosca dar! É a mais fria ren que vi!

I5 E vedes que ben se guisou de fria cozinha tẽer o infanzon, ca non mandou des ogan' i fog' acender. E se vinho gãar d' alguen,

20 ali lh' o esfrïaran ben se o frio quiser bever!

4 conzinhado - 10 festa - 14 ena - 16 teer - 19 gaar 20 effriarā

Satire auf die kalte Küche eines geizigen Junkers.

\section{(19.) CV 1170.}

Sueir' Eanes, este trobador, foi por jantar a cas d' un infançon e jantou mal, mais el vingou s' enton que ar ajan os outros d' el pavor,

5 e non quis el a vendita tardar: entanto que se partiu do jantar, trobou-lhi mal, nunca vistes peior!

Eno mundo non sei eu trobador de que s' ome mais devess' a temer

Io de x' el mui maas tres cobras fazer, ou quatro, a quen lhi maa barva for. Ca desque vo'-lh' el cae na razon, maas tres cobras ou quatr' e o son de as fazer muit' é el sabedor!

15 E por esto non sei no mundo tal ome que lh' a el devess' a dizer de non, por lhi dar mui ben seu aver, c'a Sueir' Eanes nunca lhi fal 
razon, des que el despagado vay,

20 en que lhi trob' atan mal e tan lay

por que o outro sempre lhi quer mal.

4 aia mos - 9 deuafse - 16 deuafsadizer - 18 suereanes - desque

Satire auf ein Mittagsessen, mehr aber noch auf die schlechten Verse des Sueir' Eannes. Vgl. CV 1117. 1179. 1184.

(20.) CV 1171.

Quand' eu d' Olide sai preguntei por Ayvar

e disse-mi log' assi aquel que foy preguntar:

5 ,senhor, vos creed' a mi, que o sei mui ben contar:

Eu vus conto quant' á

d' aqui a cas don Xemeno:

un dia mui grand' á i ..

Io e un jantar mui pequeno.

Disse-mi u (me) d' el parti : "quero-vus ben conselhar; a jornada que d' aqui vus oy queredes filhar,

15 será grande, pois des $i$ cras non é ren o jantar:

por én vus conto quant' á d' aqui a cas don Xemeno: un dia mui grand' a i ..

20 e un jantar mui pequeno.

I dolide -7 Wohl quanto d?

Wie ich die navarresischen Ortschaften Olite, Ayvar und Don Xemeno in Zusammenhang mit einander bringe, habe ich im CA Kap. VI in der Biogr. XXXV des Pero da Ponte mitgeteilt. Hier genügt es zu verzeichnen, dafs Don Xemeno de Ayvar zu den Navarresen gehörte, die mit König Sancho am Siege von Tolosa I 2 I 2 teilnahmen.

\section{(21.) CV 1177.}

En almðeda vi estar a un ricom' e diss' assi: "quen quer un ricome comprar?" E nunca i comprador vi

5 que o quisesse, nen en don, ca dizian todos que non darian un soldo por si. 
$E$ d' este ricome quenquer vus pod' a verdade dizer.

Io Pois non apres nenhun mester, ¿quen querrá i o seu perder? ca el non faz nenhun lavor de que nulh' om' aja sabor, nen sab' adubar de comer.

$15 \quad E$ u foron polo vender preguntaron-no en gran sen: "¿ ricom, que sabedes fazer?" e o ricome disse: „ren! non amo custa nen misson, mais compro múi de coraçon erdade, se mi-a vend' alguen."

E pois el diss' esta razon non ouvi molher nen baron que por el dar quisesse ren!

2 ouin - $12 \mathrm{cal} \mathrm{el} \mathrm{-} 17$ ricome - Vielleicht: ricome, que sabes fazer?

\section{(22.) CB 1503.}

João de Guilhade.

Vi eu estar noutro dia infançð̃es con un ricome posfaçando de quen mal come, e dix' eu que os ouvia:

Posfaçavan d' un escasso, foy-os eu ascuitando; eles foron posfaçando e díxi - $m$ ' eu pass' e passo:

Io Cada casa favas lavan!

$$
\text { Posfaçavan d' encolheito }
$$

e de vil e de spantoso

e en sa terra lixoso,

e dix' eu enton dereito:

Cada casa favas lavan!

3 u. 8 posfaçāilo. Das Metrum zwingt uns posfaçand' a quen mal come zu lesen und in Z. 7 e eu os foy ascuitando zu vermuten - 9 pasfen pasfo - 11 posfacau $\bar{a}$ - 13 tir $\bar{a}$ - 14 dizeu

Das Sprichwort bedeutet so viel wie: cá e lá más fadas ha und soll besagen, dals es im Hause der Maldizentes, was den Tisch betrifft, nicht besser bestellt war als anderwärts. Vielleicht liegt in favas auch noch ein direkter Hinweis auf spärliche Kost: Alle Tage Saubohnen? - Ob man meu passo e passo noch im Be- 
wufstsein der substantivischen Natur von passo gesagt hat? Sonst kommt im Liederbuch an ähnlichen Formen nur pouqu' $e$ pouco und mans' e manso vor.

(23.) CB $1552(=425)$.

Nunes.

Un infançon mi-á convidado que seja seu jantar loado par mi; mais (eu) non-no ei guisado e direi-vus por que mi aven:

5 ca ja des antan' ei jurado que nunca diga de mal ben.

Diss' el: „poi' - lo jantar foi dado, load' este jantar onrado." Dix' eu: „faria-o de grado;

10 mais jurei antan' en Jaen na oste quando fuy cruzado que nunca diga de mal ben!

CB I Hun Infancon mha cruidado - 2 doado - 8 onirado - 10 Die übliche alte Form ist Geen.

Ob Ayras Nunes der Verfasser ist?

\section{Pennaveira.} lautet:

Das dritte Streitgedicht, mit dem ich mich beschäftigt habe,

Ūa pregunta queir' a el rey fazer que se sol ben e aposto vistir: ¿porque foi el pena veira trager? Veer-lh'-an bon pan' e queremos riir,

5 - eu e Gonçalo Martliz, que é ome muit' aposto, per bða fé e ar queré-lo-emos én cousir. „Garcia Perez, vos ben cousecer podedes: nunca, de pran, foi falir

10 en querer eu pena veira trager velha en côrte, nen-na sol cobrir (?); pero de tanto ben a salvarei: nunca me d' ela en côrte paguei, mais estas guerras nos fazen bulir."

15 Senhor, mui ben me vus fostes salvar de pena veira que trager-vus vi; e pois de vos a queredes deitar, se me creverdes, faredes assi: 
Mandade logu' est, e non aja i al! ca peyor pena nunca d' esta vi. „Garcia Perez, non sabedes dar bon conselho - per quanto vus of pois que me vos conselhades deitar en tal logar esta pena; s' assi o fezesse, faria mui[to] mal; e muito tenh' ora que me mais val o dá'-la eu a un coteif' aqui.

(CB $465=357$.

I Hīa preguntar $\bar{q} \imath r-3$ peq̄na -4 Ich lasse veer und rïr stehen. Es bleibt dem Leser überlassen, welche von beiden Formen er kontrahieren will - 5 goncalo nirijz - 9 falquir - 10 en querer en - I4 oftas 20 Dota loguen huñ - 21 peyior - 24 con Jofhades - 25 Eutal logar esta peḡna caffi - 26 offezeffe faria mui mal - $27 \bar{q}$ muj mo ual - 28 Endata

Ein König, der sich schmuck und gut zu kleiden pflegt, hat ein minderwertiges, mit Buntwerk besetztes oder gefüttertes Gewand getragen, wird darob lachend angegriffen, entschuldigt sich damit, nicht bei Hofe, sondern im Kriege habe er den alten schlechten Pelz angelegt, hört, obwohl der Angreifer seine Verteidigung gelten lärst, die Aufforderung, denselben sofort auf den Kehrichthaufen an der nächsten Mauer zu werfen, erklärt das für einen schlechten Ratschlag und zieht vor, das abgetragene Stück einem seiner Troupiers zu schenken.

Textkritisch bietet diese vierte Königstenzone keine sonderlichen Schwierigkeiten. Nur das Reimwort von Z. 9, an das ich rühren mufste, bleibt fraglich, und unverständlich der Schlufs von Z. I 1.1 Daran, dals wir in Z. 3 und 25 pena zu lesen haben, ist nicht zu zweifeln, da pequena weder in den Zehnsilbner pafst, noch die zwei Adjektive ohne Substantiv einen Sinn geben, veira als Hauptwort aber im Portugiesischen nicht nachzuweisen ist.2

1 Ob cobrir alg. c. gleichwie cobrir-se de alg. c. bedeuten kann: „sich einer Sache als Decke bedienen, sich mit einer Sache bedecken"? Dann hätten wir zu verstehen: „ich habe nimmer den Fehler begangen, Buntwerk bei Hofe als Kleid zu tragen, und nicht einmal, solches als Decke oder Hülle zu gebrauchen", nunca fui falir en trager pena veira na côrte, nen sol (= nem tampouco) en $(n)$ a cobrir? - In einem Spottgedicht Alfons' $\mathbf{X}$. (CV 66), das sich um einen diebischen Pilger dreht, tritt cobrir dreimal als Reimwort auf - möglicherweise gleichfalls mit Bezug auf Pelzwerk ( $g$ ris). Doch ist die Bedeutung von Gris nicht sicher. Vielleicht ist Gris oder Agris der Name des Bestohlenen:

und

dagris furtaran que por en

non lhi leixaran que possa cobrir,

e sol non cata [n] como gris non ten

[ja] nunca cousa de que se cobrir.

Oder bedeutet Z. II: ,und nicht einmal Buntwerk zu bedecken - d. h. es versteckt und bedeckt als Unterfutter zu verwerten"?

2 Ueber die Entwicklung von varius und variare im Portug. spreche ich in Randgl. XVI, aus Anlafs der Olhos verdes, wie schon gesagt ward. 
Und pena veira steht ja unverfälscht in $Z$. 10 und 16 , uns den Weg weisend.

Sachlich staunt man im ersten Augenblick darüber, dals diese Pelzsorte, die man gewohnt ist in Schilderungen und Verordnungen als kostbaren Luxusstoff in einem Atem mit Zindel, Brocat, Scharlach, Sammet genannt zu sehen, 1 von einem Troubadour so verächtlich behandelt wird, als sei sie nicht gut genug für seinen Herrscher. Man mufs sich erst darauf besinnen, dafs wir am glänzenden, mit des Orients Kostbarkeiten prunkenden Hofe eines peninsularen Fürsten weilen, und dafs auch der Teilnehmer an unserer Scherz-Tenzone kein auf Lohnung durch buntes Tuch bedachter Spielmann oder Berufsdichter, sondern ein fürnehmer Herr sein mufs - wie aus dem Gegenstand und der besonnenen Redeweise, mehr aber noch aus der Fassung der königlichen Entgegnung hervorgeht. Drittens und hauptsächlich dreht sich der Disput um einen alten verbrauchten Pelz, nicht um pena veira an sich, wenn wir auch in der Angriffsstrophe die betreffende Angabe vermissen.

Darüber dafs im Süden im I 3. Jh. und heute wiederum nicht blofs zur Winterzeit, sondern selbst für Sommertrachten Pelzwerk aufserordentlich gesucht war ${ }^{2}$ - man unterschied Saisonpelz: penna de sazon und penna de verao: ${ }^{3}$ was sich von dem alten Brauch im nationalen Hirtenleben erhalten hat (camarro, safzes nebst carrao oder zurr $\tilde{a}_{0}$ ); welche heimischen und welche ausländischen Sorten hier Verwendung fanden; ${ }^{4}$ wie für die zarteren kostbareren Gattungen die aus der Provence übernommene Bezeichnung penna mit ihrer hübschen bildlichen Gleichstellung des Hermelin, Nörz, Zobel, Bunt- und Grauwerk mit Taubenflaum und Eiderdunen benutzt ward, ${ }^{\mathfrak{b}}$ für die daheim gewonnenen Felle aber pellis; ${ }^{6}$ was die Preistabellen und Kleiderordnungen uns über das Gewerbe der Schneider und Kürschner ${ }^{7}$ verraten, darüber liefse sich unter Ein-

1 Belegstellen bei Du Cange, Godefroy.

Im Elucidario findet sich nichts Brauchbares. S. alfanehe und anina.

- P. M. H.: Leges 192.

4 Leges 192-196 erfahren wir von der Haut des Hirschkalbes (aenio, neuportug. enho, vom lat. hinneus), des Damhirsches (gamito), Lammes (cordario), Kalbes (tenrom), Zickleins (cabrito), die wir nicht als Pelzwerk zu betrachten gewohnt sind; dann von Katze (gato de casa), Wildkatze (gato montes), Fuchs (gulpina), Frettchen (fuina und tourao), Otter (luntria), Marder (marterenia), Gineta (geneta) und einem mir unbekannten luberno, in dem ich lubezno, einen jungen Wolf, vermute; ferner von vestidos de coelho. Alle diese als pellis. - Die zarten flaumartigen pennas stammen von Hermelin (arminium), Otter (luntria), Haselmaus (de lirionibus) und Hase. Aufserdem wird ein Unterschied gemacht 2wischen penna blanca, purada, larga, miscrada (dies letzte Wort kommt CV 1154 vor).

5 Auch im Altspanischen haben wir natürlich per̃a und per̃a vera. S. z. B. Fita 7. 640. 1251 . 1378.

- Heute ist pelle das einzige Wort; span. pellejo.

7 Peliteiro CV 927. 
beziehung aller Stellen aus den Liederbüchern ein interessanter Modebericht zusammenstellen.

Für unseren $Z$ weck genügt es, zweierlei zu fixieren.

1. Penna veira, d. h. die zwiefarbigen Felle ${ }^{l}$ eines äufserst kleinen und darum kostbaren, dem Hermelin und Nörz verwandten osteuropäischen Nagetierchens - es sei mustela lutreola ${ }^{2}$ oder nicht -, so geschätzt sie auch waren, zählten nicht zu den pannos reaes, d. h. sie blieben so wenig wie Grauwerk, Zobel und selbst Hermelin für Könige und Fürsten durch ein Sondergesetz reserviert, sondern wurden als Futter und Verbrämung von Mänteln und Kapuzen aller Art ohne andre Beschränkung als der vom Geldbeutel des Käufers gesteckten in den Handel gegeben. Das Liederbuch selbst liefert Beweise dafür.

Der alfonsinische Spielmann Pedr' Amigo de Sevilha beklagt sich einmal, er sei bei der Verteilung von panos und penas veiras zu kurz gekommen (CV 690).

Estévam da Guarda, der spottlustige Kanzler des Königs Denis, verhöhnt einen zum Edelmann beförderten Bauern, der, um seine Glatze $\mathrm{zu}$ verdecken, sich eine ungeheure, mit pena veira ausgestattete Kopfbekleidung (caparon) zugelegt hatte (CV 827). Uebrigens wird der Flaumpelz hier ausdrücklich nobre genannt. ${ }^{3}$

Derselbe Dichter erzählt ein andermal vom Verkaufe gebrauchter pannos und pennas veiras durch einen Makler (CV 804).

2. Benutzt aber wurden die pennas varias auch von Königen, wie unsre Tenzone zeigt. Diesmal fiel es freilich dem dichtenden Alfons nicht ein, sich, wie in dem Gedankenaustausch mit Vasco Gil, mit dem Beispiel eines andern Herrschers zu decken. Sonst hätte er abermals auf einen König von Portugal hinweisen können: Sancho I., der in seinem Testament seine cintas, escarlatas und penas varias seiner Tochter D. Sancha vermacht.4

Bei muradal an den berühmten Pals der Sierra Morena zu denken, der so manches Kriegsheer gesehen hat, liegt durchaus

1 Die Uebersetzung "bunt" ist die beste, wo es sich um andre Tiere als das pelzliefernde Mäuschen handelt (Hund, Stute, Skorpion), oder gar um Menschenhaar. - Die eine der Farben war weils, die andre kaum immer die gleiche, bald rötlich, bald grau, bald schwarz. - Unzutreffend sind jedenfalls die Erklärungen der hispanischen Berichterstatter: (Sanchez-Janer: vera = muy blanca; Cueto: blanca o baya; Braga: alvo alveiro). Sie stammen alle aus einer Stelle im Werke des Erzpriesters, wo man liest: El axenus de fuera mas negro es que caldera | Es de dentro muy blanco mas que la pennavera (Str. 7). - In Str. 640 bedeutet der Satz: La penna tiene blanco et prieto, pero todos son conejos „es giebt weifse, aber auch dunkle $\mathrm{Ka}$ ninchen".

2 Londrasinha als Bezeichnung eines Pelzes bezieht sich natürlich auf eine kleine Otter-Art und hat nichts mit London zu thun.

3 Man vergleiche noch CV 890 .

- Mon. Lus. IV. Escrit. III 260. 
kein Grund vor. Man lasse dem Wort seine ursprüngliche appèlative Bedeutung.

So abgetragen, in des Dichters übertreibender Redeweise für den Müllhaufen reif, war das Stück, dals es nur einem gemeinen Soldaten überantwortet werden konnte. Wenigstens glaube ich, wie ich schon früher dargethan, 1 dals wir einen peon unter coteife zu verstehen haben. Diesen Namen versuche ich jetzt - da ein Suffix -eife -efe nicht vorkommt ${ }^{2}$ - aus dem Arabischen berzuleiten, wo kateif ein langes Schwert bedeutet (latus ensis; ferrum longum et latum). Mit dem maurischen Ausstattungsstück, dem der coteife besagten Falles die Benennung verdankte, ${ }^{3}$ ging dieselbe vermutlich wieder verloren. Sie kommt nur bei Alfons X. vor ${ }^{4}$ und einigen seiner Getreuen, ${ }^{5}$ wenn wir ein fragwürdiges Spottgedicht aufser acht lassen oder zu des Königs $\mathrm{Hab}$ und Gut rechnen, das derselben Gedichtgruppe angehört wie unser Pena-veira-Lied.

Damit sind wir zur Hauptfrage gekommen, um derentwillen ich dasselbe aus seinem Zusammenhang gelöst und neben die zwei Streitgedichte gestellt habe, die Alfons $\mathrm{X}$. zugesprochen werden müssen: wer nämlich ist der König, dem jene Gedichtgruppe angehört? 6 Alfons X.? oder Alfons IX.? Hat nur der ital. Kopist in der Ueberschrift El Rey don affonso [de Castella e] de leon die eingeklammerten Worte ausgelassen? 7 Es scheint wenig glaublich, da gerade die dichtenden Könige sowohl den Kardinal Bembo als Angelo Colocci besonders interessiert haben. Steckt also ein Fehler im Autornamen, so wird er aus der Vorlage stammen, von der wir nichts wissen, als dals sie sich anscheinend in einem argen Zustand befand. So lange die Urheberschaft des Weisen nicht

1 Randgl. I Z. 158. 168. 169 sowie S. 71-72. - Tritt der coteife meist als Fufssoldat und wie ein Gemeiner auf, so scheint Alfons X. die Gattung doch einmal (CV 74) in Stutzer.Kleidung vorzuführen (mit arminhos? und orpelados?). Ein andermal tragen sie ein Wams aus Kattun (perponto de algodon) und Hosen aus $\mathrm{Z}$ willich (calgas de branqueta) (CV 62). Langbärtig sind sie auch. Oder ist orpelados etwa eine kastilische Form von horripilatos?

- Tabefe = "Tachtel" weils ich nicht zu erklären. - Die Schreibart coitefe kommt nur einmal vor (CB 464). Vermutlich hat durch Verschreiben das $i$ seinen Platz gewechselt.

8 Solche Uebertragung eines Sachnamens auf die Person, der sie als Characteristicum dient, kommt oft genug vor. Ich erinnere nur an jaque, den jackentragenden Soldaten, und guita, Tresse, das Spottwort für den modernen portug. Polizeisoldaten. - Ein Versuch, coteife wie golfim (Cron. Alf. c. 75 p. 59) aus der Schachterminologie herzuholen, ist mir milslungen.

- CV 62. 74. CM 22 u. 194.

s Rui Queimado CV 894; Coelho CV 1024.

- Ind. $456-466$.

- Unmittelbar folgen, wie der Leser weils, eine fromme und mehrere profane Dichtungen Alfons' X. (467-496), denen die Ueberschrift El Rey don affonso de Castela e de Leon vorangeht. - Wiederholung von Namen als Ueberschrift ist aber sehr bäufig. - Auch Alfons XI. ist ausdrücklich als Herrscher beider Reiche bezeichnet (607). 
mit hinreichender Klarheit nachgewiesen ist, wird man immer wieder versuchen müssen, im Rey de Leon den Grolsvater, Alfons IX., $\mathrm{zu}$ erkennen.1 Gelungen ist mir bis jetzt weder das eine noch das andre. Der Majordomus D. Rodrigo (CB 464), Milia Fernandes aus der Familie der Pertigueiros de Santiago (460) und die Anwesenheit des Königs in Guarda (456) bringen vielleicht die Lösung des Rätsels.²

Mancherlei scheint auf Alfons X. hinzuweisen. In einem der Gedichte ist von andalusischen Städten in einer Weise die Rede, als gehörten sie zum Reiche des Dichtenden. ${ }^{3}$ So aber konnte der Leonese unmöglich von Sevilla, Lebrija und Alcalá 4 reden. Das gilt auch von dem auf die Olivenwälder von Eixarafe und die alcarias hinweisenden Spottlied. ${ }^{5}$

Was unsre Tenzone betrifft, so ist ihre Aehnlichkeit mit den beiden bereits besprochenen recht grofs, sachlich wie formell; ${ }^{6}$ von allen übrigen Streitgedichten weicht sie hingegen ab, was Gegenstand und Einkleidung betrift. Dazu kommt, dals von Krieg die Rede ist. Was wir sonst an Kriegsliedern ${ }^{7}$ besitzen, stammt aber aus den andalusischen Feldzügen Ferdinands III. und seines Sohnes Alfons und ist entweder Werk des letzteren 8 oder das seiner Grofsen. Wie ich in den nachfolgenden Glossen zeige, möchte ich dieselben in den Aufstand der sechziger Jahre verlegen - in eine Zeit also, in welcher Alfons X. noch, heiter und siegesfroh sowohl als Gesetzgeber und Eroberer, als auch als Vater und Regent, zum Dichten aufgelegt sein mochte.

1 Nimmt man Herkunft der betreffenden Lieder aus dem Besitze eines peninsularen Sammlers an, so ist ist die Bezeichnung de Leon für Alfons $\mathbf{X}$. in hohem Grade unwahrscheinlich. Und selbst gesetzt, sie stammten aus provenzalischem Gebiet, bliebe sie befremdend. Fremde Troubadous haben ihn dann und wann schlichtweg Rey de Leon genannt, doch nur wo das Metrum solche Verkürzung der Titulatur erbeischte, wie z. B. in der Tornada des polyglotten Sirventês-Descordo (Randgl. VIII), oder auch'l reys cuy es Léos (Guiraut Riquier bei Milá 217). Ueblicher ist jedoch: reys dels Castellds - Reys Castellds - reys de Castela $N^{\prime}$ Anfos - reys $N^{\prime}$ Anfos Castelds cui Leos es - Rei de Leon qu'es senhors de Castelas - el bon rey de Castela N'Anfos que rey es de Léo und ähnliches mehr.

2 Geographische Namen allein können den Ausschlag nicht geben. Doch sei bemerkt, dafs ein Val de Canas (CB 464) zum Gebiet von Palencia gehört und dafs Campos (ib.) auch von Alfons X. erwähnt wird (CV 65).

3 CB 466. S. darüber CA Kap. VI, Biogr. XIV.

- Alcalá la Real, oder de Benzaide.

6 CB 462. Vgl. z. B. Cron. Gen. p. 399 (bei Schirrmacher I p. 4II): ca en el su Axaraf hauia bien este dia cien mil alcarias.

- Alle drei bestehen aus $2 \times 2$ Strophen in Zehnsilbnern; und allen dreien fehlen die üblichen Schlufskadenzen, in denen der Sieger wie der Besiegte das Facit zu ziehen pflegt. - Was die Zeilenzahl betrifft, stimmt CB 357 nur zu CB 385; in der Reimbindung ( $a b a b c c b$ zu abbacca) nicht genau. beziehen.

7 Kriegslieder nur in dem Sinne, dafs sie sich auf Kriegszeit und Krieger

8 S. Randgl. V und VI. 
Gut wäre es, wenn wir wülsten, wer der Garcia Perez ist, der sich in so familiärer Weise an seinen Gebieter wendet - ob auch mit etwas mehr Zurückhaltung als Charinho und Vasco Gil. Er redet den König zu Anfang nicht direkt an, sondern überlä/st es ihm, ob er in eigner Person antworten oder einen Dritten damit beauftragen will, seine Entgegnung in Reime zu bringen. ${ }^{1}$ Als solchen Dritten schlägt er aber - wenn ich ihn recht verstehe einen seiner Genossen vor: Gonçalo Martins, als einen, der nicht übel gewillt schien, sich am Pelzscherze zu beteiligen. Einen Garcia Perez, der zu dem Leonesen in engeren Beziehungen gestanden hätte, kenne ich nicht. Hingegen einen, der zu Alfons' X. Vasallen gehörte: jenen Schwager des Dichters und Admirals Charinho, der 1282 als Meirinho Gallizien verwaltete, während seine Frau die Veste Zamora den Umtrieben der aufrührerischen Infanten gegenüber nicht $\mathrm{zu}$ verteidigen vermochte. ${ }^{2}$ Woher jedoch die Sicherheit nehmen, dafs er und der Dichter ein und dieselbe Person sind?

Auch von Gonçalo Martins vermag ich nichts auszusagen. ${ }^{3}$ Ich weifs nur, dafs in dem im Liederbuch CB unmittelbar folgenden Gedicht ein D. Gonçalo angeredet wird. 4 Und zwar wird er auch dort vom König vorteilhaft geschildert als aposto e fremoso cavaleiro ... de todas cousas comprido ... e apost e ben talhado. Gleichzeitig wird auf sein Talent angespielt, mit ungeheurem Schwerte sogar Feder- und Pelzwerk (pena) zu durchschneiden. ${ }^{5}$ Ferner auf seine Anwesenheit in Andalusien - lauter Einzelnheiten, die uns zu statten kämen, wenn das Gedicht als ganzes nicht gar so dunkel wäre.

Unter den Dichtern kommt Garcia Perez sonst nicht wieder vor; Gonçalo Martins überhaupt nicht. $\mathrm{Daf}$ es jedoch einen Poeten dieses Namens gegeben hat, lehrt eine portugiesische Urkunde. 6 Er führte sogar den Ehrentitel trobador de Santarem. Seine Tochter Maria Perez stand in intimen Beziehungen zu dem vornehmen Troubadour Joa Velho de Pedragaes, der $1280-82$ als Gesandter des Königs von Portugal am aragonesischen Hofe weilte, um die Heirat mit der jungen D. Isabel zu pactieren.? Ueber die Schicksale des Trobador de Santarem und seinen etwaigen

1 Portugiesische Beispiele solcher Meinungsäufserung sind nicht bekannt. Nur die provenzalischen Fälle, in denen $N^{\prime} A t$ de Mons und Guiraut Riquier im Namen Alfons' $X$. das Wort ergriffen haben.

2 Cron. Alf. c. 76; Randgl. I 22 und 45.

8 In den Adelsbüchern kommen zu viele gleichen Namens vor, als dafs sich Verläfsliches hätte auskundschaften lassen.

- CB 468 Don Gonçalo, pois queredes ir d' aqui para Sevilha.

- Schade dals jenes grolse Schwert nicht als coteife bezeichnet wird!

- Vgl. Revista Lusitana V I 36.

7 Aires de Sa, Frey Gonçalo Velho, Lisb. 1898 p. 57. 123 und 47. Ein Enkel des Paares wurde 1295 legitimiert; ein Sohn kam später an die Reihe (1300). 
1.74 CAROLINA MICHABLIS DE VASCONCELIOS, RANDGLOSSEN.

Aufenthalt in der Nähe Alfons' $X$. wissen wir nichts. Dafs aber der von König Alfons verlachte schmucke Ritter D. Gonıçalo sich auch als Dichter im satirischen Fache hervorthat, darf man vielleicht aus der Behauptung schliefsen:

$$
\begin{aligned}
& \text { a quenquer que cometestes } \\
& \text { sempre mal o escarnistes.1 }
\end{aligned}
$$

1 Cometer wie escarnir beziehen sich im Liederbuch der Riegel nach auf spottende Dichter.

Carolina Michaëlis de Vasconcellos. 


\section{Der Prosaroman Ysaȳe le Triste.}

\section{EINLEITUNG.}

Der Roman "Ysaye le Triste" ist uns, soweit bekannt ist, in zwei Handschriften überliefert. Die eine befindet sich auf der Herzoglich Gothaischen Bibliothek in Gotha als No. 688, die andere auf der Grofsherzoglich Hessischen Bibliothek in Darmstadt als No. 2524. Erstere sei hier kurz mit G, letztere mit $D$ bezeichnet.

G besteht aus einem 491 Blätter enthaltenden, mit schönen kräftigen Farbenbildern gezierten Bande, dessen Deckel mit grünem Sammet überzogen ist. Die Schrift ist ungleich und an vielen Stellen stark verblafst. Der Inhalt ist durch Herausreifsen einzelner Blätter unvollständig überliefert. So fehlen die $\$ \S \mathrm{I}-3$, die Hälfte von $\S 20$, die $\S \S 108-$ II I , die zweite Hälfte von $\S 457$, die erste Hälfte von $\S 45^{8}$ und $\S 582$. Aufserdem fehlen die Zusätze zu den $\S \S 17,102$ und 216 . Die $\S \S 4,9,13$ sind mit roten Ueberschriften versehen, die Anfänge der anderen $\$ \S$ werden nur durch rote oder blaue Anfangsbuchstaben gekennzeichnet. Die Ueberschrift zu § 4 lautet: Commant Yseut la Royne accoucha a lantree dun boys de Ysaye le Trisle loquel fut baptise et nourry duon armitte, zu § 9: Commant fees venoient de nuyt ou dorme lenfant et luy bailloient norriture subtillement dont lermitte fut moult effraye et esmerveille, zu \& 13: Commant lermitle arriva au pied de la verte forest ou il trouva lune des dames et tost luy monstra le lieu ou il demeuroit. Aufserdem befindet sich auf dem ersten Blatt ein Wappen, das bei Jacobs und Ukert „Beiträge zur älteren Litteratur oder Merkwürdigkeiten der Herzoglich öffentlichen Bibliothek zu Gotha", Band III, I, näher beschrieben ist.

D umfafst $36 \mathrm{I}$ Blätter, ist in Leder gebunden und mit einem Wappen versehen, das die Farben blau und gelb enthält. Als Schreiber nennt sich Sire Amoury de Noyelle adonc a Douay. Mai 1449. Die Schrift ist gleichmärsig, der Text vollständig. An Illustrationen sind nur vier schlechte Federzeichnungen vorhanden.

Neben diesen Handschriften sind noch zwei Drucke zu erwähnen, die 1522 in Paris bei Galliot du Pré und bei Bonfons und Philippe le Noir erschienen sind. Ueber diese Drucke haben gehandelt John Dunlop in der "History of fiction" 1810, dentsch von Liebrecht 1842 und die Herausgeber der "Histoire des Romans" 
1776, Mai. Aufserdem finden sich kleinere Notizen hierüber bei : Grässe „Die grofsen Sagenkreise des Mittelalters“, bei Schmidt in den „Wiener Jahrbüchern" I 825 Teil XXIX und bei Rosenkranz im „Handbuch der allgemeinen Geschichte der Litteratur“. Die soeben erwähnten Drucke werden hier aufser Acht gelassen, da sie den Handschriften gegenüber nur eine Verkürzung und $\mathrm{Ab}-$ änderung des Inhalts bedeuten.

Ueber den Inhalt der Handschriften ist meines Wissens nur einmal gehandelt worden und zwar durch die Herausgeber der oben erwähnten „Beiträge u. s. w.", durch Jacobs und Ukert. Die Autoren haben ihren Betrachtungen nur die Hs. G zu Grunde gelegt, da ihnen $D$ noch nicht bekannt war. Sie beschreiben die Handschrift sehr genau, geben den Inhalt ziemlich ausführlich, wenn auch mit einigen Fehlern (la fontaine au Jacant statt Jayant, Agrenam statt Agravain, Gannes statt Gaunes, De Fras le Maloit statt Desraes le Maloit) bis $\S 36$ an und drucken dann die Erlebnisse Marcs und Troncs im Feengarten (\$§ 514-516) und ein Rondeau diplomatisch ab. Im übrigen haben sie sehr geringe Mühe auf „diesen weitschweiftigen Roman" verwandt, sonst dürften sie nicht am Ende ihrer Abhandlung schreiben: „Von dem, was dann weiter folgt, haben wir uns vergebens bemüht, aus der fast ganz unleserlichen und noch überdies halb verblafsten Schrift einen zusammenhängenden Sinn zu entziffern. Nur die vier Endzeilen der letzten Seite glauben wir so lesen zu müssen: en memoire les fais u. s. w." Bei sorgfältigem Durchlesen des Romans wäre es ihnen auch nicht möglich gewesen, das Wort chrestien, das sich hundertfach in der Abkürzung $x x p$ zzz findet, für die Zahl $X X V I I$ zu halten.

Der Roman „Ysaye le Triste“ gehört dem Cyklus der Arthurromane an. Anknüpfend an die glorreiche Zeit, da König Arthur in Carduel (Wales) seinen Hof hielt, da die Ritter der Tafelrunde auszogen, den heiligen Graal zu suchen und Abenteuer zu bestehen, führt uns der Verfasser des "Ysaye le Triste" die Thaten der Nachkommen dieser Helden vor Augen. Noch leben bei Beginn des Romans der greise König Arthur von Logres, die tapferen Recken der Tafelrunde Tristan, Lancelot, Hector des mares, Lucan le boutillier, Bohort de Gaunes, Blaienor und Blioberis de Gaunes, Perceval, Brandalis, Lambeguet, Gaheriet; ferner Mordred, Palamede le mecogneu, Marc von Cornouailles nebst Gattin Yseut und deren Kammerfrau Bongyen (Nachahmung von Brangien, die mit Gouvernail das Königreich Leonois beherrscht). Aber auch der Toten: Meliadus, Merlin wird gedacht. Die Königreiche und berühmten Oertlichkeiten werden vorteilhaft in den Roman hineingeflochten, so die Königreiche Logres, Leonois, Cornouailles, Norgalles, Orcanie, die Hafenstadt Louvrezep, die Stadt Sarras (aus dem Grand Saint Graal), die Joyeuse Garde, der langjährige Aufenthaltsort Yseuts und die letzte Ruhestätte Lancelots du lac. Schliefslich bleiben nicht unerwähnt die Wälder: le Morois, Dar- 
nantes und Gaste Forest. Aufser diesen, durch die Arthurromane verbürgten Namen erwähnt der Verfasser noch Herbe le renomme, der von Tristan zum Ritter geschlagen wird, den Riesen Pincenart le juif, der von Tristan getötet wird, Hector d'Orcanie, der die Rolle des Brehus als Verfolger des chevreuil übernommen hat, den König Marsiadus von Norgalles, Bohort le picquart, Herrn von Guis, Marc le roux, einen gewissen Macon le brun de Cornouailles und Craventor de l'outrageux passage. Schliefslich führt er noch einen König Yrion ein, der zur Zeit Arthurs über Blamir und Miradir herrscht.

Aus dieser, durch die Arthurromane verbürgten und nicht verbürgten Generation schafft der Verfasser ein neues Geschlecht. Ysage le Triste ist der Sohn Tristans und Yseuts, Brandor der des Brandelis, le besgue de la halte roche der des Lambeguet, Menet le mecogneu der des Palamede, Festion le blond und Gerafil le blond sind die Söhne Gaheriets, der sot sage ist der Sohn Blaienors, Oriant le grieu der Hectors von Orcanie, Harpan du gue parfond der Herbes le renomme, Hergault (Hergo) der Bohorts le picquart, Miriol der Pincenarts. Die Söhne Macons le brun sind le brun de l'engarde, Macon l'oconge (?) und le vacquier de l'esclaire, die Neffen Craventors sind Argus und Octes. Anknüpfend an die Oertlichkeiten nennt der Verfasser folgende Personen: la douleureuse und le desorreillé de la Joyeuse Garde, und die dame du chastel de Belle Garde mit ihren sieben Söhnen, von denen vier später eine Rolle spielen: Atrides, Fidiger, Dispront und Gavain.

Dieses zweite Geschlecht zeugt dann ein drittes, so dafs wir auch die Heldenthaten der Enkel Tristans, Macons und so weiter im Romane dargestellt finden.

Diese Nachkommen aus der Zeit Arthurs mit ihren, nach dem Muster der Arthurromane verwirrt dargestellten Abenteuern verleihen dem "Ysaye le Triste" das Gepräge eines Romans der Tafelrunde, und es vermögen daran nicht die anderen gewichtigen Bestandteile des Romans, die den verschiedenartigsten Litteraturgattungen entnommen sind, zu rütteln.

Hiermit ist die Frage berührt, welchen Vorlagen die aufserhalb der Arthursage stehenden Personen und Ercignisse des Romans entnommen sind. Nun, die folgenden Ausführungen werden darauf Antwort geben.

Als wichtigste Vorlage unseres Romans kommen aufser der Arthursage die Chansons de geste in Betracht. Die Tötung des Neffen Yrions (\$ 295), die Scene, in welcher Ysaye den Pförtner gegen einen Pfeiler wirft, dals diesem die Augen aus dem Kopfe fliegen ( $(165)$ und die Ermordung des Pförtners (§ 493) sind Züge, die den Chansons de geste entlehnt sind. Die Erzählung von den vergifteten Birnen ( $\$ 476)$ ist eine Nachahmung derjenigen von den vergifteten Aepfeln in Parise la Duchesce, die Tötung der Köche (§ 306) eine Nachahmung aus der Chanson „Aliscans". Der Name 
Oriant stammt aus dem „Schwanenritter", Ysoré von Spanien aus "Anseïs de Carthage“. Diejenige Chanson aber, welche dem Verfasser des "Ysaye le Triste" den reichsten Stoff geliefert hat, ist die Chanson "Huon de Bordeaux".

Dem Einflusse dieses Werkes muls man es zuschreiben, dafs statt der in den Arthurromanen üblichen Einfälle der Sachsen die der Sarazenen getreten sind. Um seine Quelle dem Leser nicht zu verraten, giebt der Verfasser den Sarazenenführern ganz unbekannte oder mehr allgemeine Namen, so: der Admiral von Persien, der rote Löwe von Nubien, der Tartar von Cartaire, der König der fremden Wüsten, der König der eisernen Brücke, die vierzehn Riesen von den bitteren Gewässern, die Könige von Mekka, Afrika, Creta, Carthago, Ungarn und andere. Nur in dem Namen Orimonde ist eine direkte Entlehnung aus „Huon“ zu erkennen. Orimonde ist die Esclarmonde aus „Huon de Bordeaux“. Im „Ysaye“ wie im „Huon" ist die Vertreterin der beiden Namen eine Tochter des persischen Admirals, in beiden Erzählungen wird sie von leidenschaftlicher Liebe $\mathrm{zu}$ einem vernehmen, christlichen Ritter ergriffen. Ihre Liebe wird von diesem verschmäht und erst erwidert, nachdem sie Christin geworden ist. Für die Abweisung, die sie zuerst erfährt, rächt sie sich, indem sie Huon ins Gefängnis werfen und Marc hinterlistig überfallen lärst.

Als ein weiterer und wichtigerer Einflufs, den der „Huon de Bordeaux" auf den Verfasser des "Ysaye" ausgeübt hat, ist die Einführung der Feeen und besonders des Elfenkönigs Oberon anzusehen. Vom Anfang bis zum Ende des Romans begegnet uns dieser Zwerg unter dem Namen Tronc (lat. truncus), wahrscheinlich wegen seines kleinen und verkrüppelten Wuchses so genannt, ohne dals wir in ihm den verkappten Oberon vermuten. Höchstens könnte man durch zwei Andeutungen, die sich in den $\$ \S 516$ und 560 finden, zu der Ansicht kommen, dafs in der Person Troncs der alte Oberon verborgen sei. Diese Andeutungen sind enthalten in einer Mitteilung der Fee Oriande an Marc, dafs Tronc der Sohn Julius Caesars und der Fee Morgue sei, und in der Aeufserung Troncs Marc gegenüber, dafs er in Monmur geboren sein soll. Erst am Schlusse unseres Romans bekommen wir volle Klarheit darüber, dafs wir in dem schlauen Pagen Ysayes den Elfenkönig Oberon vor uns gehabt haben.

Als dritter, nicht gerade wesentlicher Einflufs des „Huon“ ist der zu erwähnen, den die drei Personen im „Huon“, der römische Kaiser Neron, die Fee Murgalle und der Riese Orgueil mit seinen zwei kupfernen Rittern auf den Verfasser des "Ysaye“ ausgeübt und ihn zu den wunderlichen Geschichten in den $\$ \$ 560-6 \mathrm{I}$, $574-78,554-55$ veranlafst haben.

Eine weitere Vorlage für unseren Roman dürfte in der Chantefable "Aucassin und Nicolette" zu erblicken sein. Es handelt sich hierbei um die Person der Nichte des Königs Yrion, Marthe, welche genau wie Nicolette die Frauenkleidung mit der Männer- 
kleidung vertauscht (der Zug, dars sie ihr Gesicht mit Kräutern dunkel färbt, um besser als Mann zu erscheinen, fehlt zwar), dann eine Harfe zur Hand nimmt und als Spielmann das Land durchstreift und den Gefahren des Meeres trotzt, nur um ihren Geliebten wiederzufinden.

Von Romanen aus anderen Sagenkreisen haben der "Eracles" des Gautier d'Arras, der „Florimont" und der „Eneas" die Namen Parides (-us), Edor (persisch $=$ Blume) und die Scene mit dem Pfeilschuls (\$ 422) dem Verfasser des „Ysaye“ geliefert.

Es erübrigt nun noch, einen Blick auf die in den Handschriften enthaltenen Gedichte zu lenken. Wie schon Jacobs und Ukert erwähnen, finden sich in den Hss. mehrere Gedichte, die man mit dem Namen "lay“ bezeichnen kann. Es sind dies die lays accordants, deren viele sich schon im Prosa-Tristan finden und auf welche nicht weiter eingegangen zu werden braucht.

Wichtig aber ist, festzustellen, was in den von Jacobs und Ukert erwähnten I 7, resp. I 5 Blätter füllenden "lays" enthalten ist.

Das erstere Gedicht ist eine Nachahmung des allbeliebten Rosenromans von Guillaume de Lorris und dessen Fortsetzer Jehan de Meung. Das Versmafs, die paarweise gereimten Achtsilber, ist vollständig gewahrt, desgleichen auch die Allegorie, wenngleich im "Ysaye" einige neue Gestalten auftreten (vgl. $\$ 363$ ). Eine Probe aus dem "Ysaye" sei hier gegeben.
Au corps m'entra sans fendre pel;
trop m'en deul, mais point n'en appel.
Beau parlers, ly gens, ly gentieux,
je croy qu'il n'en est plus de tieulx,
estoit droittement par del'es
et tenoit sa main a son les
en disant: Dame, vos amis
en cest propre lieu a mis
moy pour monstrer a vo corps bel,
qui n'est point de taint de corbel,
que nient ceux sont en paradix
qu'aiment et qu'amerent jadis.
Depuis bien garde m'en donnay,
mes tantost tout ly pardonnay.

Schliefslich ist noch zu erwähnen, dafs sich der Verfasser des "Ysaye" durch die Schilderung des vergier im Rosenroman veranlafst gefühlt haben muls, ebenfalls einen solchen vergier (\$§ 514-16) zu beschreiben, was ihm dann auch gut gelungen ist.

Das auf den 15 Blättern enthaltene Gedicht ist eine wenig getreue Nachahmung der „Vœux du paon“. Während das eigentliche Versmafs der „Vœux du paon“, der Alexandriner, durch den ganzen Roman des J. de Longuyon hindurchgeht, sind in unserer Darstellung nur die ersten zwölf Verse in dieser Versform geschrieben. Die übrigen Verse sind völlig ungleich, und hin und 
wieder taucht ein rondeau auf. Auch der ehrwürdige Pfau ist nicht mehr vorhanden, sondern durch eine Rohrdommel ersetzt, und die sogenannten "neuf preux" (Christen, Heiden, Juden) kehren wieder in Liebespaaren und deren Dienerinnen: Marc, Hergault, Henry de Lyon - Orimonde, Sardine, Englentine - Alyor, Esclade, Parianne.

Es bleibt nun noch übrig, die Frage nach dem Autor und der Abfassungszeit des Romans zu beantworten. Ueber den Verfasser wird im "Ysaye" nichts erwähnt. Es heifst immer in den Handschriften: or dist le conte, wer aber diesen conte verfafst hat, wird nicht verraten. Aus den in den Hss. enthaltenen Wappen habe ich auch nichts Belangreiches für die Person des Verfassers ermitteln können und mufs so die Frage über den Autor unbeantwortet lassen. Hinsichtlich der Abfassungszeit glaube ich eine genauere Zeit als Dunlop und Grässe feststellen zu können. Dunlop versetzt den Roman in das Ende des XIV. oder den Anfang des XV. Jahrhunderts, Grässe in das XV. Jahrhundert. Ich glaube, der Roman gehört noch dem XIV. Jahrhundert an. Das XV. dürfte vies (lat. vetus, vgl. Viesroche $\$ 417$ ) nicht mehr gebraucht haben, und für das Vorhandensein der Rotruenge $\left(\S 55^{8}\right)$ noch im XV. Jahrhundert mülste erst der Beweis gebracht werden.

\section{In halt.}

[1. Tristan von Leonois ist der Neffe des Königs Marc von Cornouailles, Yseut die Gemahlin Marcs.

2. Marc verläfst eines Tages Tintagel und begiebt sich nach einem elf Meilen von Tintagel gelegenen Schlofs. Die Abwesenheit des Königs benutzt Yseut, um Tristan herbeizurufen. Tristan bleibt eine Nacht bei ihr. Bald darauf wird Yseut schwanger.

3. Als die Zeit der Entbindung herannaht, verläfst die Königin mit ihrer Kammerfrau Bongyen ihr Schlofs und begiebt sich in den benachbarten Wald, le Morois genannt. (Marc wohnt zur Zeit bei l'estrange passage einem Tournier bei.)] ${ }^{1}$

4. Yseut und Bongyen lassen sich an der fontaine au jayant nieder. Da erscheint Lucan le boutillier, der auf Befragen der Damen erklärt, er wolle Marc bestrafen, weil dicser Tristan auf verräterische Weise tödlich verwundet habe. Yseut sinkt bei dieser Nachricht ohnmächtig zu Boden.

5. Lucan le boutillier reitet davon. Als Yseut wieder zum Bewufstsein kommt, schreit sie laut auf und schenkt um die neunte Stunde einem Knaben das Leben. Der Knabe hält in seiner linken Hand ein Schwert aus Fleisch und But. Yseut lärst einen in der Nähe wohnenden Einsiedler herbeiholen und beichtet diesem alle ihre Sünden, die sie in einem dreifsig Blätter starken Buche aufgezeichnet hat.

1 [ ] fehlt in G. 
6. Der Einsiedler macht zunächst Yseut heftige Vorwürfe, giebt ihr aber mit dem Zeichen des Kreuzes Absolution, da er aus dem Buche ersieht, dars nur der Zaubertrank die Schuld an allem habe.

7. Der Einsiedler will nun den Knaben taufen. Er will ihm den Namen Justice geben, da der Knabe ein Schwert mit auf die Welt gebracht habe. Yseut aber bittet ihn, dem Knaben einen Namen zu geben, der sowohl an sie als an Tristan erinnere. Da giebt der Einsiedler dem Knaben den Namen Ysaye le triste und tauft ihn mit dem Wasser der Quelle. - Nach fünfzehn Tagen ruft Tristan die Geliebte an sein Sterbebett. Sie eilt $\mathbf{z u}$ ihm, und als sie ihn bereits tot vorfindet, bricht sie tot an seiner Seite nieder.

8. Lancelot hört von dem Verrat Marcs und fällt mit 6000 Mann in Cornouailles ein. In seiner Begleitung befinden sich Bohort de Gaunes, Hector des Mares, Perceval de Gaunes, Gaheriet und andere.

9. Eines Nachts vernimmt der Einsiedler, unter dessen Obhut sich nun Ysaye le triste befindet, einen schönen Gesang und sieht, wie vier weifs gekleidete Feeen in sein Haus eintreten, das Kind nehmen, es baden und ihm Nahrung geben. Der Einsiedler will seine Cousine, die die Amme Ysayes ist, wecken; die schläft jedoch zu fest. Da nun die Feeen alle Abende wieder erscheinen und immer dieselben Handlungen mit dem Kinde vollziehen, fafst der Einsiedler endlich Mut, die Damen anzureden.

10. Er fragt sie und erfährt von ihnen, dafs sie den Knaben ernährten, weil die Amme dazu nicht imstande sei.

11. Die eine der Feeen erzählt ihm ferner, wie Tristan und Yseut ums Leben gekommen sind. Sie wisse das von Merlin, dessen Seele im Walde Darnantes in Grofs-Britannien sich befinde, wo sie unter einem schönen Baume auf Befehl der Dame vom See eingeschlossen sei.

12. Merlin habe ihnen dort von den grölsten Rittern der Welt erzählt und Tristan als den hervorragendsten geschildert. Dieser habe mit Yseut einen Sohn gezeugt, der sich bei Sarban befinde. Hier erschrickt der Einsiedler, als er seinen Namen hört. Schliefslich sagt ihm dic Fee noch, dafs sic den Knaben mit der Milch der Clarisse, der Gemahlin des Königs Caradoc, ernährten.

13. Eine zweite Fee beflehlt ihm, die Amme im Stich zu lassen und mit dem Kinde sich nach einem Kreuze $z u$ begeben, das sich am Ende des Waldes befinde. Der schlafenden Amme steckt sie einen goldenen Ring an den Finger. Dieser Ring vault un tresor. Hierauf nehmen sie den Einsiedler Sarban nebst Ysaye mit und verschwinden bei dem Geschrei eines Hahnes in der Nähe einer Einsiedelei. Der Einsiedler findet das Kreuz und sieht am Meeresufer ein Schiff, das für vier Tage Lebensmittel enthält. Am Kreuze läfst er sich nieder, wie die Fee es ihm befohlen hatte.

14. Die Amme, welche in der Einsiedelei allein zurückgeblieben 
ist, bemerkt zu ihrem Entsetzen, dafs Ysaye verschwunden ist. Sie sucht ihn, und als sie ihn nicht findet, setzt sie sich weinend auf die Schwelle der Hausthür. Hier bemerkt sie den Ring und sieht in dem Steine desselben das Bild Ysages. Ein vorbeireitender Ritter erkundigt sich nach ihrem Schmerze und erfährt von ihr, was sich zugetragen hat. Sie bittet den Ritter, Sarban zu verfolgen und ihr das Kind zurückzubringen.

15. Der Ritter, Namens Agravain, macht sich auf und findet Sarban mit dem Kinde am Fufse des Kreuzes. Er verlangt das Kind, Sarban aber weigert sich, es auszuliefern. Da bindet Agravain sein Pferd an einen Baum und versetzt Sarban mit einem Baumzweig einen wuchtigen Hieb. Ysaye stölst hierbei einen derartigen Schrei aus, dafs das Rols des Ritters sich losreifst und Agravain so gezwungen ist, Sarban zu verlassen und das Pferd wieder einzufangen.

16. Sarban nimmt den Zweig in der Hoffnung, dals Ysaye ihn später einmal damit rächen werde. Da beginnt das Meer zu steigen, der Einsiedler mufs das Schiff besteigen und wird drei Tage und drei Nächte auf dem Meere herumgetrieben.

17. Am Morgen des vierten Tages kommt er an einen Felsen. Dort trifft er eine der Feeen wieder, die ihm befiehlt, in den Wald zu gehen. Im Walde begegnet er den vier Feeen insgesamt, wie sie sich in einer Quelle die Hände waschen. Er redet sie an, erhält aber keine Antwort. Er geht weiter und trifft einen Zwerg, la plus laide creature du monde. Von diesem wird er in ein Haus geführt, das die Feeen erbaut hatten. Nun verlangt der Zwerg das Kind, Sarban giebt es ihm aber nicht. Es entspinnt sich ein Streit, der erst durch die Feen geschlichtet wird. Diese erklären nun auch Sarban, dals er, Ysaye und der Zwerg künftig zusammenleben müfsten. [In diesem Hause bleiben die drei so lange, bis Ysaye $3 \frac{1}{2}$ Jahr alt ist. $]^{1}$

18. Eines Tages meldet ein Ritter dem König Arthur in Carduel (Galles), ein Kind sei geboren, welches ihn (den Ritter) später einmal töten werde. Dies habe ihm eine weise Frau gesagt.

19. Das Kind, das jetzt erst ein Jahr alt sei, sei der Sohn Tristans von Leonois. Auch werde noch sein Bruder, Craventor de l'outrageux passage, von dem Sohne Tristans getötet werden. Der Ritter heifst Nabel de l'outrageux passage. Als der König den Ritter angehört hat, sagt er, er glaube nichts von all dem, denn Tristan habe keinen Sohn gehabt.

20. [Eines Morgens begeben sich der Zwerg, Namens Tronc, und Ysaye in den Wald und begegnen einem Ritter in Begleitung zweier Damen. Der Ritter spottet über Troncs Häfslichkeit und fragt, wer der hübsche Knabe sei. Da sagt Tronc, das werde er noch erfahren.] ${ }^{2}$ Ueber diese Antwort erzürnt, ergreift der Ritter

1 [ ] ist Zusatz der Hs. D.
fehlt in Hs. G. 
den Zwerg und zerdrückt ihn falst. Da holt Ysaye den Baumzweig Agravains (\$16) herbei und schlägt den Ritter derart damit auf den Kopf, dafs diesem das Blut vom Kopfe strömt. Gefragt, weshalb er das gethan habe, erwidert er dem Ritter: pour ce que tu faisois crier mon verlet.

21. Der Ritter freut sich über Ysaye, umarmt ihn und reitet davon. Von einem anderen Ritter, Mordrec, erfährt Tronc den Namen des vorigen. Es war Agravain. Als Mordrec davongehen will, sagt ihm Tronc, der nie lügende Merlin habe ihm erzählt, Nordrec werde seinen Vater umbringen, und der beste Ritter werde so durch den schlechtesten ums Leben kommen. Wütend will sich nun Mordrec auf Tronc stürzen, dieser aber flüchtet in den dichtesten Teil des Waldes, wohin der Ritter ihm nicht zu folgen vermag.

22. Ein halbes Jahr nachher begeben sich Sarban, Tronc und Ysaye in den Wald Darnantes, um das Grab Merlins aufzusuchen. Sie suchen, aber finden es nicht. Da hören sie auf einmal Merlin aus dem Grabe heraus stöhnen. Sie gehen zu ihm und finden, dafs sein Grab vollständig bewachsen ist. Tronc fragt Merlin, was ihm fehle, worauf Merlin antwortet, er möchte etwas über Arthur, den er erzogen habe und der jetzt tot sei, erfahren.

23. Merlin fragt Ysaye, wer er, seine Eltern, Grols- und Urgrofseltern seien. Ysaye, der die Frage nicht versteht, lacht darüber und sagt: "Gesegnet seist du, mein Freund, und verflucht seien meine Feinde, denn ich hasse sie."

24. Hierauf fragt Merlin Ysage, was er gern sein möchte. "Ein Adler." $\mathrm{Ob}$ er aber lieber laboureur oder chevalier werden möchte. „Chevalier.“ $\mathrm{Da}$ sagt ihm Merlin, er werde einmal von Lancelot du lac zum Ritter geschlagen werden.

25. Als Ysaye fünfzehn Jahre alt ist, eröffnet er dem Einsiedler den Wunsch, sich von Lancelot zum Ritter schlagen zu lassen. Sarban und Tronc reden ihm ab, geben aber doch seinen Bitten nach und machen sich auf den Weg. Sie durchschreiten die verde forest, den Wald Darnantes, eine prairie und gelangen schliefslich in die gaste forest. Beim Eintritt in diesen Wald erklärt Tronc seinen Begleitern, dafs infolge eines Brudermordes, den Dimustra an Dedalus le vis (beide Söhne des Königs Seben von Grofs-Britannien) verübte, der Wald als gaste forest bezeichnet werde. Sie treffen ein Häuschen an, aus welchem eine Stimme ihnen zuruft, sie möchten für Lancelot, der hier begraben sei, ein Gebet verrichten. Sie gehen zum Grabe, heben einen grolsen Stein ab und erblicken ein Skelett in einem bleiernen Kasten. Die Nacht verbringen sie in der Kapelle. Am folgenden Morgen, nach der Messe, erfüllt der Einsiedler Ysayes Bitte, indem er Ysaye mit dem rechten Arme Lancelots den Ritterschlag erteilt. Diese Ceremonie begleitet er mit einer Rede, worin er Ysaye ritterliche Pflichten mitteilt.

26. Nach dieser Feierlichkeit erscheinen die vier Feeen wieder 
und überreichen Ysaye ein Pferd, ein Schwert, einen Schild und einen Helm. Tronc, Ysaye und der Einsiedler kehren hierauf in ihre Klause zurück.

27. Das Pferd Ysayes erhält die grölsten Freiheiten. F.s läuft den ganzen Tag im Walde herum, kehrt aber des Abends pünktlich zurück. Eines Tages befinden sich die drei Gefährten an dem puits de l'aventure und vernehmen ein lautes Geschrei. Sie gehen dem Geschrei nach und treffen einen valet, der ihnen unter Thränen berichtet, dals sein Herr, Herbe le renomme, von einem Pferde getötet sei, als er ihm habe den Sattel umschnallen wollen. Sein Herr sein ein berühmter Ritter gewesen, der von Tristan zum Ritter geschlagen sei. Ysaye verspricht nun dem Knappen, dem Sohne Herbes, eine Entschädigung zu teil werden zu lassen.

28. Eines Tages bittet Ysaye den Einsiedler, ihn das Fechten zu lehren. Sie fechten zuerst mit Schwertern, dann mit Baumzweigen. In beiden Fechtarten zeigt sich Ysaye überlegen.

29. Ysaye, der zum Manne herangereift ist, reitet eines Tages mit Tronc in den Wald. Hier wird er von einem Ritter, Harpan du gue parfond, angehalten und gefragt, wo der Ritter wohne, dessen Pferd seinen Vater getötet habe. Ysaye giebt sich als den betreffenden Ritter zu erkennen und bietet Harpan Sühne an. Dieser schlägt sie aus und es kommt zum Kampf.

30. Harpan wird getötet. Ysaye und Tronc kehren in ihre Klause zurück und finden den Einsiedler tot vor. Harpan hatte ihm den Kopf abgeschnitten. Sie begraben den Einsiedler in der Kapelle und verlassen ihren langjährigen Aufenthaltsort. Sie kommen vor ein schönes Schlofs und klopfen an. Eine Dame antwortet ihnen, sic werde keinem Ritter Eintritt in ihr Schlofs gewähren, aufser demjenigen, der sie an einem Ritter rächen werde.

31. Dieser letztere Ritter, Namens Desrayes le maloit, habe den Leichnam Lancelots aus diesem Schlosse geraubt und in die gaste forest geschleppt. Der Ritter sei dann in der folgenden Nacht wiedergekommen und habe ihre Eltern getötet, die Knechte und Mägde verstümmelt. Sie selbst habe ein $\mathrm{Ohr}$ dabei verloren. Dieses Schlofs heifse die Joyeuse Garde und sie la douloureuse de la Joyeuse Garde. Desraes wohne auf dem chastel redoute am Ende des Waldes.

32. Ysaye verspricht der Dame, sie an dem Ritter rächen zu wollen, und begiebt sich zu diesem Zwecke mit Tronc nach dem chastel redoute. Durch einen Knappen läfst er Desraes zum Kampfe herausfordern.

33. Nach einiger Zeit erscheint der Ritter mit seinen fünf Söhnen auf dem Plan.

34. Ysaye überwindet alle sechs Ritter und lärst sie lebend auf einem Wagen nach der Joyeuse Garde fahren. Die Namen der Ritter sind: Desraes, Vester, Duon, Thom, Perlus le roux de la verte montagne und Bruneil.

35. Auf Wunsch der douloureuse de la J. G. schneidet Ysaye 
den Rittern die Fäuste und Füfse ab und lärst ihnen so für ihre Grausamkeit Gerechtigkeit widerfahren. Die Nacht verbringt Ysaye im Schlosse, Tronc wacht über die Waffen, und das Pferd Ysayes läuft frei herum.

36. Am anderen Morgen sieht Ysaye, wie die douloureuse und eine andere Dame die Herzen der sechs Ritter essen. Auf Ysayes Frage, weshalb sie das thäten, erklären sie, sie thäten es, um sich besser an ihren-Feinden zu rächen. Hierauf tritt der achtzehnjährige Bruder der douloureuse ein und dankt Ysaye. Er besitzt nur ein Ohr - das andere hatte ihm Desraes abgeschnitten - und heilst daher le desoreille de la Joyeuse Garde. Ysaye schlägt ihn am folgenden Morgen zum Ritter.

37. Die Erzählung wendet sich zur Amme Ysayes.

38. Die Amme, Bise, begiebt sich nach Tintagel zu einem Goldschmied, um sich nach dem Werte des Ringes zu erkundigen. Sie erfährt von dem Goldschmied, dals der Ring einen tresor wert sei. Neugierig, woher der Ring stammt, bittet er Bise, ihm dies zu sagen, und erfährt so die Geschichte von der Entführung Ysayes durch Sarban. Er will den Ring kaufen, da aber Bise nicht einwilligt, bittet er sie, in einem halben Jahre wieder $\mathrm{zu}$ kommen. Bise begiebt sich hierauf nach Loisemont zu ihrem Vater Clabant, einem ribault. Dieser läfst sich die Geschichte Ysayes ruhig erzählen und sagt ihr dann, Sarban habe den Knaben zu ihrer Tante getragen, woselbst er sehr gut gepflegt werde.

39. Ysaye und Tronc begegnen auf ihrem Marsche einem valet, der ihnen erzählt, dals man seit dem Tode Arthurs seines Lebens nicht mehr sicher sei, da jeder Ritter jetzt selber den Herrscher spielen wolle. Auf ihrem Wege würden sie das Schlofs Menets le mecogneu, des Sohnes Palamedes le mecogneu, antreffen. Dieser Ritter sei sehr grausam und lasse von seiner coustume nur ab, wenn ihn jemand besiege. Ysaye beschliefst, den Kampf gegen Menet aufzunehmen. Er reitet nach dem Schlosse und läfst durch eine Zwergin, die unter einem Baume sitzt, den Ritter herausrufen. Diese bediente sich hierbei eines Klingelzuges, der von dem Baume aus nach dem Schlosse führte. Der Ritter erscheint sofort. Es kommt zum blutigen Kampfe, in welchem Menet vom Pferde geworfen wird und mit gebrochenem Arm in sein Schlofs getragen werden mufs.

40. Tronc benachrichtigt nun den Pförtner von dem Unglück des Schlofsherrn. (Das Pferd Menets schenkt er einem vorbeigehenden Armen.) Dieser läfst nun Menet auf einer Bahre ins Schlors tragen. Menet selbst lädt Ysaye ein, in dem Schlosse, welches ihm jetzt gehöre, zu übernachten. Ysaye folgt der Einladung. Tronc aber, der sich auch mit ins Schlors begeben will, wird die Thür vor der Nase geschlossen.

4I. Im Schlosse angekommen, wundert sich Ysaye, dafs Tronc nicht bei ihm ist. Er bittet deshalb den Pförtner, Tronc zu suchen. Dieser fürchtet sich vor Tronc, und so muls ein anderer den Zwerg 
suchen. Tronc wird bald darauf vor seinen Herrn geführt. Alle : Bewohner des Schlosses sind über Troncs Härslichkeit entsetzt, , und Menet fragt Ysaye, Tronc mache ihm wohl mehr Schande als ; Ehre. Y'saye aber nimmt Tronc in Schutz. Ysaye wird nun von 1 Menet nach seinem Namen gefragt, worauf Ysaye ihm ausweicht $t$ und ihn bittet, er möge ihm am folgenden Tage die vier Wege, , die vom Schlosse abführen, erklären.

42. Menet klärt Ysaye sofort darüber auf. Die vier Wege seien der rote, schwarze, grüne, weilse. Der rote Weg sei der Weg der Schlacht oder des Blutes. Diesen halte Paumart le vermeil mit sechzig Rittern besetzt. Jeder Ritter, der an seinem Schlosse vorbeikomme, müsse mit ihm fechten. Wird er besiegt, so ist er Paumarts Gefangener, siegt er aber, so darf er auf Paumarts Schlofs jede andere coustume einführen. Der schwarze Weg, so fährt Menet fort, sei der des Todes. Er führe nach dem chastel de l'engarde, welches sich im Besitze eines Sohnes des Macon le brun de Cornouailles befinde. Dieser habe die üble Gewohnheit, Ritter sowohl wie Damen gefangen zu nehmen. Die Ritter werfe er in den Kerker, die Damen aber gebrauche er. Sollte sich eine Dame sträuben, so würde sie ebenfalls eingekerkert, oftmals sogar verbrannt.

43. Ysaye ist über diese Grausamkeit erregt. Ueber den grünen Weg erfährt Ysaye von Menet, er führe nach einer grünen Wiese. Dort hielten sich zwölf Feeen auf, die jeden Wanderer fortschleppten, und man wisse nicht, was aus diesem werde. Der weirse Weg sei vollständig ungefährlich.

44. Auf Ysayes Frage, woher diese coustumes stammen, erzählt Menet: Drei Jahre nach dem Tode Arthurs veranstalten Ramant le prince de Galles und der roi des cent chevaliers ein Turnier. Nach dem Feste kehrten alle Ritter heim, zwanzig jedoch blieben bei Ramant. Als sie eines Mittags bei der Tafel salsen, trat dessen Schwester mit einem limosin auf silberner Platte herein und sagte, derjenige von den Rittern, der den besten Plan habe, solle den limosin bekommen, demjenigen aber, der die kühnste That vollbringe, wolle sie ihre Liebe schenken. Da gelobt Marc le roux, er wolle dem König Bohort le picquart, le sire de Guis, die Krone entreifsen. Die übrigen Ritter an der Tafel waren Vettern Bohorts und versprachen ihm, ihn in diesem Kampfe zu unterstützen. Als es aber nachher zum Kampf kam, übten die Vettern Verrat. Bohort wurde besiegt. Marc schlug ihm den Kopf $a b$, verwüstete das Land und baute in der Nähe sein Schlols Clermoustier auf. Als der Sohn Macons le brun von diesem Verrat der Vettern hörte, beschlofs er, nicht mehr die Pflichten eines Ritters erfüllen zu wollen. Auch Paumart beschlofs dasselbe.

45. Am folgenden Morgen schlagen Ysaye und Tronc den roten Weg ein. Sie sehen vier Häuser am Wege liegen. Kaum sind sie bis hierher gelangt, als vierzig Reiter auf sie losstürzen und von Ysaye Waffen und Pferd verlangen. 
46. Ysaye weigert sich. Die Ritter stürzen auf ihn los, müssen s sich aber vor den wuchtigen Hieben Ysayes wieder zurückziehen.

47. Als Paumart seine Leute fliehen sieht, rüstet er sich selbst $\imath$ und stürzt auf Ysaye los, wird aber von Ysaye aus dem Sattel kgeworfen.

48. In dem darauf folgenden Schwerterkampf ergeht es PauI mart nicht besser. Er wird besiegt und erklärt Ysaye, er könne 1 mit ihm und seinem Schlosse machen, was ihm beliebe. Ysaye 1 und Tronc gehen nun zunächst mit Paumart ins Schlofs.

49. Hier bittet Ysaye Paumarl, er möchte seine Hand in die s seines Knappen legen. Paumart weigert sich zuerst, da er Tronc I für einen Teufel hält, bald aber thut er es auf Zureden Ysayes.

50. Nun sagt ihm Ysaye, er solle für die doulce dame ein Kloster bauen und siebzehn Mönche hineinsetzen. Dann würde ' Christus ihm seine bösen Thaten verzeihen. (Die Zahl 17 wählt Ysaye zum Andenken an 17 tote Ritter, von denen 12 durch Paumart, 5 durch Ysaye getötet sind.)

5 I. Paumart dankt Ysaye und lälst das Kloster bauen. „Es führt noch heute den Namen chastel de l'aumosne." Nun reiten Tronc und Ysaye weiter und kommen zu einem Schlosse, vor welchem vier scheinbar schlafende larrons liegen, die unter dem Rufe: vassaux a la belle dame vous estes prins entfliehen. Ysaye tritt in den Schlofshof ein. Dort hört und sieht er niemand. Kaum aber hat er sein Pferd in den Stall gebracht, als mehrere Ritter über ihn herfallen und ihn gefangen nehmen. Tronc wird vor den Schlofsherrn geführt. Dieser wundert sich über Troncs Hälslichkeit, findet ihn aber sehr spafshaft und nennt ihm auch seinen Namen: le brun de l'engarde. Den Namen Ysayes aber erfährt er von Tronc nicht. Im Laufe des Gesprächs erhält Tronc auch die Erlaubnis, in Begleitung des Kerkermeisters seinen Herrn besuchen zu dürfen. Beide begeben sich zu Ysaye. Kaum hat aber der Kerkermeister die Thür geöffnet, als ihn Ysaye schon ergreift und ihm den Kopf abschlägt.

52. Tronc bittet nun Ysaye, ihm in kurzer Zeit in den Saal zu folgen. Tronc geht in den Saal und läfst alle Ritter hereintreten. Kaum aber sind sie hier versammelt, so erscheint Ysaye bis an die Zähne bewaffnet.

53. Ysaye hält nun vor den Rittern eine Rede, in welcher er sie auffordert, von ihren Gräuelthaten abzulassen und lieber ein Gott wohlgefälliges Leben $z u$ führen. Le Brun spottet darüber.

54. Ysaye wird wütend und erschlägt alle 34 im Saal befindlichen Ritter. Tronc steckt das Schlofs in Brand.

55. Ysaye kehrt hierauf in das chastel de l'aumosne zurück, freut sich über Paumert und die siebzehn Mönche und drückt dann noch den Wunsch aus, die douloureuse de la Joyeuse Garde und Menet le mecogneu mögen in Zukunft hier ihren Wohnsitz aufschlagen.

56. Während Ysage mit den Mönchen redet, erscheint eine 
Dame zu Pferde und fragt nach Ysaye. Sie ist von der Witwee eines reichen Ritters, die sieben Kinder hat, abgeschickt worden,l, um Ysage zu bitten, sie gegen die Belästigungen eines Ritters,;, Craventor de l'outrageux passage, der sie wegen ihres Reichtumss und ihrer Schönheit begehre, zu schützen. Die Dame wohnt auff dem chastel de belle garde. Ysaye fragt, woher die Dame ihn kenne. Da antwortet die Dame, man kenne sein Schwert Justice, , seinen Zwerg, sein Pferd und nenne ihn überall den chevalier dée grace. Ysaye verspricht $\mathrm{zu}$ helfen.

57. Die Amme Bise pflegt Driant, das Kind ihres Onkels, , sehr gut, weil sie es für Ysaye hält. Eines Tages erblickt sie in 1 dem Steine des Ringes nicht mehr das Bild eines Knaben, sondern 1 das eines Ritters. Da erinnert sie sich zufällig der Mahnung des; Goldschmiedes, sie möchte in einem ${ }^{1}$ Jahre wiederkommen. Sofort $i$ bricht sie mit Driant auf, und sie erfahren von dem Goldschmiede,, dafs der Knabe zum Ritter herangereift sei, er trage einen escu: blanc a l'espee vermeille. Diesen solle sie aufsuchen. Bise und 1 Driant machen sich nun auf den Weg und erkundigen sich überall, , ob jemand den Ritter mit dem weifsen Schild gesehen habe.

58. Die Dame $(\S 56)$, Ysaye und Tronc brechen vom chastel de l'aumosne auf und kehren am Abend bei einem forestier, Gartus de la forest aux lyons, ein. Daselbst werden sie gut bewirtet. Während des Essens erzählt ihnen der Wirt, dafs bei ihm noch zwei Ritter übernachteten. Diese wollten am nächsten Tage nach dem chastel de l'aumosne aufbrechen, um den Tod ihres Bruders zu rächen. Diese Ritter hiefsen Macon l'oconge (?) und le vacquier de l'esclaire und seien Brüder des brun de l'engarde. Ysaye bittet nun den Wirt, die Ritter am folgenden Morgen nicht fortzulassen, da er ihnen noch etwas $z u$ sagen habe. Hierauf gehen alle zu Bett. Am folgenden Morgen sind die beiden Brüder schon zur Abreise fertig, als der Wirt sie darauf aufmerksam macht, dals im Erdgeschols ein Ritter logiere, der sie zu sprechen wünsche. Sofort vermuten sie in diesem Ritter den Mörder ihres Bruders. Sie klopfen an die Thür und als ihnen nicht geöffnet wird, schlagen sie die Thür ein. $\mathrm{Da}$ aber tritt ihnen Ysaye, der vollständig gewappnet ist, entgegen.

59. Die Brüder fragen nun Ysaye, ob er etwas von dem Mörder ihres Bruders wisse. Ruhig erklärt ihnen Ysaye, dafs er ihn getötet habe. Nun stürzen sich die Brüder wie wahnsinnig auf Ysaye, werden aber schon nach kurzem Kampfe getötet.

6o. Als die Wirtsleute und die Dame die Leichen sehen, sind sie entsetzt. Ysage aber beruhigt sie, indem er sie über den Vorgang aufklärt. Hierauf reiten Ysaye, Tronc und die Dame weiter bis zum Abend. Da sie kein Wirtshaus finden, wohl aber in einem Gehölz ein Feuer erblicken, schicken sie Tronc ab, um zu sehen, was das Feuer bedeute.

${ }^{1} \S 38$ : in einem halben Jahre. 
61. Tronc sieht, wie vier Schurken ein gewaltiges Feuer an६ gezündet haben, und ruft Ysaye herbei. Bei dessen Ankunft ent1 fliehen sie. Nun reiten die drei Gefährten weiter, bis sie nach (Cannes kommen. Dort zeigt ihnen eine gute alte Frau ein 'Wirtshaus.

62. Sie klopfen an die Thür des Hauses. Ein Mädchen i öffnet, erschrickt aber beim Anblick Troncs und ruft den Wirt. Dieser sieht Tronc auch und erklärt, ihnen kein Nachtquartier (geben zu können. Da Ysaye sieht, dafs er Troncs wegen kein Unterkommen finden kann, so setzt er Tronc hinter sich aufs Pferd und verdeckt ihn mit seinem Schild. Dann reitet er nach ' einem anderen Gasthaus und erhält ohne weiteres Quartier.

63. Während Tronc auf dem Pferde bleibt, begeben sich Ysaye und die Dame in das Speisezimmer. Der Wirt sals mit seiner Frau und seinen beiden Kindern ( 12 und 11 Jahre alt) bereits an der Tafel. Als Ysaye und die Dame sich niedergelassen haben, verbietet die Mutter den Kindern, das Beste vom Tische zu nehmen. Da befiehlt ihnen der Vater, der der Meinung ist, dafs er die Kinder ernähre, die Mutter zu prügeln. Dies führen die Kinder sofort aus. Ysaye, hierüber erzürnt, hält dem Vater eine Rede über Kindererziehung. $\mathrm{Da}$ aber der Vater nicht verstehen will, so bricht Ysaye mit den Worten ab: car l'avengle n'a que faire de chandelle et le sours n'a que faire de sermon. Der Wirt heifst Damas de Cannes. Nach dieser aufregenden Scene gehen alle zu Bett. Am folgenden Morgen brechen die drei Reisenden auf und treffen unterwegs einen varlet, der ihnen folgendes erzählt: In dem Hause des Damas hätten sich um Mitternacht die Kinder geschlagen und wären dabei aus dem Fenster gestürzt. Der Vater sei aufgestanden und habe seine Frau getötet, da diese die Kinder nicht genügend bewacht habe. Ihn selbst aber hätte man ins Gefängnis geworfen und werde ihn nun hängen.

64. Nachdem sie den valet verlassen haben, kommen sie nach einem Schlofs, aus welchem ein Ritter, Bisart le navarois, heraustritt und Ysaye zum Zweikampf herausfordert. Bisart wird besiegt. Beim Abschied bittet er Ysaye, er möge seinen Sohn, Duma le mordreur, zum Ritter schlagen. Ysaye will diesen Wunsch erfüllen.

65. Allmählich nähern sich die drei Gefährten dem chastel de la belle garde. Sie kommen an einen Flufs, auf dessen jenseitigem Ufer sich das Schlofs befindet. Ysaye und die Dame besteigen einen kleinen Kahn, während Tronc auf dem Rücken des Pferdes Ysayes über den Flufs gelangt.

66. Die Besitzerin des Schlosses begrürst vom Fenster aus die Ankommenden, steigt dann die Treppe herunter und öfnet die Thür. Ysaye wird nun von allen wegen seiner Schönheit bewundert, aber auch Tronc wegen seiner Härslichkeit angestaunt. Erregte nun Tronc schon bei den Menschen Anstols wegen seiner härslichen Figur, so war dies noch vielmehr bei den Hunden des 
Schlosses der Fall. Diese hätten ihn sicher totgebissen, wenn er sich nicht auf den Rücken des Pferdes geschwungen hätte.

67. Die Dame des Schlosses und Ysaye beraten nun, was siie gegen Craventor thun sollen. Ysaye sagt ihr, er wolle gegen alle Mannen Craventors kämpfen. In dieser Absicht beschliefst err, Tronc mit einer Herausforderung an den feindlichen Ritter abzulschicken.

68. Die Dame wundert sich, dafs Ysaye sich Troncs in sı wichtigen Angelegen bediene. Da entgegnet Ysaye: Force vaull plus sans sens, mais sens est bon sans force; car je le vous prouveray. Marsiadus, der König von Norgalles, war in einen Krieg mit Ysayess Grofsvater, Meliadus von Leonois, verwickelt. Der letztere hattie nur halb so viel Truppen als Marsiadus.

69. Trotzdem siegte Meliadus durch die Schlauheit eine:s Krüppels, dem zwei Glieder fehlten und der fünf Jahre hindurch krank gewesen war.

70. Tronc begiebt sich nach dem Schlosse Craventors und bittet dort um Einlals. Da Craventor gerade schläft, mufs Tronc warten, bis Craventor ihn vorlälst.

7 I. Vor Craventor geführt, erklärt Tronc, er komme im Auftrage der Dame von Belle Garde und eines tapferen Ritters, der es sich zur Aufgabe gemacht habe, alle Bedrängten zu schützen, und fordere ihn auf, von seinen Liebesanträgen abzulassen, da die Dame sich doch nicht, besonders nicht mit ihm, verheiraten werde.

72. Craventor erwidert, er werde die Dame nie in Ruhe lassen und lieber mit dem Ritter kämpfen. Sollte der Ritter besiegt werden, so verlange er folgende Geiseln: die Dame, die sieben Kinder, Marcadigeil (Bruder der Dame), Duridron (Onkel d. D.), Dromedia (Schwester d. D.), Alise (Kammerfrau), Tradition (Vater d. D.). Sollte er besiegt werden, so werde er eine gleiche Anzahl von Geiseln stellen.

73. Tronc überbringt Ysaye die Antwort Craventors und teilt dann diesem die Namen der Geiseln mit, die die Dame verlange. Es sind dies: Nabel (Bruder des Cr.), Vidira de Castrange, Ariste de Fluyr, Helpas le bleu (Onkel des $\mathrm{Cr}$.) und drei cousins germains.

74. Craventor ist bei dieser Nachricht sehr betrübt, da diese Geiseln seine besten Ritter sind. Dann sagt er Tronc, dafs er am nächsten Tage zum Kampfe bereit sei.

75. Nach dieser Unterredung führt Craventor seine Geiseln nach dem Schlosse de Belle Garde, und sonderbarer Weise frag: ihn nun die Dame, was er mit ihren Geiseln zu thun gedenke. worauf Craventor erwidert, er werde sie und ihre Kinder verbrennen, die anderen Geiseln hängen lassen.

76. Am folgenden Morgen rüstet sich Ysaye zum Kampfe Als ihn ein Ritter Craventors erblickt, wendet sich dieser an Trone mit der Frage, ob jener der chevalier chetif sei, der gegen seiner. Herrn kämpfen wolle. Tronc weist ihn ob dieser Beleidigung zurecht und sagt $\mathrm{ihm}$, dafs sein Herr der berühmte Ritter Ysaye le 
' Triste, der Sohn Tristans, sei. Da bricht der Ritter in Thränen : aus und sagt, jetzt sehe er, dafs es für Craventor keine Rettung mehr gäbe.

77. Der Kampf beginnt, und Ysaye siegt.

78. Craventor und seine Geiseln werden vor die Dame des Schlosses geführt. Diese lälst sofort ein grolses Fest feiern und donna a Ysaye son corps et ses biens a sa volonte.

79. Im Schlosse wendet sich Ysaye an den Ritter, dem Tronc den Namen Ysayes mitgeteilt hatte - es war Senecques le bleu und bittet ihn, Stillschweigen über seinen Namen und seine Person zu beobachten. Senecques verspricht dies.

8o. Nichts desto weniger geht Senecques in der Nacht zu Craventor, teilt diesem den Namen Ysayes mit und erbietet sich, im Verein mit Craventor Ysaye im Bette zu ermorden. Craventor ist mit diesem Plane einverstanden, und beide schleichen nach Ysayes Schlafzimmer. Senecques klopft an und bittet Tronc zu öffnen, da er seinem Herrn die traurige Botschaft zu übermitteln habe, dals Craventor gestorben sei. Tronc entgegnet ihm, sein Herr schlafe jetzt, er möge später wiederkommen.

81. Craventor und Senecques entfernen sich. Tronc weckt seinen Herrn und bittet ihn sich hinter die Thür zu stellen. Darauf kommen Craventor und Senecques wieder, Tronc öffnet, sie finden das Bett leer vor. Tronc erklärt ihnen nun, sein Herr sei in jenem Zimmer, dessen Thür sie geöffnet sähen. Sofort begeben sie sich dorthin, Tronc eilt ihnen nach und schliefst sie ein.

82. Ysaye tritt nun aus seinem Versteck hervor, läist die Thür des anderen Zimmers öffnen und schlägt den Verrätern das Haupt ab.

83. Ysaye schlägt nun noch den übrigen Geiseln Craventors die Köpfe ab und läfst sie von Tronc in einen Sack werfen.

84. Tronc schleppt diesen Sack nach dem Schlosse Craventors und überreicht ihn den dort versammelten Rittern. Dann entfernt er sich schleunigst. Ysaye will nun vom chastel de Belle Garde aufbrechen. Da fragt ihn die Dame, wie sie ihm danken könne. Ysaye befiehlt ihr, für die Toten eine Messe lesen zu lassen. Aufserdem solle sie vier von ihren Söhnen zu Rittern, drei zu Geistlichen heranbilden lassen. Auch solle sie wieder einen Gatten nehmen, der sie gegen die Angriffe der Freunde Craventors schützen könne.

85. Während Ysaye mit der Dame redet, erscheint ein Knappe und bittet Ysaye, er möge sein Versprechen einlösen und ihn zum Ritter schlagen. Er heifse Duma le Mordreur urd sei der Sohn Bisarts le Navarois. Um Ysaye ein Zeichen seiner Tapferkeit zu geben, brüstet er sich damit, dafs er bereits zwölf Menschen aus geringfügigem Grunde getötet habe. Ysaye rät ihm, erst die Gesinnung zu ändern und $\mathrm{zu}$ seinem Vater zurückzukehren. Doch bleibt Duma noch eine Nacht hier. Als er am folgenden Morgen Ysayes Frage, ob er sich eines besseren besonnen habe, mit nein 
beantwortet, befiehlt ihm Ysaye, sein Haupt zu beugen. Anstatt.t des Ritterschlages versetzt ihm Ysaye den Todesstreich.

86. Kurze Zeit hierauf tritt eine Frau mit einem jungen : Manne ein und erkundigt sich nach einem Ritter, der ihr Sohn 1 sei und der ihr vor neunzehn Jahren im Morois in Cornouailles s geraubt sei. Es ist Bise mit Driant.

87. Sie erzählt ferner, wie Sarban aus Loisemont und sie den 1 Knaben erzogen hätten, wie der Knabe geraubt sei, und erzählt t auch die Geschichte mit dem Ringe. Da fragt Ysaye, wie der $r$ Knabe geheifsen habe, worauf sie erwidert: Ysaye le Triste.

88. Als Bise ausgesprochen hat, erscheint eine Fee, giebt $t$ Ysaye einen neuen Schild, nimmt der Amme den Ring von dem 1 Finger und verschwindet wieder. Erstaunt fragt Ysaye Tronc, was ; das bedeute. Da erzählt ihm Tronc, die Fee sei dieselbe, welche: der Amme den Ring an den Finger gesteckt habe. Sie habe ihn 1 wieder zurückgeholt, weil die Amme den wiedergefunden habe, den sie gesucht habe. Ysaye külst nun seine Amme und begrülst : auch seinen frere de layt. Bise wird von der Dame des Schlosses; reichlich mit Kleidern beschenkt.

89. Ysaye vertraut nun seine Amme dem Schutze der Dame: an. Driant äufsert den Wunsch, zum Ritter geschlagen zu werden.. Ysaye weist ihn darauf hin, dafs er erst Heldenthaten vollbringen müsse, ist aber bereit, ihm das Waffenhandwerk beizubringen.

90. Ysaye, Driant und Tronc nehmen hierauf Abschied. Unterwegs treffen sie einen valet, der einen Wagen mit Lebensmitteln mit sich führt. Ysaye fragt ihn, wohin er wolle. „Zum chevalier sot sage du chastel mal assis" ist die Antwort des valet. Neugierig, weshalb dieser Ritter den wunderbaren Namen sot sage führe, bittet Ysaye den Knappen, ihm diesen Ritter zu schildern.

91. Der valet erzählt hierauf: In diesem Lande lebte ein Ritter Blaienor, ein Bruder des Blioberis de Gaunes. Blaienor war mit der Tochter des Königs von Norgalles verheiratet und zeugte mit dieser einen Sohn. Letzterer wurde der gelehrteste Mann dieses Landes, so dafs viele Leute Rat bei ihm holten. Eines Tages erschien auch ein Fräulein bei ihm, Claire la plus belle mit Namen. Zu dieser fafste der clerc, wie er genannt wurde, eine unaussprechliche Liebesncigung und bat um ihre Hand. Sie war nicht abgeneigt, doch zog sie es vor, zuerst ihre sechs Brüder um Rat zu fragen.

92. Die Brüder wünschten ihr aber eher den Tod als diese Heirat. Als der clerc davon Kunde erhielt, wurde er vor Zorn wahnsinnig. Von da ab nannten ihn die Leute den sot sage. Von dem Unglücke dieses Königssohnes erfuhren Bohort de Gaunes und Hector des Mares und eilten herbei, um die sechs Brüder zu strafen. Sie töteten die Brüder, und nun stand dem sot sage kein Hindernis mehr im Wege, Claire zu heiraten. Der sot sage wurde wieder gesund, gab sich aber von nun an dem Ritterhandwerke hin. Jedoch habe er eine eigentümliche Fechtweise. Er 
fechte nur mit Baumzweigen. Denjenigen, den er besiegt, nimmt er mit auf sein Schlofs mal assis (wegen der Niedermetzlung der sechs Brüder Claires so genannt) und beschäftige ihn dort, denjenigen aber, der ihn besiegt, schlage er zum Ritter. Ysaye falst nun sofort den Plan, Driant in diesem Kampfe zu erproben. Ysaye, Driant und Tronc reiten nun nach dem Schlosse. Da begegnen ihnen drei Ritter, die ihnen erzählen, dals der sot sage früher die Angewohnheit gehabt habe, die Besiegten zu seinen Dienern zu machen.

93. Jetzt befolge er einen Rat Claires, alle schönen Frauen im Umkreise von einer Meile um sein Schlofs einfangen zu lassen, um sie dann zu verbannen. Diesen Rat hatte Claire dem sot sage aus dem Grunde gegeben, weil sie es nicht dulden wollte, Frauen von ihrer Schönheit in ihrer Nähe zu haben.

94. Die Ritter verabschieden sich, und Ysaye erfährt von dem valet, der noch bei ihm ist, die Namen der drei Ritter. Der erste sei Brandor, der Sohn des Brandalis, eines Ritters der Tafelrunde. Der zweite sei der Sohn Lambeguets, der Palamedes le mecogneu besiegt habe, als dieser die Königin Yseut vom Hofe Marcs entführen wollte. Man nenne ihn le besge de la haulte roche. Der dritte sei Festion le blond, der Sohn Gaheriets. Als Ysaye dies vernommen hat, schickt er Tronc zum sot sage und lälst ihn zum Kampfe herausfordern. Tronc trifft den sot sage mit Claire an. Claire erschrickt bei Troncs Erscheinen. Der sot sage nimmt die Forderung Ysayes an. Unterdessen lehrt Ysaye Driant fechten.

95. Bald darauf findet der Kampf statt. Der sot sage und Driant sind mit Baumzweigen bewaffnet. Driant erhält zwei wuchtige Hiebe auf den Helm, so dafs er den Kampf aufgeben will.

96. Da Driant sich sehr feige benimmt, fragt ihn der sot sage, woher er stamme, worauf Driant erwidert: aus Loisemont bei Tintagel in Cornouailles. Darauf fragt der sot sage, ob nicht sein Begleiter (Ysaye) vielleicht den Kampf gegen ihn aufnehmen wolle, wenn er $\mathrm{zu}$ feige sei. $\mathrm{Da}$ antwortet Driant, dafs sein Begleiter dies sehr gern thun, er aber lieber 15 Tage barfuls gehen würde.

97. Ysaye schneidet zunächst für sich einen Zweig ab von $41 / 2$ Fufs Länge und einer Dicke von 3 Fäusten. Dann tritt er in den Kampf ein. Der Kampf ist für Ysaye schwer, doch gelingt es ihm bald, dem sot sage einen Hieb zu versetzen, dafs dieser ohnmächtig vom Pferde stürzt und I 2 Zähne verliert.

98. Als der Besiegte wieder zur Besinnung kommt, lobt er Ysayes Stärke. Ysaye will aber davon nichts wissen und schreibt seinen Sieg der Unterstützung des pere glosieux zu.

99. Nun befiehlt Ysaye dem sot sage folgendes. Er solle ihm huldigen, seine Geliebte solle verbannt werden, an dem Todestage der sechs Brüder (le lendemain de la Trinité) solle er für alle, die durch seine follie umgekommen sind, beten und beten lassen, und das Schlols solle fortan den Namen chastel revertiz führen. Den gefangenen Rittern schenkt er die Freiheit.

Zeitschr. $f$ rom. Phil. XXV. 
100. Am folgenden Tage bricht Ysaye mit Driant und Tronc : auf, ohne dem sot sage seinen Namen zu nennen.

IOI. Auf ihrem Wege kommen sie nach Louvrezep, einem । Meereshafen. Dort wird Tronc von einem valet angeredet. Dieser : wünscht Troncs Herrn zu sprechen, von dem man sage, er habe : Paumart besiegt und das rote Schlofs eingenommen. Tronc ruft t Ysaye herbei.

102. Als Ysaye herankommt, überreicht ihm der valet einen Brief, welchen Marthe, la nièce au roy Yrion de Blamir, ihm sende. Ysaye läfst den Brief von Tronc vorlesen. [cest la fille Huslin lem. pereur de Gresse qui est freres Yrion.] ${ }^{1}$

103. In diesem Briefe teilt Marthe Ysaye mit, dals sie ihn unsterblich liebe, obwohl sie ihn noch nie gesehen habe. Sie träume von ihm, sie mache chansons seinetwegen, sie sei liebeskrank. Er möge kommen und sie von ihrer Krankheit heilen. Von ihm hänge es $a b$, ob sie am Leben bleibe oder sterbe. Am Schlusse bittet sie, Ysaye möge ihr durch den valet Nachricht zuteil werden lassen.

104. Nachdem Ysaye den Inhalt vernommen hat, seufzt er tief und bittet den valet, einstweilen bei ihm zu bleiben. Dann werde er ihm Antwort geben. Darauf begeben sich die vier Gefährten $z u$ einem reichen Bürger, um dort $z u$ logieren. Bei diesem erkundigt sich Ysaye, auf welchem Wege er nach Sollenoys gelangen könne. Darauf erwidert ihm der Bürger, er müsse einen halben Tag lang über das Meer fahren, dann komme er zu einer Burg, dic von gens d’armes belagert würde. Auf Ysayes Frage, was dort vorgefallen sei, erzählt der Bürger folgendes:

105. Eine Anzahl junger Leute seiner Stadt hätten in der Maizeit einmal sich den Scherz erlaubt, ein der Burg gehöriges Schiff zu kapern. Dies war ihnen aber nicht gelungen, wohl aber hätten sie es sich gefallen lassen müssen, dals 25 ihrer Leute gefangen und gehängt wurden. Am Schlusse seiner Erzählung bittet er Ysaye, er möge seinen Landsleuten helfen, die Burg einzunehmen.

106. Ysaye entgegnet ihm hierauf, er könne nur die Partei der Burgleute ergreifen, da diese im Rechte seien. Nun wendet sich Ysaye an Tronc und beauftragt ihn, einen Brief an Marthe zu verfassen. Diesen Brief übergeben sie dem valet. Am folgenden Tage bestcigen sie ein Schiff und fahren nach der Burg.

107. Nachdem sie ans Land gestiegen sind, entlassen sie den valet. Da dieser aber für seine Herrin noch ein Geschenk wünscht, geben sie ihm auf Troncs Rat Driant mit. Driant und der valet entfernen sich, Tronc aber begiebt sich in das Hauptzelt der Belagerer und verlangt den Führer zu sprechen.

[108. Bald erscheint auch Ysaye und lälst sich von dem Führer die Ursache des Krieges darstellen. Da diese Erzählung

${ }^{1}$ [ ] Zusatz von D. 
genau den Thatsachen, die ihm der Bürger mitgeteilt hat, entspricht, sagt er, die Belagerten seien im Recht, und er werde ihnen helfen. Tronc und Ysaye verlassen unbehelligt das Hauptzelt und begeben sich nach der Burg, woselbst ihnen, allerdings erst nach Ablegung der Waffen, Eintritt gewährt wird.

I09. Ysage bemerkt lauter abgemagerte Leute und erfährt von diesen, dafs bereits alle Lebensmittel, ja sogar alle Katzen, Hunde, Pferde und biestes aufgegessen seien. Ysaye weint, als er dies hört, und bittet Gott, den Armen zu helfen.

I I 0 . Ferner erfährt er, dafs bereits Kinder geschlachtet, gekocht und gegessen seien.

II I. Ysaye, der ermüdet ist, legt sich zur Ruhe, während Tronc das Pferd bewacht, damit es nicht auch noch aufgezehrt werde. Um Mitternacht weckt Tronc seinen Herrn, da er bemerkt hat, wie die Belagerer am Gestade Lebensmittel aus den Schiffen holten. Sie verlassen beide die Stadt.. ${ }^{1}$ Ysaye legt sich in einen Hinterhalt, während Tronc den Befehl erhält, aufzupassen en quel point ceulx de l'ost estoient.

I 1 2. Kaum hatte sich Ysaye in den Hinterhalt gelegt, als Tronc die Nachricht bringt, die Feinde seien eingeschlafen und nur 50 Mann hielten Wache; ferner kämen vom Gestade her sechs Wagen mit Lebensmitteln, die nur durch 20 Mann geschützt seien. Ysaye sprengt sofort aus seinem Versteck hervor und stürzt sich auf die Bedeckung der Fouragewagen. Er tötet zunächst den Führer, dann stürzt er sich auf die andern. Sein Pferd ist ihm im Kampfe behülflich dadurch, dafs es furchtbare Fufstritte austeilt.

I 1 3. Während Ysaye gegen die Bedeckung kämpft, geht Tronc zu den Trofsknechten und erzählt ihnen, es seien Ioo vor Hunger wahnsinnig gewordene Männer aus der Burg entflohen, die nun alles, was ihnen entgegentritt, niederhauen. Jener Ritter, der gegen ihre Bedeckung kämpfe, sei auch einer von den Wahnsinnigen. Schleunigst verlassen nun die Trolsknechte die charettes, Tronc aber holt Leute aus der Burg herbei, die die Wagen in die Stadt ziehen.

I 14. Nachdem Ysaye die Bedeckung niedergemetzelt hat, eilt er nach der Burg. Schon aber folgen ihm neue Feinde. Vor der Burg entspinnt sich nun ein mörderischer Kampf.

115. Tronc, der in der Burg ist, erinnert sich, dals sein Herr derjenige ist, der draufsen gegen eine Uebermacht von Feinden kämpft. Er bittet die Fallthür herunter zu lassen, damit sein Herr eintreten könne, dann aber die Thür schleunigst wieder zu heben.

116. Die Einwohner der Burg erfüllen seinen Wunsch. Ysaye weicht nach der Fallbrücke zurück. Als Ysaye gerettet ist, wird die Thür gehoben. Dabei fallen 8 von den nachdringenden Feinden in den Graben, 16 aber werden gefangen genommen.

1 [] fehlt in G. 
Nach dieser Anstrengung lassen sich die Bewohner der Burg die e erbeuteten Lebensmittel gut schmecken.

I 17. Ysaye hält während der Nacht am Thore Wache. Amn nächsten Morgen sieht er zwei Ritter kommen, die ihn auffordern, , die Gefangenen herauszugeben. Sollte er dies nicht thun, soo würden sie die Burg angreifen. Ysaye lälst sich durch diese e Drohung nicht einschüchtern, sondern erwidert ihnen, falls ihree Führer bis zum nächsten Tage nicht Frieden geschlossen habenn sollten, würde er allen Gefangenen die Köpfe abschlagen. Et avant't ce je suis prest de moy mustrer corps a corps contre les plus hardis.

1 18. Um ihnen auch ein Beispiel seiner Kraft zu geben, geht $t$ er zum Thor hinaus und schlägt dem einen der beiden einen Arm 1 ab. Entsetzt fliehen die Boten davon.

I I9. Bei ihrem maistre angekommen, erzählen sie, dafs der $\mathrm{r}$ Ritter, den Gott den Feinden geschickt habe, kein Mensch, sondern I eine Art fouldre de tempête sei. Er sei in der Nacht ganz allein I aus der Burg gezogen, habe 45 Mann der ihrigen getötet und ihnen 1 6 Wagen mit Lebensmitteln abgenommen. Aufserdem habe er noch 1 viele Gefangene in der Burg.

120. Dann zählen sie die Bedingungen auf, die Ysaye ihnen : gestellt habe. Da treten zwei Boten ein, die über das Meer ge- kommen waren, um dem souverain de ceulx lesquelz estoient clos einen । Brief zu übermitteln.

I 2 I. Sie sagen dem bailly von Louvresep, sie seien gekommen, um den berühmten Ritter zu suchen, der Paumart u. s. w. besiegt. habe. Sie hätten den Auftrag, ihm die Krone des Königreiches: Logres anzubieten. Sie erkundigen sich, ob er vielleicht unter ihnen sei.

122. Als der bailly dies vernimmt, beschliefst er, sich Ysaye $\mathrm{zu}$ untewerfen. Sofort treten 500 Mann barfülsig und barhäuptig den Weg zur Burg an.

123. Sie fallen vor Ysaye nieder und bitten um Verzeihung für ihre oultrages. Ysaye erwidert ihnen, er sei garnicht derjenige, den sie suchten. Er sei ein pauvre chevalier.

124. Die Bürger entgegnen ihm darauf, sie wüfsten wohl, wen sie vor sich haben, und bitten nun um Freigabe der Gefangenen, sic wollten dagegen auch die gestellten Bedingungen eingehen.

1 25. Ysaye giebt nun die Gefangenen frei, die Städter ziehen ab. Er bleibt noch acht Tage in der Burg, um seine Wunden verheilen $z \mathrm{u}$ lassen. Dann bricht er mit Tronc auf.

1 26. Driant und der valet der Marthe kommen an dem Schlosse Vadans de Drangor vorbei, dessen Besitzer die Gewohnheit hatte, jeden bewaffneten Mann anzufallen.

1 27. Als Driant den Ritter auf sich zukommen sieht, wirft er vor Angst die Waffen fort.

128. Vadan läIst nun Driant unbehelligt durch sein Gebiet ziehen. Nach vier Tagen erreichen Driant und der valet das König- 
reich Miradir. Der valet verschafft nun zunächst dem Driant ein gutes Logis bei einem reichen Bürger, welcher mit Marthe gut befreundet ist. Dann begiebt er sich zu Marthe, erzählt ihr, wie er Ysaye gefunden hat, giebt ihr den Brief und erzählt ihr, dafs Ysaye seinen Bruder Driant vorausgeschickt habe.

1 29. Hierauf schildert er Ysaye näher.

1 30. Als Marthe den Brief gelesen hat, fält sie in Ohnmacht. Als sie wieder $\mathrm{zu}$ sicht kommt, ruft sie laut: Tres doulx amy, venez, venez, vous perderez votre amye.

131. Sie steckt den Brief in ihren Busen und begiebt sich zu Driant. Sie umarmt und külst ihn heftig. Dann bittet sie ihn, fortan im Schlosse zu wohnen. Mais bien saichez que oncques ne fust telle feste que Yrion luy feist quant il fut venu a la court.

132. Nach einiger Zeit erscheint Yrion in Marthes Kammer und findet sie, wie sie ein Schriftstück abfafst. Sie ist so sehr in ihre Arbeit vertieft, dafs sie ihren Onkel garnicht bemerkt, dann aber jäh erschrickt, als er ihr das Schriftstück fortnimmt. Yrion liest es durch und lacht darüber.

133. Das Schriftstück ist eine chanson, in welcher Marthe Ysaye als die Blume der Ritterschaft verherrlicht.

134. Der König liest die chanson zwei- bis dreimal durch und erkundigt sich dann bei Marthe, wer der Ritter sei, den sie liebe. $\mathrm{Da}$ antwortet sie ihm, sie kenne ihn selbst noch nicht, und bittet ihren Onkel, ein Turnier zu veranstalten. Dann würde er ihn schon sehen. Yrion verspricht ihr, das Turnier bald $\mathrm{zu}$ veranstalten.

135. Yrion teilt nun seine Absicht Driant mit. Da sagt ihm Driant, es gäbe keinen tüchtigeren Ritter als Ysaye. Er selbst habe einmal gesehen, wie Ysaye dem sot sage einen so gewaltigen Hieb versetzte, dafs dieser ohnmächtig zusammenbrach. Nun ist Yrion aufs höchste gespannt, wie dieser Ritter wohl aussehen mag. Er schickt sofort Herolde ab und läfst als besten Preis im Tournier ein Pferd und 40 besaus d'argent aussetzen.

136. Ysaye kommen zum Schlosse des $\mathrm{Va}(u)$ dan de Drangor, villette sur la mer. Ysaye wird von Vadan angegriffen, siegt jedoch. Ysaye erkundigt sich nun nach dem Namen des Gegners. Dieser nennt seinen Namen und erzählt Ysaye, dafs er ein Kind bei sich habe, das man l'orphelin de Guis nenne. Dieses Kind habe er gegen einen Ritter zu schützen, der auf dem zwei Meilen entfernten Schlosse Clermoustier wohne und dem Kinde nach dem Leben trachte.

137. Ysaye erkundigt sich nun, woher dieses Kind stamme. Da erzählt ihm Vadan, das Kind sei der Sohn Bohorts le piquart, sire de Guis, und führt nun dieselbe Geschichte an, die wir schon aus $\S 44$ kennen. Er habe nach dem Tode Bohorts das Kind zu sich genommen. Ysaye verspricht ihm nun, den Tod Bohorts an Marc le roux zu rächen.

138. Ysaye, Tronc und Vadan betreten das Schlors. Der 
Knabe öfnet ihnen. Ysaye külst ihn. Am folgenden Morgen erkundigt er sich bei dem Knaben nach dessen Alter und erfährt von ihm, dafs er I5 Jahr alt ist. Im Verlaufe des Gespräches bittet der Knabe Ysaye, seinen Vater an Marc le roux zu rächen. Ysaye befiehlt nun Vadan, sich sofort mit seinen 40 Rittern zu rüsten und in einen Hinterhalt zu legen. Auch der Knabe solle sich rüsten.

139. Ysaye und Tronc reiten nun nach Clermoustier.

140. Tronc will sich zu Marc le roux begeben, wird aber von dessen Rittern angehalten und gefragt, wer ihn sende. Da antwortet ihnen Tronc: le maistre des chastieux. car il les chastie d'une verge qu'il porte a la resun de espee. Die Ritter sagen ihm, solch thörichtes Geschwätz hätten sie seit Arthurs Tode noch nicht gehört, er möge seinen Herrn selbst kommen lassen.

14I. Ysaye erscheint und fordert sämtliche Ritter auf, sich zu bewaffnen und in einem grofsen Saal zusammenzutreten, woselbst er ihnen dann seine Mission mitteilen werde.

142. Sobald die Ritter versammelt sind, erklärt ihnen Ysaye, dafs er gekommen sei, den Tod Bohorts le picart zu rächen. Da verhöhnt Marc Ysaye, indem er ihn einen questerez (lat. castratus) nennt. Wütend hierüber zieht Ysaye sein Schwert und haut auf die Ritter ein. Die Mannen Marcs hören die wuchtigen Hiebe im Saale und eilen ihrem Herrn zu Hilfe.

143. Tronc verlälst das Schlofs, um Hilfe zu holen. Er wird verfolgt, rettet sich aber dadurch, dafs er in einen in der Nähe des Schlosses fliefsenden Flufs springt. Vorher jedoch war es ihm noch gelungen, das Haus eines Bürgers in Brand zu stecken.

144. Beim Anblick des Feucrs geraten die Bürger sowohl als auch die Mannen Marcs in Bestürzung. Diese Bestürzung benutzt der hartbedrängte Ysaye, um zu entfliehen. Da aber trifft Vadan mit seinen 40 Rittern ein, besiegt die Ritter und nimmt die reichsten Bürger gefangen. Am folgenden Morgen lälst Ysaye, an dessen Seite sich das enfant de Guis befindet, die gefangenen Bürger, 40 an der Zahl, vor sich treten.

145/6. Auf einem Stuhle stehend, hält nun Tronc eine gewaltige Rede darüber, dals Gott mit seinem Herrn und Vadan gewesen sei und die Feinde wegen ihrer Grausamkeit vernichtet habe. Sein Herr verlange Sühne.

147. Die Bürger ziehen sich zu einer Beratung zurück und beschlielsen auf Anraten des Siasaries, jede Forderung der Sieger $\mathbf{z u}$ erfüllen.

148. Nach der Beratung teilen sie Ysaye ihren Entschlufs mit. Da befiehlt ihnen Tronc, sie sollen das enfant le Guis, Hergault le blond, als König von Clermoustier anerkennen.

149. Ysaye schlägt nun Hergault zum Ritter. Hergault veranstaltet ein Fest. Während dieses Festes werden nun noch Siasaries und Josue, ein Sohn des Garlus de la forest aux lyons, von Ysaye zu Rittern geschlagen. 
150. Auf den Wunsch Marthes hin begeben sich der valet und Driant nach der Hauptstralse von Miradir, um von einem dort befindlichen Zelte aus die Ankunft Ysayes zu erwarten. Auf dem Wege nach dem Zelte zeigt Driant wieder seine grolse Feigheit, so dafs der valet $\mathrm{zu}$ ihm sagt: Si vous fussiez un autre Je deisse que vous feussiez ou erragies ou couart on que vous eussiez la vene bestournee.

I5I. Nachdem sie eine Zeitlang im Zelte verweilt haben, kommt ein Trupp Reiter vorbei. Nach wiederholten Aufforderungen seitens des valet begiebt sich Driant zu dem Führer des Trupps und erfährt von diesem, dafs in kurzer Zeit ihm ein Ritter folgen werde, der sehr berühmt sei und einen escu blanc a lespee vermeille trage. Da sagt ihm Driant, dals dieser Ritter sein Bruder sei, und bittet den Ritter, er möchte seinem Bruder mitteilen, dals er (Driant) wieder nach Cornouailles gehen werde pour ce que je scay bien que sil me trouvoit que mener me vouldroit au tournoy.

152. Der Ritter lacht über die Feigheit Driants, bittet ihn aber, seinem Bruder einen Grufs vom Ritter Hergault zu übermitteln. Dann erzählt er (Hergault), wie er seine Güter durch Ysaye wiedererlangt habe. Dieses hört auch der valet und macht sich eiligst auf, Marthe diese Nachricht zu überbringen. Driant aber ferit cheval des esperons par telle maniere quil fut un au avant que Ysaye le vist.

153. In kurzer Zeit sind die Ritter des ganzen Königreiches zum Turnier eingetroffen. Marthe, die noch immer nichts von Ysaye hört, läfst in allen Zelten nach dem Ritter mit dem escu blanc a lespee vermeille fragen. $\mathrm{Da}$ ihr Bote ihr aber mitteilt, dafs Ysaye noch nicht da sei, fällt sie in Ohnmacht.

154. In diesem Zustande findet sie Yrion. Als sie wieder zu sich kommt, erklärt sie auf ihres Onkels Frage, was ihr fehle, sie wolle nichts wieder essen, bevor sie nicht ihren Geliebten gesehen habe. Sie wolle lieber sterben, als den Zustand, in dem sie sich jetzt befinde, länger ertragen.

155. Yrion sucht Marthe zu beruhigen. $\mathrm{Da}$ ihm das aber nicht gelingt, geht er zu seinem Ratgeber Henry und erzählt diesem von Marthes Kummer. Da rät Henry, der König solle alle Ritter aus den Zelten treten lassen. Dann würde er sehen, welcher von den Rittern einen solchen Schild trage.

156. Von Marthes Kummer und dem Anlasse dazu erfahren bald alle Ritter, aber niemand hat den Ritter mit dem escu blanc a lespee vermeille gesehen. Nur einen Ritter mit einem escu blanc (aber ohne rotes Schwert) hatte man bemerkt.

157. Yrion folgt nun dem Rate Henrys und lärst sämtliche Ritter an seinem Palaste vorüberreiten. Marthe und er betrachten von den Fenstern aus die Ritter. $\mathrm{Da}$ bemerken sie einen, dessen Schild genau wie derjenige Ysayes aussieht. Es hatte nämlich der in $\$ 156$ erwähnte Ritter Paumart d'Arbise, de la marche de Logres, 
sire de Perrorentin, auf seinen escu blanc ein rotes Schwert malen lassen.

158. Marthe ist sehr erfreut bei dem Anblicke des Ritters, da sie ihn für Ysaye hält. Sie holt ein rotseidenes Herz und giebt es ihrer Kammerfrau mit der Bestimmung, es dem Ritter zu überreichen und ihm zu sagen, er möchte in der Nacht zu ihr kommen.

159. Yrion veranstaltet ein grolses disner, an welchem 400 ducs, contes, chevaliers und eine grolse Anzahl Damen teilnehmen. Mais saichez que Marthe fut la plus belle et la plus joyeuse de toutes.

160. Während des Essens tritt ein Zwerg, ohne Hut und ohne Schuhe, wohl aber mit einem grofsen Stock versehen, in den Saal und verlangt Marthe zu sprechen. Der Portier führt ihn zu Marthe. Ueber seine Häfslichkeit staunen alle Festteilnehmer, car trop estoit hideux.

161. Der Zwerg übergiebt Marthe einen Brief Ysayes. Marthe erkennt sofort in dem Zwerge den Pagen Ysayes. Sie befiehlt nun einem valet, Tronc in ein besonderes Zimmer zu führen und ihn dort gut $z u$ bewirten.

162. Nach dem Essen geht Marthe in ihr Zimmer und liest den Brief.

163. Hierin teilt Ysaye ihr mit, dafs er am Abend als armer Ritter, ohne Waffen und zu Fufs, in Miradir eintreffen werde.

164. Als Marthe den Brief gelesen hat, singt sie vor Freude und umarmt Tronc. $\mathrm{Da}$ erscheint der Ritter Paumart, der seinen Schild geändert hatte ( $(157)$. Seine Fälschung wird von Tronc sofort aufgedeckt, denn Tronc weils, dals der Vater Paumarts, Patrides du chastel noir, und sein Grolsvater, Hector le bleu, nur einen escu blanc getragen haben. Er sagt dem Paumart: Et si vous fustes fils de bonne mere si portez ses armes demain au tournoy. certes vous noseries. Ueber diese Abfertigung ist der Ritter wütend, aber Marthe verabschiedet ihn mit folgenden Worten: Allez vous en et pensez en vous purger de ceste besoigne. car sil est ainsi mort avez desservie. Beschämt zieht der Ritter von dannen. Aber auch Tronc verlälst Marthe, um Ysaye herbeizuholen. Er findet seinen Herrn noch an derselben Stelle schlafend, an welcher er ihn verlassen hat.

165. Tronc weckt Ysage. Ysage geht nun zu Fufs nach Blamir (Miradir), während Tronc zu Pferde folgt. Er findet den Palast Yrions verschlossen und ruft den Pförtner. Dieser aber will Ysaye wegen dessen schlechter Kleidung nicht einlassen und schimpft ihn ribault escrimelle. Wütend hierüber ergreift Ysaye den Portier, dreht ihn mehrmals im Kreise herum und wirft ihn dann mit solcher Wucht gegen einen Pfeiler, dafs ihm Augen und Hirn aus dem Kopfe fliegen. Als das Yrion erfährt, lärst er Ysaye vor sich kommen und fragt ihn nach seinem Namen. Ysaye aber entgegnet ihm barsch, er sei nur gekommen, um an dem Turnier teilzunehmen. Seinen Namen aber werde er nicht nennen.

166. Marthe kommt hinzu. Sie vermutet in dem ribault ihren 
Geliebten und bittet den König um Gnade für ihn. Der König gewährt Ysaye Gnade.

167. Marthe läfst nun Ysaye in ihr Zimmer kommen und fragt ihn nach seinem Namen. Je suis le votre Ysaye. Als sie dieses hört, küfst sie Ysaye, und beide vergiefsen Thränen der Freude. Hier tritt ein escuyer ein mit der Meldung, der König bitte Marthe und Ysaye, sich zum Turnier zu begeben. Alle Ritter seien schon zum Kampfe bereit.

I68. Es seien aufser den ihrigen etwa 800 Ritter aus Lothringen, Brabant, Burgund, Deutschland, Gales und der Lombardei erschienen. 169. Marthe, die zunächst ein Waffenstück Ysayes sehen will, schickt eine ihrer Dienerinnen zum König mit der Bitte, das Turnier erst am folgenden Tage stattinden zu lassen. Darauf solle sie zu den einzelnen Zelten gehen und fragen, ob ein Ritter zu einem Lanzenkampf bereit sei. Die Dienerin führt den Befehl Marthes aus und meldet dann, dafs ein Ritter Yreult de l'isle estrange zum Kampfe bereit sei.

170. Yreult erscheint bald darauf und fordert Ysaye mit den Worten: Je vous deffie.

17 I. In dem darauf folgenden Zweikampfe siegt Ysaye. Er wirft Yreult vom Pferde und beendet damit den Kampf. Er verlärst den Kampfplatz und wird von allen Leuten ob seiner That angestaunt.

172. Yreult wird in sein Zelt getragen. Von seinen Leuten gefragt, qui mouvoit a fin telle jouste, schildert Yreult den Kampf und sagt, er sähe seine Niederlage nicht als eine Schmach, sondern als eine Ehre an.

173. Ysaye und Tronc werden von einem Bürger eingeladen, bei ihm zu logieren. Dieser hat von dem Zweikampfe bereits gehört, weils aber nicht, dafs sein Gast der Sieger ist. Erst von seinem Nachbar wird er darauf aufmerksam gemacht.

174. Vom Turnier zurückgekehrt, erkundigt sich Marthe bei ihrer Kammerfrau, welchen Weg der Sieger eingeschlagen habe. $\mathrm{Da}$ diese ihre Frage nicht beantworten kann, weint Marthe heftig, indem sie dabei ausruft: amy puisque je tay perdu je veul estre perdu.

175. Während Marthe sich in Klagen ergeht, erscheint der bourgeois, bei welchem Ysaye und Tronc wohnen, und meldet ihr, dals in seinem Hause ein Ritter logiere, der in dem Zweikampfe gesiegt habe.

176. Marthe dankt dem Bürger und sagt ihm, sie werde in der Nacht vor seinem Hause erscheinen. Als der Bürger sie verlassen hat, lälst sie ihren pallefroy satteln und begiebt sich zu Ysaye. Tronc öffnet die Hausthür und führt Marthe zu Ysaye. Ysaye entschuldigt sich, Marthe verlassen zu haben. Die entfernt gelegene Wohnung habe er nur deshalb bezogen, damit ihre Freundschaft nicht entdeckt werde. Marthe verzeiht Ysaye und sagt: Je le vous pardonne, mais je vous prie, faites estaindre celle torche.

177. Dann legen sie sich zu Bett. Das Resultat ihrer Liebe 
ist, wie wir später sehen werden, ein Knabe, Marc l'essilliet. Am folgenden Morgen begeben sich Ysaye, als Ritter gekleidet, und Marthe, als Knappe verkleidet, nach dem Palaste Yrions. Tronc folgt später. Kaum sind sie hier angekommen, so erscheint Yrion und bittet Marthe, sich zum Turnier zu begeben.

178. Ysaye begiebt sich zum Kampfplatz und trifft mit Hergault zusammen.

179. Das Turnier beginnt. Marthe schaut von einem eschafault aus dem Kampfe zu. Als sie Ysaye und Hergault erblickt, ruft sic vor Freude aus: Regardez, comment ils feront.

180. Ysaye vollführt Heldenthaten, Hergault kämpft an seiner Seite.

181. Ysaye besiegt Bizon mit seinen drei Knappen. Er versetzt ihnen solche Hiebe, dafs sie nicht wufsten, ob es Tag oder Nacht war.

182. Bizon wird mit entblöfstem Haupte durch Tronc $z u$ Marthe geführt. Diese harte Strafe traf ihn, weil er, trotzdem dafs er besiegt war, Ysaye noch einmal hinterlistig überfallen hatte.

183. Hierauf kämpft Ysaye mit Samuel l'Allemant und Dacras le Provenchois.

184. Ysaye besiegt beide und erregt dadurch grofse Bewunderung.

185. Alles weicht vor ihm zurück. Tabart von Coulogne, der Widerstand $\mathrm{zu}$ leisten versucht, erhält von Ysaye einen derartigen Hieb, dafs ihm die Augen aus dem Kopfe fliegen.

186. Während des Turniers pflegte Ysaye die Pferde der besiegten Ritter Marthe zuzuführen. Am Abend des Turniers zählt Marthe 28 solcher Trophäen.

187. Nach dem Turnier begeben sich die Ritter in ihre Zelte. Die Toten, 12 an der Zahl, werden begraben.

188. Ysaye und Tronc begeben sich zu Marthe, die sie herzlich empfängt.

189. Sie giebt ihnen reichlich zu essen, verlä/st dann aber Ysaye, da der König nach ihr verlangt hat.

190. Nachdem Ysaye gegessen hat, legt er sich in Marthes Bett. Tronc begiebt sich in ein benachbartes Zinmer. Kurze Zeit hierauf erscheint Marthe und legt sich zu Ysaye.

191. Während der ganzen Nacht hören Ysaye und Marthe Tronc im Nebenzimmer heftig weinen. Als Marthe sich am folgenden Morgen nach seinem Schmerze erkundigen will, nimmt Tronc seinen Herrn zu sich und erzählt ihm folgendes:

192. Die Feeen, die ihm die Ueberwachung Ysayes anvertraut hätten, hätten ihm auch befohlen, darauf zu achten, dafs Ysaye sich mit keinem Weibe einlasse. Diesen Befehl habe er ungeachtet gelassen, und deshalb hätten ihn die Feeen in der vorhergehenden Nacht mit Stöcken gezüchtigt. Daher tel doeul.

193. Als Ysaye dies vernimmt, beschliefst êr das Land inner- 
halb dreier Tage zu verlassen. Diesen Entschlufs teilt er Marthe mit, die aber nicht recht daran glauben will.

194. Ysaye begiebt sich hierauf zur Messe, woselbst er von allen Rittern bewundert wird. Nach der Messe fragt Yrion Ysaye nach dessen Namen. Ysaye aber weicht ihm aus.

195. Ysaye begiebt sich zum disner. Als er den Saal betritt, erstaunt alles über seine Schönheit.

196. Während des Essens bringt Tronc eine Schüssel in den Saal und reicht sie Hergault. Dieser bietet sie seiner Nachbarin, der dame de Fragoire, an, die diese aber mit der Bemerkung zurückweist, sie könne die Speise nicht essen, die der häfsliche Page gebracht habe. Kurze Zeit hierauf erscheint Tronc wieder mit einem hairon in der blofsen Hand und überreicht diesen Ysaye. Er trug den hairon in der blofsen Hand, weil ihm der Koch keine Schüssel hatte geben wollen. Als nun der Koch gar sieht, dafs Tronc den hairon dem besten Ritter, Ysaye, in dieser Art überreicht, steigert sich seine Wut aufs höchste, und er beschliefst, Tronc ins Feuer zu werfen.

197. Als Tronc in der Küche erscheint, will ihn der Koch ergreifen. Tronc aber entschlüpft, nimmt einen Kessel mit siedendem Wasser und wirft ihn dem Koch an den Kopf. Der Koch heult laut und läuft hinter Tronc her, der inzwischen aber schon bei Ysaye Schutz gefunden hat. Als Yrion diesen Zwischenfall erfährt, lacht er herzlich.

198. Nicht lange Zeit hierauf erscheinen zwei Damen, die Herzogin von Caradan und die Tochter des Herzogs von Ostrisse, und überreichen Ysaye den Preis des Turniers: ein Pferd, das mit Silber beschlagen ist und einen Elfenbeinsattel trägt.

I99. Ysaye dankt für die Ehre, die ihm zu teil wird, sagt aber, der Preis gebühre seinem Herrn, Hergault, der alle die wuchtigen Hiebe ausgeteilt habe.

200. Erst auf Hergaults Bitten nimmt Ysaye den Preis an, bemerkt aber dabei: ce ne fuge pas, che fu dieux.

201. Hierauf erhebt sich Yrion, lobt Ysaye und führt seine Heldenthaten aus früherer Zeit an. Darauf wird noch ein zweiter Preis an Samuel l'Allemant verteilt.

202. Nach dem Essen tritt eine schwarz gekleidete Dame ein und überreicht Ysaye ein Brief, der von dem gaiant du hault hurt aus der forest noire (Grofs-Britannien) herrührt.

203. In diesem Briefe fordert der Riese Ysaye höhnisch auf, er möge zu ihm kommen und versuchen, die coutumes, welche er eingeführt habe, abzuschaffen.

204. Ysaye fragt nun die Dame nach ihrem Namen und erfährt von ihr, dafs sie Claire, die verbannte Gemahlin des sot sage sei.

205. Ysaye giebt ihr den Bescheid, er werde ihr bald eine Antwort an den Riesen mitgeben.

206. Yrion fragt Marthe, ob sie sich näher mit Ysaye ein- 
gelassen und ob Ysaye ihr ein Versprechen gegeben habe. Den ersten Teil der Frage bejaht Marthe, aber hinsichtlich des zweiten Teils bittet sie ihren Onkel, persönlich mit Ysaye Rücksprache zu nehmen. Yrion thut dies, und Ysaye verspricht ihm, alle seine Wünsche zu erfüllen, sobald er seine Reise vollendet haben werde.

207. Tronc schreibt im Auftrage Ysayes einen Brief an den Riesen und übergiebt ihn der Claire.

208. Ysaye nimmt am folgenden Tage Abschied von Marthe, da er, wie er sagt, eine secrete besoigne auszuführen habe. Sie bittet ihn, bald zurückzukehren. Dann bricht Ysaye mit Tronc und Hergault auf.

209. Unterwegs treffen sie einen Ritter mit ausgerenkter Schulter, Namens Oriant li grieux, Sohn Hectors von Orcanie und Vetter des Königs von Orcanie. Dieser war aus Arragonne gekommen und war soeben von einem wilden Pferde zu Boden geworfen worden. Tronc setzt ihn nun auf Ysayes Pferd. Nach einem langen Marsche erreichen sie Clermoustier. Hier erfährt Hergault von seinem fermier folgendes:

2 10. Während Hergaults Abwesenheit sei der Onkel Marcs le roux in das Gebiet Hergaults eingefallen und habe in 15 Tagen 50 Leute getötet. Erst durch einen Ritter, der einen vergoldeten Schild mit einem halben Löwen getragen habe, sei der Onkel Marcs besiegt worden.

211. Sofort wird Oriant als der Besieger des Feindes erkannt und sehr geehrt. Die Leute aus der Stadt begrülsten ihn: benoiste soit celle qui te porta et benoist soies tu.

2 1 2. Hergault begleitet Ysaye, Tronc und Oriant bis zur „Burg“, woselbst man vor Ysaye Kleider ausbreitete, über welche er gezwungen war zu gehen. Hier nimmt Ysaye Abschied von Hergault.

213. Claire, welche über das Meer gefahren ist und sich jetzt in Logres befindet, trift auf ihrem Wege $z u$ dem Riesen einen Ritter Ostentins li navarois, bei welchem sie übernachtet. Sie erzählt diesem, dafs sie von Ysaye komme, welcher in den nächsten Tagen nach dem chastel du hault hurt kommen werde. Da sagt ihr Ostentin, dafs er ebenfalls Ysaye suche, um an ihm den Tod seines Bruders Dumas le mordreur zu rüchen.

214. Claire bittet nun Ostentin, den Brief Ysayes zu dem Riesen zu tragen, da sie sich vor der maulvaise coustume fürchte.

215. Am folgenden Morgen begiebt sich Ostentin zu dem Riesen, Namens Miriol, und giebt ihm den Brief.

216. Hierin schreibt Ysaye, dafs er gedenke, ihn (Miriol) mit Gottes Hilfe zu besiegen. [Et jay pendu mon seel escript a Blamir lan VIc et XIIII (614) estamps de Grasce et ou mois de may.] ${ }^{1}$

217. Als Miriol den Brief gelesen hat, lacht er höhnisch.

218. Ysaye, Oriant und Tronc fahren zu Schiff nach der

' [ ] Zusatz in D. 
Bretagne. Dort erblicken sie einen grofsen Wald. Ysaye erfährt auf sein Befragen von den Schiffsleuten, dafs in diesem Walde der stärkste Ritter hause. Ysaye läfst hierauf ans Land fahren, er und Oriant steigen aus, während Tronc zurückbleibt, um die Seeleute am Weiterfahren zu hindern. Ysaye und Oriant reiten in den Wald hinein und legen sich ermüdet unter einen Baum. Kaum haben sie sich gelegt, so werden sie durch grofsen Lärm geweckt und Ysaye sieht, wie ein berittener Mann ein cheoreul verfolgt und tötet.

219. Ysaye und Oriant reiten nun diesem merkwürdigen Ritter die ganze Nacht hindurch nach. $\mathrm{Da}$ sie ihn aber nicht erreichen können, legen sie sich unter eine Tanne. Da aber kommt der Reiter wieder und verfolgt einen Wolf, der ein anderes Tier in seinem Maule hat.

220. Sie reiten ihm wieder nach, verirren sich aber in der Dunkelheit. Am hellen Morgen kommen sie an einen Felsen. Hier finden sie $z u$ essen und $z u$ trinken. An einem Baume erblicken sie 20 Schilde, darunter einen, der auf goldenem Grunde mit einem halben Löwen bemalt war. Diesen Schild erkennt Oriant als denjenigen seines Vaters und glaubt, dals sein Vater von dem hier wohnenden Ritter getötet sei.

221. Während sich Ysaye und Oriant in Betrachtungen ergehen, kommt Tronc herbeigelaufen mit dem Rufe helas. Ihm folgte der chevalier de la forest. Dieser stürzt sich zunächst auf Oriant und schlägt diesen mit einem Hiebe nieder. Schwerer wird ihm der Kampf mit Ysaye. Beide Recken teilen gewaltige Hiebe aus, bis sie eine halbe Stunde lang bewufstlos liegen bleiben.

22 2. Der Kampf entbrennt von neuem, schliefslich aber müssen sie wegen allzugrofser Erschöpfung vom Kampfe ablassen.

223. Tronc holt Moos und Blätter und heilt die Wunden Ysayes in zwei Tagen mit Wein. Nach dem Kampfe giebt sich der chevalier de la forest zu erkennen. Er heirst Hector d'Orcanie. Er habe, so erzählt er, mit seiner ersten Frau einen Sohn gezeugt. Dieser sei aber zwei Jahre nach der Verheiratung mit der zweiten Frau ausgewandert. Er habe sich darauf aufgemacht, seinen Sohn wieder $z \mathbf{u}$ finden.

224. Ein Jahr lang sei er gewandert, dann sei er in diesen Wald gekommen und habe mit einem Einsiedler lange Jahre zusammengelebt. Jetzt sei der Einsiedler aber gestorben.

225. Hier fällt Oriant seinem Vater um den Hals und erzählt ihm dann, wie es ihm ergangen ist. Seine Stiefmutter habe ihn töten wollen, man habe ihn dann aber an Kaufleute von Argesille verkauft. Von hier sei er zum Könige von belle marine geflohen, sei von da wieder aufgebrochen und habe seine Stiefmutter, die sich wieder verheiratet habe, wiedergesehen. Da dankt der Vater Oriants Gott, küfst seinen Sohn und fällt ihm infolge des Blutverlustes tot in die Arme.

226. Ysaye und Oriant beschliefsen nun, Hector in einem 
Kloster zu begraben, und schicken Tronc behufs näherer Erkundigung ab. Tronc wird von einem Ritter nach einem Kloster gewiesen. Dann meldet er das Resultat seiner Erkundigung seinem Herrn. Sie legen nun den Leichnam auf ein Pferd und reiten nach dem Kloster. Auf dem Wege hierhin wirft Ysaye, der sehr geschwächt ist, den Ritter, dem Tronc begegnet war und der Ysaye herausforderte, vom Pferde.

227. Im Kloster angekommen, lassen sie vigiles sprechen. Am folgenden Morgen, nach der Messe, begraben sie Hector. Tronc mufs nun sämtliche Schilde, die Hector besessen hat, im Kloster aufhängen. $\mathrm{Zu}$ seinem grofsen Erstaunen gewahrt Ysaye unter den Mönchen seinen frère de lait Driant, welcher vor Scham gar nicht zu sprechen wagt.

228. Ysaye erfährt von ihm, dals seine Mutter Bise auf dem chastel de belle garde wohne und die Frau eines reichen Ritters geworden sei. Dieu en soit loe, sagt Ysaye.

229. Ysaye, Oriant und Trunc verlassen das Kloster, reiten an einem Schlofs vorbei und gelangen in einen Wald. Hier stofsen sie auf einen Trupp Reiter. Den Führer desselben, den König Estrahier de Sorlyon, läfst Ysaye durch Tronc zu einem Lanzenkampfe herausfordern.

230. Estrahier nimmt die Herausforderung an.

231. Ysaye besiegt nun I I Ritter. Unter diesen befinden sich Estrahier, Ysas le roux, Cadra, der Bruder Estrahiers, Vrinant, Moraint, sire du blanc isle.

232. Ysaye besiegt Eduart, fils au conte de Noirhantonne (Northhampton). Oriant besiegt Romart du rouge isle, Alixandre le sage, Blanchandin des angles. Die besiegten Ritter begeben sich nun zu Fufs (die Pferde hatte ihnen Tronc abgenommen) nach dem Kloster, in welchem sich Driant befindet, und erfahren hier, dafs am vorhergehenden Tage zwei Ritter und ein Zwerg einen Toten in dem Kloster begraben hätten.

233. Bald darauf erblicken Romart und Moraint ihre Schilde an der Wand und erkennen sofort in dem toten Ritter Hector d'Orcanie. Sie beschliefsen nun, Ysaye und Oriant sofort nachzureiten.

234. In kurzer Zeit erreichen sie Ysaye, Oriant und Tronc, und Estrahier erkundigt sich bei Oriant, ob er der Sohn Hectors sei. Auf Oriants Frage, weshalb er dieses zu wissen wünsche, erklärt ihm Estrahier, er habe ihn schon drei Monate lang gesucht, um inm die Krone von Orcanie anzubieten.

235. Ysaye und Tronc verabschieden sich von Oriant und Estrahier. Estrahier krönt hierauf Oriant und erkundigt sich bei ihm, wer der tapfere Ritter gewesen sei. Oriant zählt nun Ysayes Thaten auf, wodurch Estrahier vollständig über den Begleiter Oriants unterrichtet ist.

236. Ysaye und Tronc gelangen nach Sarras und übernachten hier. Während des Abendessens fragt der Wirt, bei welchem Ysaye 
übernachtet, ob sie vielleicht von einem Ritter gehört hätten, der gegen den Riesen Miriol, den Sohn Pincenarts le juif, kämpfen wolle. Ysaye erwidert ihm, dieser Ritter werde in zwei Tagen ankommen.

237. Am folgenden Morgen reitet Ysaye weiter. Als er an den Flufs, der bei Sarras vorbeifliefst, gelangt, bittet er einen Schiffer, das Pferd, auf welchem sein Page sitze, zum König Yrion zu bringen und der Nichte des Königs einen Grufs von dem Ritter zu übermitteln, der den Sieg im Turnier zwischen Miradir und Blamir davongetragen habe. Hierauf reitet er weiter und erblickt ein Schlofs, das auf einem Felsen liegt und von Wasser umflossen ist. Am Rande des Wassers sieht er die Leichen zweier Frauen. Er erschrickt darüber und weifs nicht, was er denken soll.

238. Von einem valet erfährt er, dafs der in dem Schlosse wohnende Riese die Frauen getötet habe. Dieses wäre seine coutume. Der Riese besitze die Kraft von zehn Männern.

239. Der valet erzählt weiter. Als einmal der König Estrahier mit dem duc de Bretagne habe Krieg führen wollen, habe es ihm an Geld gefehlt. Da habe ihm der Riese 3000 Stück esterlings geliehen. Hierfür habe er das Schlofs von Estrahier erhalten. Die coustume habe er von seinem Vater, dem Juden Pincenart, dem Tristan von Leonois den Garaus gemacht habe. Kaum hat der Knappe dies erzählt, da erscheint der Riese und ruft Ysaye zu: Defendez vous, varlet.

240. Es kommt zum Kampf. Der Riese unterliegt, und Ysaye schneidet ihm den Kopf ab. Den Kopf trägt Ysaye nach dem Schlosse und befiehlt den Leuten, denselben im ganzen Lande herumzutragen und den Frauen mitzuteilen, dafs sie jetzt ruhig das Land passieren könnten. Ysaye und Tronc reiten weiter und gelangen nach einem Schlosse, welches den Brüdern Argus und Octes gehörte. Diese waren Söhne der Venisse, einer Schweser Craventors de l'outrageux passage. Von dem Siege Ysayes über Miroul hat Venisse bereits gehört und ist deshalb sehr erfreut, einen solchen tapferen Ritter beherbergen zu können.

241. Nachdem Ysaye seine Waffen abgelegt hat, entblöfst einer der Brüder Ysayes Schild, der in Zeug eingehüllt ist, und erkennt sofort in Ysaye den Mörder ihres Onkels. Diese Fntdeckung teilt er seiner Mutter mit. Während die Brüder die Absicht haben, Ysaye zu ermorden, rät die Mutter, Ysaye in der Nacht gefangen zu nehmen und dann in den Kerker zu werfen, den Schild Ysayes aber als Siegeszeichen über der Thür des Schlosses aufzuhängen.

242. Diesen Vorschlag nehmen die Brüder an. Sie überfallen Ysaye und kerkern ihn sowohl als Tronc ein.

243. Ysaye kann sich nicht erklären, wie es möglich gewesen ist, ihn einzukerkern.

244. Als Marthe eines Tages mit ihrem Onkel zusammen ist, wird ihr unwohl. Ihr Oheim verlärst sie und befiehlt ihr, sich zu 
Bett zu legen. In Gegenwart ihrer Damen beklagt sie sich nun darüber, dafs Ysaye schon $81 / 2$ Monate von ihr fort sei. Dann fällt sie in Ohnmacht.

245. Yrion sitzt in seinem Zimmer. Da verdunkelt sich die Sonne und eine Stimme ruft zwei- bis dreimal ganz laut: Lenfant est ne qui ja nara peur. Yrion erschrickt und fragt seine Weisen, was dieser Ruf zu bedeuten habe.

246. $\mathrm{Da}$ tritt ein Fräulein in sein Zimmer und sagt ihm: Sire Roy, votre niepce Marthe est accouchee dun enfant.

247. Yrion geht in Marthes Kammer und als er von einem Fräulein hört, dafs der Knabe von dem Ritter au blanc escu a lepee vermeille stammt, ist er im höchsten Grade erfreut.

248. Da erscheint der Schiffer aus Sarras (\$ 237) und überreicht Yrion das Pferd. Der König ist sehr erfreut und schenkt dem Schiffer vier besans d'or und ein Pferd.

249. Hierauf tritt ein Ritter Yrions, Namens Marc, ein und bittet um die Ehre, den Knaben erziehen zu dürfen. Diese Bitte wird ihm gewährt. Nach ihm wird der Knabe Marc genannt.

250. Ysaye klagt Tronc sein Leid im Kerker. Tronc aber tröstet ihn und hofft, noch Mittel und Wege zu ihrer Befreiung zu finden.

251. Ein Diener bringt ihnen Wasser und Brot und verhöhnt sie.

252. Argus erscheint nun an der Kerkerthür und fordert Ysaye auf, gegen die beiden Brüder zu kämpfen. Würde er siegen, so sollte ihm die Freiheit $z u$ teil werden, im andern Falle der Tod. Ysaye fleht nun Gott um Hilfe an. Er tritt in den Saal, und da er sehr geschwächt ist, bittet er um Speise und Trank, erhält aber nichts.

253. Ysaye verlälst den Saal und besteigt sein Pferd. Er bittet Tronc, hinter ihm aufs Pferd zu steigen und ihn während des Kampfes zu halten.

254. Ein Ritter kommt herbei und fragt Ysaye, ob er krank sei. Ysaye erzählt ihm nun, wie er gefangen genommen und wie er behandelt worden ist.

255. Wütend eilt der Ritter in den Saal, wirft den Brüdern ihre Feigheit vor und erbietet sich, für Ysaye zu kämpfen. Er zieht sein Schwert und schlägt Argus zu Boden.

256. Octes stürzt nun auf den fremden Ritter. Auch Argus rafft sich wieder auf, erhält aber einen Hieb in die Brust bis auf die Leber. Der fremde Ritter schlägt dann Octes den Kopf ab. Als die Mutter ihre beiden Söhne tot liegen sieht, heult sie laut. Der Ritter aber packt sie bei den Haaren und bedroht sie mit dem Tode. Hierauf verkündet der Ritter seinen Erfolg Ysaye und giebt sich diesem als Yreult de l'isle estrange zu erkennen (\$ I69).

257. Ysaye, Yreult und Tronc begeben sich in das Schlofs. Auf Ysayes Frage, was er mit Venisse, dem Kerkermeister u. s. w. thun solle, erwidert Tronc, man solle sie einkerkern. 
258. Dieser Vorschlag findet Beifall und wird von Yreult ausgeführt. Dann wird Ysaye gepflegt.

259. Vier Wochen nach dieser Affaire erscheint Claire, die verbannte Gattin des sot sage. Vor Ysaye geführt, bereut sie alle ihre Thaten und bittet diesen, ihr zu gestatten, zum sot sage zurückkehren zu dürfen. Ysaye erlaubt ihr dies und giebt ihr einen Brief mit. Claire kehrt nun zu ihrem Gatten zurück, der sich sehr über Ysayes Brief freut.

260. Marthe beklagt sich über Ysayes Fernbleiben. Sie weint und schreibt einen lay.

Lied 2. Je vueil faire un joly lay

pour lamour de mon amy

Lyray querant si jay tant vye.

26r. Marthe liest ihr Gedicht laut vor. Dann nimmt sie ihren Sohn, küfst ihn, sagt ihm, sie müsse ihn jetzt verlassen und nennt ihn [Marc] essiliet. Darauf rüstet sie sich zur Reise und verläfst in später Stunde den Palast Yrions. Sie reitet zu einem Bürger und erhält Einlars.

262. Auf die Frage der bourgeoise, weshalb sie in so später Stunde komme, antwortet sie, sie habe mit ihrem Onkel einen Streit gehabt.

263. Die Flucht Marthes wird sofort bemerkt, und es werden Reiter zu ihrer Verfolgung ausgeschickt.

264. Eines Tages verlassen Ysaye und Yreult ihren neuen Wohnsitz, um in den Wald zu reiten. Tronc wird zur Bewachung des Schlosses zurückgelassen. Kaum haben sich Ysaye und Yreult entfernt, als zwei Ritter vor dem Schlosse erscheinen und nach Argus und Octes verlangen. Die beiden Ritter heifsen Ardant d'Acre und Perceval le noir. Tronc sagt ihnen, er öfne ihnen nicht, sie möchten vielmehr den beiden Rittern nachreiten, die soeben das Schlols verlassen hätten.

265. Sie reiten nun Ysaye und Yreult nach und fordern sie zum Kampfe heraus. Ysaye tötet Perceval, Yreult kämpft gegen. Ardant.

266. Der Kampf zwischen Yreult und Ardant blcibt unentschieden. Auf Ysayes Vorschlag hin geben sie den Kampf auf. Yreult ist ganz erschöpft und mufs zwei Jahre warten, um seine Wunden zu heilen.

267. Nach geraumer Zeit verlälst Marthe das Haus des Bürgers in der Kleidung eines escuyer. Bei Blamir begegnet sie einem Ritter, der sich mit ihr in ein Gespräch einlälst. Auf seine Fragen erklärt sie ihm, dals sie nach Clermoustier zum Ritter Hergault wolle, den sie aus dem Turnier zwischen Miradir und Blamir kenne. Da sagt ihr der Ritter, diesem Turnier habe auch ein tüchtiger Ritter beigewohnt, der einen silbernen Schild mit rotem Schwerte getragen habe.

Zeitschr. L rom. Phil. XXV, 
268. Als der Ritter ihren Geliebten erwähnt, weint Marthe, und als er nach dem Grunde ihres Weinens fragt, sagt sie, ihres toten Vaters wegen. Dann fragt der Ritter sie nach ihrem Stande. Jongleur, war Marthes Antwort. So reiten sie bis Clermoustier. Der Ritter Ostentin de lisle, ein guter Freund Hergaults, findet diesen bei Tisch. Auf Hergos Frage, ob er allein gekommen sei, sagt er, er sei in Begleitung eines menestrel gekommen. Dieser (Marthe) wird geholt und spielt so schön auf seiner Harfe, dafs alle Ritter und Damen im Saale vergessen zu speisen. Das Lied, welches Marthe dazu singt, handelt von einem Mädchen, das ihren Geliebten Ysaye le tristre sucht.

269. Hergo fragt nun, wer das schöne Gedicht verfafst habe, worauf Marthe ihm erwidert: Marthe, die Nichte des Königs Yrion, auf ihren Freund Ysaye le triste. Hergo bittet nun den menestrel, bei ihm zu bleiben. Er aber erwidert, sein Weg führe zum König Estrahier von Sorlion, der nach ihm verlargt habe. Reich beschenkt verläfst der menestrel am folgenden Morgen Clermoustier und kommt zur „Burg“. Hier bleibt er drei Monate, dann fährt er auf einem Schiff nach Sorlion. Als der Schiffsherr Geld von ihm verlangt, nimt er seine Harfe und singt:

\section{Lied 3. Je sui en mer pour querre Celly que voel amer.}

270. Solchen schönen Gesang haben die Schiffer noch nie gehört. Das Schiff fährt ab. Unterwegs erhebt sich ein Sturm, der menestrel wird ohnmächtig. Die Schiffer beschliefsen, ihn zu plündern und ins Meer zu werfen. Sie entkleiden ihn und entdecken, dafs sie es mit einer Frau zu thun haben. Als Marthe sieht, dafs sie erkannt ist, stölst sie mit dem Kopf gegen die Schiffswand, so dals ihr das Blut aus der Nase strömt. Die Schiffer geben ihr nun die Kleider zurück. Auf die Frage des Schiffsherrn, weshalb sie die Kleider gewechselt habe, erklärt sie, sie werde es ihm später erzählen. Unterdessen ist das Schiff in la haulte Bretagne angekommen.

271. Nun erzählt Marthe auf Verlangen des Schiffsherrn, sie heifse Betris und habe früher einmal eine gefährliche Krankheit gehabt. Infolge dieser Krankheit sei sie gezwungen worden, Mannskleider $\mathrm{zu}$ tragen.

272. Der Schiffsherr ist sehr ärgerlich und sagt Marthe, wenn er gewulst hätte, dals sie eine solche Krankheit besessen hätte, so hätte er sie nicht aufs Schiff genommen. Marthe verläfst nun das Schiff samt ihrem Pferde und reitet singend in den Wald. Sie freut sich, dafs sie entschlüpft ist.

Lied 4. Refrain: Il ne men cault de meschief.

273. Als sie ihre chanson beendet hat, erscheint ein Ritter und lädt sie, die immer noch als menestrel verkleidet ist, ein, beì ihm $\mathrm{zu}$ bleiben, um ihn und seine dame zu unterhalten. Marthe 
willigt ein. Sie kommen en la tente, wo sich die schönste Dame der Welt befindet. Ihr singt Marthe eine chansonette vor:

Lied 5. Jayme che que doy amer.

274. Die Dame findet Gefallen an dem menestrel und bittet ihn, drei Wochen bei ihr zu bleiben. Nach acht Tagen gesteht sie ihm ihre Liebe. Der menestrel Marthe geht darauf ein: ta volonte soit la myenne, und erzählt der Dame, er stamme aus Blamir. Sein Vater sei Kaufmann in Clermont in Barcaire. Er habe drei Brüder, die über 33 Jahre alt seien. Er selbst sei 30 Jahre alt. Das glaubt aber die Dame Sanne nicht, weil der menestrel keinen Bart hat. Infolge dieser Lüge wird der menestrel entlassen. Marthe reitet nun weiter. Am Ende des Waldes angekommen, erblickt sie ein Schlofs. Sie zieht nun ihr Frauenkleid an und reitet nach dem Schlors. Dort erblickt sie einen Ritter, es ist Ysaye, und ruft ihm zu. Ysaye, der sie nicht bemerkt, geht vom Fenster fort. Tronc fragt Ysaye, ob er öffnen soll, eine jongleresse begehre Eintritt. Ysaye erlaubt dies. Tronc führt sie zu Yreult, der noch immer krank ist. Sie erhebt ihre Harfe und singt einen lay.

\section{Lied 6.}

In diesem klagt sie über ihren treulosen Geliebten, der sie geschändet und verlassen habe. Je suis riche femme a pooir.

275. Ysaye ist über den lay erstaunt. Auf seine Frage, von wem das Lied stamme, antwortet Marthe, sie habe es von der Nichte Yrions gehört, die jetzt ausgezogen sei, um ihren Geliebten zu suchen. Marthe erkennt Ysaye nicht, wohl aber Tronc und fragt diesen, warum er nicht mehr bei seinem Herrn sei. Tronc antwortet, sein Herr sei in St. Jacques en Galisse gewesen und sei jetzt zum König Estrahier von Sorlion aufgebrochen. Tronc belügt Marthe, da er sie erkannt hat, denn er hat Grund zur Lüge et bien le scavez selong che que le livre le devise chy devant. (\$ 191).

276. Tronc erzählt ihr weiter, er sei seinem Herrn nicht gefolgt, weil er einen kranken Ritter zu pflegen habe. Dann bittet er Marthe, sie möge zum König von Sorlion gehen. Dort werde sie gut aufgenommen, da sie mit ihrer Harfe die Tochter des Königs, die dieser wegen ihrer Schönheit gefangen halte, erfreuen könne.

277. Tronc giebt Marthe zu essen. Als sie sich schlafen gelegt hat, fragt Ysaye Tronc, wer diese jongleresse sei. Die Tochter eines Schneiders des Königs Yrion. Ysaye beauftragt nun Tronc, ihr zu sagen, sie möchte ihm sofort Nachricht bringen, wenn sie etwas von Marthe erfahre. Am folgenden Morgen bricht Marthe auf und erreicht in der Nacht das Schlols Ardants d'Acre, erhält aber keinen Eintritt.

278. Sie reitet noch mehrere Tage hindurch, bis sie nach Sorlion gelangt. Hier erhält sie von Estrahier die Erlaubnis, ihre neuen lays und chansons vortragen $z u$ dürfen. Während des Essens singt sie: Ein Mädchen sucht ihren Geliebten.

Lied 7. Refrain: Mais certes je ne pourroye. 
279. Der König fragt sie nach dem Verfasser des Gedichtes. Narthe, die Nichte des Königs Yrion, habe den lay gedichtet um ihres Geliebten Ysaye le triste willen. Marthe erkundigt sich nun beim König, ob Ysaye, den sie zu sprechen wünsche, nicht bei ihm weile. Als Estrahier ihre Frage verneint, bittet sie ihn, sie so lange Zeit in Sorlion zu bewirten, bis er ankomme. Estrahier gestattet ihr dies gern, bittet Marthe aber, seiner Tochter Gesellschaft zu leisten. Von vier Rittern und der Schwester des Königs, der Königin von Schottland, begleitet, wird Marthe in den Turm geführt.

280. Die Königin stellt nun ihrer Nichte Yvoire Marthe als die schönste Sängerin der Welt vor. Yvoire bedankt sich. Die Königin verlälst hierauf die Zelle. Marthe giebt sich Yvoire gegenüber als Chrestienne aus. Marthe singt:

Lied 8. Jay par maintes fois chante

plus aise que je ne soye.

28I - 5. Marthe und I'voire klagen einander ihr Leid. Beide lieben unglücklich, und Marthe sagt: plus aime on fort, plus est on sot.

286. Alle, die aufserhalb des Kerkers die Worte Marthes hören, sind über ihre Klugheit erstaunt.

287. Als Ardant d'Acre noch krank zu Bett liegt, erscheint sein cousin germain Elias und lärst sich den Kampf Ardants und Percevals mit Ysaye und Yreult erzählen. Darauf entfernt er sich, ohne ein Wort zu sagen.

288. Er holt eine Anzahl Armbrust- und Bogenschützen herbei und zieht gegen Ysayes Schlofs, das sich inzwischen um drei Insassen vermehrt hat, denn Ysaye hatte drei ribaults aufgenommen.

289. Ysaye, Tronc und die drei ribaults verteidigen das Schlofs. Wegen ihrer Tapferkeit schlägt Ysaye die drei ribaulls zu Rittern.

290. Nun machen die ribaults einen Ausfall. Sie dringen siegreich vor, bis schliefslich der eine von ihnen getötet und ein zweiter schwer verwundet wird. Da eilt Ysaye ihnen zu Hilfe und schlägt die Feinde zurück. Nur mit grofser Mühe entflieht Elias.

29r. Elias eilt zu $\Lambda$ rdant und teilt diesem den Verlauf des Kampfes mit. Da erklärt ihm Ardant, an seiner Niederlage sei nur der Zwerg Ysayes Schuld. Dieser trage auch dic Schuld an Percevals Tode, da er ihm geraten habe, gegen Ysaye zu kämpfen.

292. Am folgenden Morgen macht sich Elias wieder auf den Weg nach dem Schlosse Ysayes, dieses Mal aber als armer Mann gekleidet. Kurz vor dem Schlosse bindet er sein Pferd an einen Baum und geht nach dem Schlosse. Hier wirft er sich zur Erde und fängt an, laut zu klagen. Tronc geht $z u$ ihm und fragt ihn, was ihm fehle. Da sagt ihm Elias, seine Frau liege in der Nähe und gebäre gerade ein Kind, Tronc möge mitkommen und sie holen. Tronc geht nun mit Elias. Sobald sie aber aufser Sicht 
des Schlosses sind, nimmt Elias den Zwerg unter den Arm, besteigt sein Pferd und reitet zu Ardant.

293. Ysaye bemerkt bald das Fehlen Troncs.

294. Zwei Tage lang klagt er über seinen Pagen. Dann vertraut er sein Schlofs der Obhut des immer noch kranken Yreult und der zwei ribaults an und macht sich auf, Tronc zu suchen.

295. Marc wächst auf. Er wird ein übermütiger Junge. In der Küche zerbricht er die Töpfe und schüttet die Speisen aus. Einen Neffen des Königs wirft er in einen Brunnen. Um ihn an weiteren Ausschreitungen $z u$ hindern, lälst ihn Yrion in einem Turm einsperren.

296. Dieses hilft aber nichts. Denn als ihn Yrion einmal besuchen will, wirft er ihm einen Topf mit Wasser auf den Kopf. Er wird num in ein Zimmer gebracht, das nach der Strafse gelegen ist. Hier aber wirft er seine Kleider auf die Stralse, so dafs man ihn oft ganz nackt antrifft. Nun wird Marc in einen anderen Turm gebracht, wo er 14 Jahre bleibt.

297. Ein Jahr ist es her, seitdem Ysaye sein Schlofs verlassen hat. In vollständig heruntergekommenem und blödsinnigem $\mathrm{Zu}$ stande an einem Brunnen in der lande verte sitzend, findet ihn ein Ritter Barut le breton. Dieser fragt Ysaye, ob er wisse, wie die sechs Ritter hiefsen, die soeben vorbeigezogen seien, worauf Ysaye erwidert, der Ritter solle ihm lieber ein Stück Brot geben. Ein anderer Ritter, Condely d'Arbise, erscheint und kämpft mit Barut. Nach dem Kampfe erfährt Barut von Condely die Namen der soeben erwähnten sechs Ritter: Hergault, le desorreillé de la Joy. Garde, Menet le mecogneu, Paumart le vermeil, le sot sage, Titus de l'ombre (cousin germain a Hergo).

298. Barut erfährt weiter, dafs diese sechs Ritter von Yrion ausgeschickt seien, um Ysaye le triste zu suchen, und dafs sie in nächster Woche nach Blamir zurückkehren würden, um über ihren Erfolg zu berichten.

299. Eines Tages vernehmen die ribaults aus den Kerkern des Schlosses Klagen. Schnell erkundigen sie sich bei Yreult und erfahren, dafs diese Leute Ysaye haben meuchlings ermorden wollen. $\mathrm{Da}$ öffnen die ribaulls die Kerkerthüren und schlagen den Gefangenen die Köpfe ab.

300. Estrahier veranstaltet ein grofses Fest und lädt viele Ritter dazu ein. Unter diesen befindet sich auch Barut. Barut begiebt sich in Begleitung Ysayes nach Sorlion. Am ersten Abend ihrer Reise kehren sie bei Yreult ein.

30I. Yreult erzählt nun Barut, wie Ysaye und er in den Besitz des Schlosses gekommen sind. Da Ysaye während des Gespräches sich komisch gebärdet, fragt Yreult Barut, was für einen Narren er nit sich führe, und lacht über Ysaye.

302. Ysaye verbringt die Nacht auf dem Hofe.

303. Ysayes Pferd erkennt seinen Herrn wieder. Es wiehert und versucht die Thür des Stalles aufzubrechen. Als ein Stall- 
knecht (ribault) am folgenden Morgen die Thür öffnet, ergreift das Pferd die Flucht.

304. Der ribault will nun das Pferd wieder einfangen, kehrt aber unverrichteter Sache wieder zurück. Er verhehlt die Flucht des Pferdes einen Monat hindurch dem Yreult, dann aber erzählt er ihm davon, worüber Yreult sehr ärgerlich ist.

305. Barut und Ysaye kommen in Sorlion an, woselbst Ysaye wegen seiner zerlumpten Kleidung von den Kindern geneckt wird. Am Hofe Estrahiers finden Turniere statt. Am dritten Tage nach der Ankunft Baruts findet eine quintaine statt. Dem Sieger wird ein Pferd als Preis versprochen. Kein Ritter bringt das Waffenkunststück fertig. Da bittet Ysaye seinen Herrn Barut, sich an dem Wettbewerb beteiligen zu dürfen. Ysaye erhält die Erlaubnis und übertrifft alle Ritter. Da fragt ihn der König nach seinem Namen. Jehan nenne man ihn, sagt Ysaye. Obwohl der König ihn für sot hält, gestattet er ihm doch, an der Tafel teilzunehmen. Hier wird er der Yvoire und Marthe vorgestellt. Marthe erkennt ihn aber nicht.

306. Eines Tages findet der Küchenmeister Ysaye schlafend in der Küche. Wütend hierüber verbrennt er Ysaye den Bart. Ysaye aber ergreift ihn und wirft ihn samt drei anderen Köchen ins Feuer. Als der König von dieser That Ysayes hört, ist er zunächst sehr erregt. Nachdem er aber den Sachverhalt gehört hat, lobt er Ysaye. Seit dieser Affaire wagte es niemand, Ysaye irgend welches Leid zuzufügen.

307. Hergault kehrt mit seinen Genossen nach Blamir zurück und erstattet dem König Yrion Bericht über seine erfolglose Reise. Vor Gram wird nun Yrion 17 Jahre lang krank.

308. Yrion ist alt und schwach. Er läfst Marc zu sich kommen. Ein Ritter, der Marc holen soll, giebt diesem gute Ratschläge: Amy, il faut que soyes dautre condition que vous navez este et que vous soyez humble, de bonnayre, patient aux pauvres, cruel aux ennemys, honnorez ceulx qui sont a honnorer, amez vos amys, allez volontiers a leglise u. s. w.

309. Marc erscheint vor Yrion. Vous me demandes, que vous fault il?

310. Yrion übergiebt ihm nun die Verwaltung des Königreiches. Marc verspricht ihm, ein tüchtiger Mann zu werden. Die erste That ist nun, ein Turnier zu veranstalten. Er schickt zu diesem Zwecke sechs Boten aus, welche in Armuse, Murtoire, Dormalie, Sorlion, Bretaigne und Allemaigne die Ritter zum Turnier einladen.

(Fortsetzung folgt.)

ZEIDLER. 